\title{
Contrasting evidence of phylogenetic trophic niche conservatism in mammals worldwide
}

Article

Accepted Version

Olalla-Tarraga, M. A., Gonzalez-Suarez, M., Bernardo-Madrid, R., Revilla, E. and Villalobos, F. (2017) Contrasting evidence of phylogenetic trophic niche conservatism in mammals worldwide. Journal of Biogeography, 44 (1). pp. 99-110. ISSN 1365-2699 doi: https://doi.org/10.1111/jbi.12823 Available at https://centaur.reading.ac.uk/65807/

It is advisable to refer to the publisher's version if you intend to cite from the work. See Guidance on citing.

To link to this article DOI: http://dx.doi.org/10.1111/jbi.12823

Publisher: Wiley

All outputs in CentAUR are protected by Intellectual Property Rights law, including copyright law. Copyright and IPR is retained by the creators or other copyright holders. Terms and conditions for use of this material are defined in the End User Agreement.

www.reading.ac.uk/centaur 
Central Archive at the University of Reading

Reading's research outputs online 
Original article for Journal of Biogeography

\section{Contrasting evidence of phylogenetic trophic niche conservatism in mammals} worldwide

Miguel Á. Olalla-Tárraga ${ }^{1,{ }^{*}} \dagger$, Manuela González-Suárez ${ }^{2,3} \dagger$, Rubén Bernardo-Madrid ${ }^{2}$, Eloy Revilla ${ }^{2}$, Fabricio Villalobos ${ }^{4,5}$

Author affiliation:

${ }^{1}$ Department of Biology and Geology, Physics and Inorganic Chemistry, Rey Juan Carlos University, Móstoles, 28933, Madrid, Spain

${ }^{2}$ Department of Conservation Biology, Estación Biológica de Doñana (EBD-CSIC), Calle Américo Vespucio s/n, 41092 , Sevilla, Spain

${ }^{3}$ Ecology and Evolutionary Biology, School of Biological Sciences, University of Reading, Whiteknights, Reading, RG6 6AS, UK

${ }^{4}$ Departamento de Ecologia, Instituto de Ciências Biológicas, Universidade Federal de Goiás, 74001-970, Goiânia, GO, Brazil ${ }^{5}$ Red de Biología Evolutiva, Instituto de Ecología, A.C., Carretera antigua a Coatepec 351, El Haya, 91070 Xalapa, Veracruz, Mexico

*Corresponding author: Miguel Á. Olalla-Tárraga (miguel.olalla@urjc.es)

$\dagger$ Both authors contributed equally

Short running title: Dietary niche conservatism in mammals

Keywords: Brownian motion, dietary specialization, ecological niche, Eltonian niche, Grinnellian niche, macroecology, macroevolution, phylogenetic comparative methods, phylogenetic niche conservatism. Word count: abstract (312), main text (6135); Number of references: 49; plus 2 tables and 4 figures. Estimate of journal pages for figures and tables: 2 


\begin{abstract}
Aim Phylogenetic niche conservatism (PNC), a pattern of closely related species retaining ancestral niche-related traits over evolutionary time, is well documented for abiotic (Grinellian) dimensions of the ecological niche. However, it remains unclear whether biotic niche (Eltonian) axes are also phylogenetically conserved, even though knowledge of biotic niches is essential to an understanding of the spatiotemporal dynamics of ecological communities. We conduct the first analysis of biotic PNC by evaluating dietary specialization in a vertebrate class.
\end{abstract}

\title{
Location Global
}

Methods We analysed two global compilations of diets of living mammals and a more detailed database for large carnivores together with a species-level phylogeny to evaluate trophic PNC. We searched for evidence of PNC by estimating the phylogenetic signal in distinct descriptors of dietary niche.

Results Trophic niches were generally similar among related species but not strongly conserved under a niche-drift macroevolutionary model (Brownian Motion). The degree of similarity in trophic niche varied among different taxonomic groups and was, importantly, even within the same group, contingent on the metric of dietary preferences used and the quality of information on the database.

Main conclusions Overall, our results showed limited support for PNC in the trophic niche of mammals. However, different data sources and metrics of dietary preferences sometimes offered different conclusions, highlighting the importance of gathering high-quality quantitative data and considering multiple metrics to describe dietary niche breadth and to assess PNC. The fully quantitative database for large carnivores provided some interesting evidence of PNC that could not be detected with semi-quantitative or presence/absence descriptors. Subsequent assessments of phylogenetic imprints on dietary specialization would benefit from considering different metrics and using well-resolved phylogenies jointly with detailed quantitative diet information. While Eltonian trophic niches did not show the same high levels of evolutionary conservatism often 
displayed by Grinnellian niches, both niche components should be considered to understand range limits of species and clades at biogeographic scales.

\section{Introduction}

In 1957, Hutchinson formalized the concept of ecological niche as a multidimensional hypervolume that describes the set of biotic and abiotic conditions where a species can persist. Traditionally, ecological niches have been conceptually divided into two main classes: Grinellian and Eltonian (Soberón, 2007). While the former can be defined by broad scale non-interactive environmental variables, the Eltonian niche (also named functional or trophic niche) focuses on biotic interactions and resource-consumer dynamics. Certain axes of the ecological niche change slowly and closely related species tend to retain their ancestral niche-related traits over evolutionary time, resulting in a pattern known as "phylogenetic niche conservatism" (PNC, Wiens \& Graham, 2005; Wiens et al., 2010). Phylogenetic niche conservatism is usually assessed estimating phylogenetic, signal which is a measure of the statistical dependence among species' trait values due to their phylogenetic relationships (Revell et al., 2008). Most research on PNC has centred in evaluating the extent to which realized Grinnellian niches are phylogenetically conserved, whereas much less effort has been directed at examining conservatism in Eltonian aspects of the niche (Soberón, 2007). Beyond their relevance for a number of basic and applied questions in ecology and conservation biology (Wiens \& Graham, 2005), realized climatic niches can be readily characterized from geographic distribution ranges (Olalla-Tárraga et al., 2011). However, the data that define Eltonian niches are more difficult to obtain (Cooper et al., 2010). This may explain why PNC in Grinnellian traits (e.g. those determining abiotic niche axes) has been studied at a variety of spatial and temporal scales (Pearman et al., 2008; Peterson, 2011), but PNC in Eltonian traits (e.g. those determining resource utilization and biotic interactions) remains largely unexplored. 
Phylogenetic niche conservatism is not ubiquitous and the extent to which many niche-related ecological traits are conserved or labile over evolutionary time still remains unclear. Considering that the detection of PNC depends on the trait and spatiotemporal scales of analysis, its existence should not be a priori assumed but needs to be tested (Losos, 2008; Wiens, 2008). With some exceptions (e.g. Pearman et al., 2014), there is overall growing evidence for PNC in climatic niche dimensions such that closely related species occupy similar, albeit not necessarily identical, environments (Wiens \& Graham, 2005; Wiens et al., 2010; Olalla-Tárraga et al., 2011). Regrettably, even for mammals and birds that have typically received most of the attention in the macroecological and macroevolutionary literature, empirical evidence of PNC in Eltonian traits is more limited and equivocal. In two seminal papers, Böhning-Gaese \& Oberrath (1999) and Brändle et al. (2002) found patterns consistent with PNC in the diets of bird species in central Europe. In contrast, Pearman et al. (2014) could not find evidence for PNC in the trophic niches of 405 species of breeding birds in Europe. With the exception of Kamilar \& Cooper (2013), who found a weak phylogenetic signal in the diets of 213 primate species worldwide, there are no studies of PNC in mammal dietary specialization at any spatial or phylogenetic scale. In primates, the consumption of leaves, fruits and animal matter was largely disconnected from phylogenetic relatedness and diet was identified as one of the most evolutionary labile traits among the set of morphological, behavioural, life-history, ecological and climatic niche variables that were examined by Kamilar \& Cooper (2013).

Ecological specialization in mammals is strongly linked to a wide array of specialized dentitions and anatomical morphologies and, hence, to dietary niche breadth. In fact, evolutionary transitions in trophic strategy and dietary innovations within lineages have been proposed as critical factors determining mammalian diversification (Price et al., 2012; Cantalapiedra et al., 2014). Here we conducted the first phylogenetically-comprehensive global analysis of PNC in dietary specialization among mammals. If PNC exists, it may be more easily detectable at higher phylogenetic levels (Losos, 2008). We, therefore, used two recently published global datasets of dietary preferences in 
living mammals (Kissling et al., 2014; Wilman et al., 2014), together with a nearly complete species-level phylogenetic supertree (Fritz et al., 2009) to explore whether mammalian dietary specialization tends to be conserved over evolutionary time or not. These large databases provide qualitative and semi-quantitative species-specific dietary descriptions for extant mammals (Kissling et al., 2014; Wilman et al., 2014). Complementarily, we compiled from the scientific literature a high resolution dataset, including both qualitative and quantitative diet information, to analyse three families in the order Carnivora (Canidae, Ursidae and Felidae) in more detail and assess the extent to which our inferences regarding PNC were affected by the way niche dimensions were defined and measured. Carnivora is an ideal taxonomic group to investigate the phylogenetic structure in trophic niche specialization as it covers a wide dietary spectrum from hypercarnivory to opportunistic omnivory and even strict herbivory. The majority of felids are active predators with highly carnivorous diets, whereas most ursids are omnivores and canids show an intermediate position across this gradient of dietary specialization. Accordingly, although macroevolutionary patterns in dietary specialization may not be apparent in Carnivora as a whole, trends may emerge within lineages or for different niche dimensions.

There has been much debate in the literature about which is the best definition and method to test for PNC, with some researchers arguing that phylogenetic signal alone can provide evidence of PNC and others insisting that PNC is only present when phylogenetic signal is stronger than expected under Brownian motion (Losos, 2008; Wiens, 2008; Cooper et al., 2010; Wiens et al., 2010). Because there is consensus that evidence of phylogenetic signal is necessary to demonstrate PNC, we first calculated empirical values of Blomberg's K (2003) to evaluate the tendency for related species to resemble each other more than they resemble species drawn by chance in a phylogeny. We then searched for evidence of niche-drift PNC (sensu Cooper et al., 2010) evaluating the level of fit in the data to a Brownian motion (BM) model. Under such a scenario, species are viewed as having inherited their niches from their ancestors, after which interspecific differences have accumulated gradually over time following a random walk or BM model. This is a 
classic macroevolutionary model to test for PNC although, as mentioned above there is current disagreement as to the thresholds at which we can regard the phylogenetic signal as high enough to be considered evidence of PNC (Losos, 2008; Kamilar \& Cooper, 2013). Here, we adopted the view that if niche evolution fits a BM model, it is indicative of PNC (Cooper et al., 2010; Kamilar \& Cooper, 2013). Evidence of PNC could also be tested using different evolutionary models, for example assuming stabilizing selection towards one or multiple optima (i.e. Ornstein Uhlenbeck model), particularly if we expect slow evolving traits and phylogenetic inertia (Cooper et al., 2010). However, a recent study (Cooper et al., 2016) has shown that the Ornstein Uhlenbeck model is often incorrectly favoured over simpler models, particularly for data with measurement error and/or intraspecific variability. Given limitations in the data (see results) here we followed a precautionary approach and only tested the simpler drift model (BM).

Beyond the above-mentioned investigations for birds and mammals, there is a striking paucity of work evaluating congruence in PNC between Grinnellian and Eltonian niches. Larson et al. (2010) called attention to the possibility that the evolutionary trajectories of Grinnellian and Eltonian niches may be decoupled, as they found for the signal crayfish (Pacifastacus leniusculus). Galapagos finches and African Rift lake cichlids are instances of adaptive radiations in which trophic niches were not evolutionary conserved but Grinnellian climatic niches were (Cooper et al., 2010; Wiens et al., 2010). Larson et al. (2010) predicted that highly vagile species with greater capacities to overcome geographic barriers and hence, more similar realized and fundamental Grinnellian niches, should show PNC in both Grinnellian and Eltonian niches. Accordingly, we expected that trophic niches would be phylogenetically conserved in mammals, in synchrony with the evolutionary pattern documented for their Grinnellian niches (Olalla-Tárraga et al., 2011). In mammals, diet and habitat specialist species tend to have more evolutionarily conserved thermal niches than generalists (Cooper et al., 2011), a finding that further supports our a priori prediction of consistency between Grinellian and Eltonian niche conservatism. We also predicted that 
evolutionary lability in trophic niches may be detectable at lower taxonomic levels of analysis (i.e. some mammal orders such as Carnivora may not display patterns consistent with PNC).

\section{Materials and Methods}

\section{Dietary Databases}

We estimated phylogenetic signal in dietary diversity and composition from three datasets that provide species-level data. First, we analysed MammalDIET (Kissling et al., 2014), a large semiquantitative database including observed dietary data for 2033 species representing 27 of the 29 mammalian orders recognized by Wilson \& Reeder (2005), all except Sirenia and Cetacea (Fig. 1). Data extrapolated from genus or family information for an additional 3331 species were not included to avoid biasing the phylogenetic signal. Diet was described for each species using ranked importance for each of 12 food categories: Mammal, Bird, Herptile (including amphibians and reptiles), Fish, Invertebrate, Fruit, Nectar, Leaf: woody (Woody), Leaf: herbaceous (Grass), Seed, Root and Other. The importance of each item was ranked according to four levels: 0 (absent), 1 (primary food item), 2 (secondary food item) and 3 (occasional food item). Since, to our knowledge, estimating phylogenetic signal in an ordinal trait is not currently possible, we converted importance into a binary trait: absent (original score of 0 ) or present (grouping original scores of 1 , 2, or 3), and into a continuous trait (numerical rank importance ranging from 1 to 4 with absence redefined to 4 to generate a range from commonly eaten to absent).

The second database, EltonTraits (Wilman et al., 2014), describes semi-quantitative dietary information for 4352 mammalian species representing 28 mammalian orders (all except Sirenia; Fig. 1). Although not analysed here, EltonTraits also provides dietary data for bird species and for 1048 mammals for which diet is extrapolated from genus or family information. For each species, diet was described using ranked percentages (in 10\% increments) reflecting the estimated relative usage of 10 food categories: unclassified or general vertebrates (Vert), mammal and bird (Vend), Herptile, Fish, Invertebrate, Carrion, Seed, Fruit, Nectar, and unclassified or general plant material 
(Plant). We analysed the ranked percentages as a continuous trait and also reclassified them into binary format: absent (percentage $=0$ ) or present (percentage $>0$ ).

The third database, CUFdiet, was compiled from the scientific literature (a list of the consulted data sources is found in Appendix S1 in Supporting Information) for three families of large carnivores: Canidae, Ursidae and Felidae (73 species). While taxonomically limited, this dataset is the only one that provides detailed quantitative dietary data. Dietary composition was described according to 12 food categories: Mammal, Bird, Herptile, Fish, Invertebrate, Fruit, Pollen, nectar and/or flower (Nectar), Leaf/branch (Woody), Grass, Seed, Root and/or tuber (Root), and Carrion. Note that although dietary categories were different in the three datasets, most categories were directly comparable. Dietary composition in CUFdiet was described using presence/absence data obtained from diverse types of evidence (e.g., direct observations, fecal samples, stomach contents) which included qualitative descriptions and quantitative estimates from the different sources (Appendix S1). We defined a category as present in a species' diet if there was evidence from at least one study that the item was consumed even if infrequently. In addition, CUFdiet includes two quantitative estimates of dietary composition based on numerical frequency (proportion of the total items found per sample that belong to a given food category) and frequency of occurrence (proportion of samples that contained at least one item from a given food category). When multiple quantitative estimates were available for one species we recalculated proportions combining all samples across studies rather than using average values to account for large variation in sample sizes among studies.

\section{$\underline{\text { Data Analyses }}$}

We searched for evidence of PNC estimating the phylogenetic signal in distinct descriptors of dietary niche. First, dietary diversity was computed as: (1) dietary breadth: total number of dietary categories consumed, based on presence/absence data (available for all three datasets); and (2) the standardized Levin's index of dietary diversity: calculated as $B_{A}=(B-1) /(n-1)$, where $n$ is the 
number of possible food categories and $B=1 / \sum \hat{p}_{j}^{2}$, where $\hat{p}_{j}$ is the observed frequency of each food category. For CUFdiet $\hat{p}_{j}$ was calculated using numerical frequency data, and for EltonTraits using ranked proportions. Second, we defined dietary niches in relation to the consumption of the different dietary categories using qualitative presence/absence descriptors (available for all datasets), and quantitative descriptors defined as: ranked numerical importance for MammalDIET, ranked percentages for EltonTraits, and numerical frequency and frequency of occurrence for CUFdiet.

To facilitate interpretation we compared the phylogenetic signal detected in dietary preferences with values from other species' traits that represented a range of characteristics expected to vary in their phylogenetic signal. We included traits likely to show similar values among related species (strong signal) reflecting morphology (average adult body size) and life-history (average gestation length); as well as more labile traits like social organization (average group size), space use (average home range size), and biogeographic distribution (native range size). Data on adult body mass were obtained from EltonTraits, whereas gestation length, group size and home range size data were obtained from PanTHERIA (Jones et al., 2009) with additional values available for some carnivores included in CUFdiet. Native range size was estimated from IUCN distribution range maps, selecting only areas described as native or reintroduced in origin and currently occupied (presence classified as extant or probably extant). Trait data were $\log _{10}$-transformed prior to analyses.

Because estimates of phylogenetic signal are dependent on the degree of phylogenetic relatedness among the species in the focal taxon for which data are available, a significant degree of phylogenetic clustering among the species represented in MammalDIET or EltonTraits could affect our results. To explore this potential source of bias, we quantified the net relatedness index (NRI) of species represented in these databases. NRI is a standardized measure of the mean pairwise phylogenetic distance of species, which quantifies the extent of phylogenetic clustering and overdispersion (Webb et al., 2002). NRI is expressed in units of standard deviation and its 
significance can be determined from the value itself, with values $<-1.96$ being significantly overdispersed and $>1.96$ being clustered. We calculated NRI using the mpd.query procedure of the 'PhyloMeasures' package (Tsirogiannis \& Sandel, 2015) in R 3.1.1 (R Core Team 2014). In addition, to allow for a strict comparison of PNC in both global datasets, we also analysed phylogenetic signal considering only species represented in both datasets.

To estimate phylogenetic signal in dietary diversity metrics we calculated $\mathrm{K}$ values (Blomberg et al., 2003) using the mammalian supertree (Bininda-Emonds et al., 2007) as updated by Fritz et al. (2009). This supertree describes phylogenetic relationships, inferred using molecular data, for 5020 mammalian species. We tested two hypotheses regarding observed K values: (1) lack of phylogenetic signal: observed $\mathrm{K}$ is not greater than would be expected if trait values for species were randomized among tips (with 1000 randomized samples); and (2) consistency with BM: we calculated whether K significantly departed from the phylogenetic signal estimated from 1000 simulated datasets in which BM was the evolutionary model. The simulations drew random trait values from a normal distribution (mean $=0$ and variance equal to that observed in the empirical dataset), starting with an ancestral root value equal to the empirical mean from the dataset. We also defined biologically meaningful bounds (e.g., for dietary breadth values bounds were $[1$, maximum number of categories] and for the standardized Levin's index bounds were 0 and 1). We used the phylosig and fastBM procedures from the package 'phytools' (Revell, 2012) in R.

To estimate phylogenetic signal in presence/absence data we calculated D as defined by Fritz \& Purvis (2010). D values around 1 imply a random distribution of the binary trait across the tips of the phylogeny whereas values around 0 imply BM; negative values indicate highly conserved traits. We used 5000 permutations to estimate the probability of the observed $\mathrm{D}$ under a null model of no phylogenetic structure (data were randomly shuffled along the phylogeny to estimate possible D values) and under simulated BM. We used the procedure phylo.d from the package 'caper' (Orme et al., 2013) in $\mathrm{R}$. 
Incompletely resolved phylogenies (like the mammalian supertree we used which includes polytomies) can inflate estimates of phylogenetic conservatism. Davies et al. (2012) have proposed a rarefaction-based approach to calculate unbiased $\mathrm{K}$ values. Their approach consists in repeatedly constructing new phylogenies in which individual species from existing polytomies are selected at random to define new, completely resolved (but smaller) phylogenies for which phylogenetic signal is calculated. Unfortunately, because in our case data were not available for all species, defining new smaller phylogenies by breaking polytomies at random also affected sample sizes (as by chance a species selected from a polytomy could have no data). Therefore, we did not estimate all $\mathrm{K}$ values using this approach. Nevertheless, we explored the influence that unresolved polytomies had on the estimates of K for the general species traits analysed, including dietary breadth and Levin's index. We used 100 replicates to estimate the mean and range of unbiased $\mathrm{K}$ values for each trait.

To facilitate reproducibility and encourage open science the complete dataset analysed in this study is available on (https://dx.doi.org/10.6084/m9.figshare.3250540.v1). The complete R script used to generate reported results is also available as Appendix S2.

\section{Results}

The mammalian supertree included 5020 species. MammalDIET provided dietary information for 1921 of these species (112 species with dietary data were not represented in the phylogeny), EltonTraits provided dietary data for 4246 mammals (106 species were not in the phylogeny), and CUFdiet, for 73 species (all of which were present in the phylogeny). In total, 1730 species were represented in both MammalDIET and EltonTraits. All 73 species in CUFdiet were in EltonTraits, but seven of these carnivores were not included in MammalDIET. Mammalian diversity was generally well represented in both global datasets, but MammalDIET over-represented some groups, such as Primates, Carnivora and Artiodactyla (Fig. 1). Despite this over-representation, 
phylogenetic structure in these datasets was not significantly clustered, but was instead overdispersed (NRI $=-2.05$ and NRI $=-5.35$ for MammalDIET and EltonTraits, respectively).

In general, we found evidence of phylogenetic signal in dietary diversity (both for dietary breadth and Levin's index) indicating that diets of related species tend to resemble each other more often than would be expected by chance (Fig. 2; Table S1 in Appendix S3). However, this signal did not provide strong evidence of PNC (Revell et al., 2008). Dietary breadth from MammalDIET and dietary breadth and Levin's index from CUFdiet resulted in a K value significantly lower than expected under BM. On the contrary, the signal in dietary breadth and Levin's index calculated from EltonTraits was apparently consistent with BM. These results could be biased by unresolved polytomies, as unbiased estimates obtained from the rarefaction-based approach were much smaller than the estimates based on the complete dataset (Table S2 in Appendix S3). To explore whether these smaller unbiased values were consistent with BM, we simulated 1000 datasets for each of 50 randomly thinned trees and determined the probability that these $\mathrm{K}$ values were consistent with BM $\left(P_{B M}\right)$. Although unbiased estimates of diet breadth were generally consistent with those expected under BM, in 17 out of the 50 thinned trees the $\mathrm{K}$ values were significantly smaller than expected $\left(P_{B M}<0.05\right)$. On the other hand, unbiased estimates of phylogenetic signal in Levin's index were all consistent with $\mathrm{BM}$ (for all 50 thinned trees, $P_{B M}>0.05$ ). For the other traits and databases unbiased estimates were largely equivalent to those based on the complete datasets and phylogeny, and thus apparently not greatly affected by the presence of polytomies (Table S2 in Appendix S3). We note that although it is often assumed that $\mathrm{K}=1$ under BM (Cooper et al., 2010), this is not necessarily true for traits with defined bounds, as we show in our results.

Considering other species' traits for comparison, we found higher $\mathrm{K}$ values than expected under BM for gestation length, non-significant departures from BM for adult body mass, and lower signals than expected under BM but still stronger than expected if values were randomly distributed 
along the phylogeny for home range size, group size and native range size (Fig. 2; Table S1 in Appendix S3).

Phylogenetic signal in dietary breadth differed among mammalian orders (Table 1), with some groups having strong signals (e.g., Afrosoricida) while for others, dietary breadth was not clearly associated with evolutionary relatedness (e.g., Carnivora). However, results for many orders were not consistent between databases (Spearman correlation of estimated $\mathrm{K}$ values, rho=0.46) affording contradictory inferences about niche conservatism. For example, dietary breadth in bats and rodents (Chiroptera and Rodentia), as measured using EltonTraits, showed a phylogenetic signal consistent with BM, whereas data from MammalDIET for both taxa revealed a signal lower than expected under BM (Table 1). These discrepancies are unlikely to be explained by differences in the clustering and number of species evaluated, since both datasets were significantly overdispersed in the mammalian phylogeny and analyses for the subset of species with data on both sources $(\mathrm{N}=1730)$ also showed discrepancies (Fig. 3; Table S3 in Appendix S3). For instance, phylogenetic signal in dietary breadth for 41 species of Lagomorpha was consistent with BM if measured with MammalDIET, but indicated faster evolution based on data from EltonTraits. The opposite pattern was observed in Rodentia (531 species) and Chiroptera (366 species) for which dietary breadth was consistent with BM using data from EltonTraits but not using data from MammalDIET (Fig. 3; Table S3 in Appendix S3). In both datasets the strength of the phylogenetic signal was not clearly associated with the mean dietary breadth or its variability among species (Spearman correlation rho values $<|0.25|$. Table 2). Note that inferences regarding phylogenetic signal from groups with relatively small sample sizes (more prevalent in the MammalDIET database) should be made with caution.

Analysing the phylogenetic signal of dietary composition based on the presence/absence of particular food items, we also found differences across categories and databases (Fig. 4). Fritz and Purvis' D estimates for MammalDIET and EltonTraits were always significantly different from 
those expected if values had been randomly distributed along the phylogeny, but differed inconsistently from values based on BM simulations (Table S4 in Appendix S3). In both datasets the number of species classified as consuming a dietary category comprised a small percentage of the total (median $<10 \%$, ranging from $6-55 \%$ in MammalDIET and 4-65\% in EltonTraits. Table S4 in Appendix S3). For all categories, presence data from EltonTraits fitted the results expected under BM, while estimates from MammalDIET differed in some cases (e.g., Fruit or Woody. Fig. 3). Presence data from CUFdiet suggested weaker phylogenetic signals which often did not significantly differ from that expected from randomization.

We also found significant phylogenetic signal in semi-quantitative descriptions of dietary composition in MammalDIET and EltonTraits (Table 2). Values were generally low and inconsistent with BM for MammalDIET, but mostly consistent with BM for EltonTraits. The detailed quantitative estimates from CUFdiet showed more variable patterns with consumption of certain types of food, such as Bird, being more closely associated with phylogeny than others (e.g. Fish). Interestingly, within this database we found that different quantitative estimates can lead to different results (e.g., numerical frequency versus frequency of occurrence of Bird) and that quantitative estimates of commonly consumed categories, such as Mammals, can reveal patterns that are not detectable with simpler presence/absence data (Table 2).

\section{Discussion}

Our global comparative analyses showed that dietary specialization is phylogenetically structured in mammals, with phylogenetic signal values similar to those of other ecological traits such as home range or group size (Fig. 2). In terms of their dietary diversity, and irrespective of the metric of dietary specialization, related mammalian species tended to resemble each other more than expected by chance. However, the existence of phylogenetic signal, albeit necessary to demonstrate niche conservatism, is not sufficient evidence that a trait has been strongly conserved over time. Under 
our test of niche-drift PNC, the evolution of trophic preferences in mammals needed to be Brownian to be indicative of niche conservatism (Cooper et al., 2010; Kamilar \& Cooper, 2013). The two global datasets on mammal diets that we analysed provided potentially contrasting evidence. While values of Levin's dietary diversity index and, possibly, dietary breadth calculated from EltonTraits appeared to be phylogenetically conserved in mammals, dietary breadth estimates from MammalDIET suggested that trophic niches diverged faster than expected under BM with no evidence for PNC. Similarly, analysing mammalian dietary composition based on the presence or absence of particular food items showed that trophic preferences are non-randomly distributed across the phylogenetic tree. All dietary categories exhibited phylogenetic signal, but not all were consistent with BM (and again there were differences between datasets). Nectar consumption, a food resource that appears to be almost exclusively exploited by a few families of tropical bats (e.g. Phyllostomidae and Pteropodidae), and predation on Mammal and Bird were both consistent with $\mathrm{BM}$ in both datasets suggesting PNC. However, consumption of Fruit was only consistent with BM for EltonTraits.

The discrepancies between global databases cannot be explained by the different numbers of species represented in each case. MammalDIET provides dietary information for less than half the species in EltonTraits, but differences still existed when analysing subsets of species with dietary breadth data from the two sources (Fig. 3). A possible explanation for these discrepancies could be the effect of polytomies. For example, after accounting for the potential bias due to polytomies, which should be noted also greatly reduced sample size, patterns in dietary breadth using EltonTraits were not as clearly consistent with PNC. Even so, results from Levin's index still supported PNC once we accounted for the effect of polytomies. This leads us to suggest that underlying data quality played an important role in our ability to detect PNC in dietary specialization. Dietary preferences may vary temporally and spatially for the same species and such variation may be differently reflected in MammalDiet and EltonTraits (Fig. S1 in Appendix S3). Our analyses suggest that qualitative dietary descriptions and analyses of dietary breadth based on 
the total number of food items consumed are not detailed enough for exploring PNC in trophic niches.

Niche conservatism is an emergent unifying concept for ecological and evolutionary theory with profound implications for the understanding of the origins of biogeographic patterns (Wiens \& Graham, 2005; Wiens et al., 2010). The geographic distributions of species and the existence itself of large-scale diversity gradients ultimately reflect dispersal, speciation and extinction dynamics. These three processes depend on the spatial configuration of the habitat and the combination of abiotic and biotic factors that determine the ecological niches of species. A tenet of biogeography posits that the range limits of species are primarily set by abiotic factors, which are typically conserved through evolutionary time (Wiens \& Graham, 2005). For instance, the emergence of the latitudinal gradient in species richness across mammals is overall consistent with a process of climatic niche conservatism concomitantly acting with periodic niche shifts over evolutionary history (Buckley et al., 2010). On the contrary, the importance of biotic interactions in shaping large-scale biogeographic patterns remains largely unexplored.

Analyses of Eltonian niches have typically been restricted to ecological studies focusing on the role of resource utilization for species coexistence in local communities (Ackerly et al., 2006). Wiens (2011) recently called for a more integrative usage of Grinnellian and Eltonian traits to gain a better understanding on the factors that set the range limits of species and clades at biogeographic scales. He argued that climatic niche evolution may be constrained by species interactions that lead to niche pre-emption over macroevolutionary time scales. An indirect effect of trophic specialization limiting the rates of climatic niche evolution has been documented recently for damselfishes (Litsios et al., 2012). Highly specialized trophic groups showed slower evolutionary rates in their environmental niches than generalists, a pattern also detected in mammals (Cooper et al., 2011). Although not explicitly designed to explore these links, our analyses are also indicative of a possible connection between Eltonian and Grinnellian niches in determining the observed 
geographic distribution of species. In bats, the inability of most New World lineages to radiate to temperate regions seems to be determined by their metabolic demands and the energetic costs associated to their highly specialized diets (Buckley et al., 2010). This biogeographic pattern is consistent with the high degree of evolutionary conservatism in trophic niches detected for Chiroptera and for nectar consumption. All in all, these findings reinforce the view that the detection of phylogenetic conservatism is scale-dependent and highlight the importance of considering the evolution of Eltonian niche dimensions when studying physiological adaptations to novel climate regimes.

Globally, the biogeography of mammalian distributions is consistent with a scenario of prevailing climatic niche conservatism in the tropics and most novel adaptations, involving the expansion of niche breadth to new habitats and climatic regimes occurring in temperate regions (Buckley et al., 2010; Olalla-Tárraga et al., 2011; Safi et al., 2011). This non-stationary pattern is congruent between studies that characterised either realized (Olalla-Tárraga et al., 2011) or fundamental thermal niches in mammals worldwide (Khalik et al., 2015). Within carnivores, for instance, Buckley et al. (2010) detected that the Feliformia clade with a tropical origin exhibits stronger phylogenetic conservatism of thermal niches than the largely temperate Caniformia clade. Such disparate sister-clade responses may also be present in trophic Eltonian niche dimensions (i.e. the highly specialized carnivore diets of felids against the more opportunistic diets of canids) and could obscure the detection of phylogenetic signal at the level of taxonomic order.

In this study we also analysed a more-detailed database (CUFdiet) that includes quantitative estimates of food resources consumed by 73 species in the order Carnivora. We found that macroevolutionary patterns emerged when we considered quantitative estimations of the food items consumed. While a binary qualitative treatment of dietary preferences did not reveal any evidence of PNC, our analyses based on quantitative diet data did. For example, even though nearly all canids, bears and felids consume mammalian prey, the proportion of Mammal in their diet was 
variable and more similar among related species. This was not the case for the consumption of other vertebrate classes. Further, dietary specializations in Nectar, Woody and Seed were strongly phylogenetically conserved in Carnivora, showing pronounced PNC. These strong evolutionary signatures cannot be detected in analyses based on qualitative dietary descriptors again highlighting the importance of going beyond categorization and verbal descriptions in reporting and analysing diet data (Pineda-Munoz \& Alroy, 2014).

Mammals and birds have both received a great deal of attention in the macroecological and macroevolutionary literature (e.g. Diniz-Filho et al., 2009; Fritz et al., 2009; Jones et al., 2009; Cardillo, 2011; Morales-Castilla et al., 2012). Despite efforts to develop characterization schemes for their dietary preferences (Pineda-Munoz \& Alroy, 2014), it is only very recently that comprehensive species-level datasets on mammalian diets have become available for conducting global-scale analyses (Kissling et al., 2014; Wilman et al., 2014). As noted by Kissling et al. (2014), previous macroecological and/or macroevolutionary analyses of mammalian diets predominantly categorized species into three simple trophic levels, namely carnivores, omnivores and herbivores (see e.g. Kelt \& Van Vuren, 2001; Price et al., 2012; Pineda-Munoz \& Alroy, 2014; Tucker et al., 2014). This tripartite categorization prioritises trophic niche position, which characterizes the feeding resources used, but does not consider trophic niche breadth, which describes the number of feeding resources (Brändle et al., 2002). As far as we know, only Ossi \& Kamilar (2006) and Kamilar \& Cooper (2013) have examined the relationship between diet and phylogenetic relatedness in a mammalian taxonomic order. Ossi \& Kamilar (2006) analysed a small dataset for Eulemur species which was later reanalysed by Kamilar \& Cooper (2013). This second study evaluated 31 traits for 213 primate species and found that dietary and climatic niches were among the most labile traits. Kamilar \& Cooper (2013) described dietary niches based on the percentage of fruit, leaves and animal matter in the diet and report values of $\mathrm{K}$ similar to those we found for dietary breadth in Primates. Despite being low, our significance tests using biologically 
meaningful bounds suggest K values for diet breadth are consistent with BM (Kamilar \& Cooper did not test for significant departure from BM).

The paucity of phylogenetic comparative analyses of dietary specialization in mammals limits the interpretation of our findings on the evolution of this Eltonian niche-related trait. Studies of avian fauna, based on single datasets, have also yield contradictory messages. Böhning-Gaese \& Oberrath (1999) found that phylogeny accounted for $7.2 \%$ of the variation in diet for 151 bird species in central Europe, much higher than the proportion accounted for by behavioural traits but lower than that explained by morphological or life history traits. Brändle et al. (2002) estimated that half the cross-species variation in dietary breadth of birds in eastern Germany was explained at the family and genus level, which they interpreted as a clear indication of phylogenetic conservatism. However, these studies did not explicitly test for PNC. On the other hand, Pearman et al. (2014) found no evidence for PNC in climatic, habitat and trophic niches of 405 species of breeding birds in Europe. All their niche axes exhibited phylogenetic signals lower than expected under a BM model based on a theoretical $\mathrm{K}=1$. However, as we show here, smaller $\mathrm{K}$ values may actually be consistent with BM. In our analyses $\mathrm{K}$ values were also generally $<1$, but our simulation results show some of these low values support PNC.

Our study is the first global analysis of a vertebrate class aimed at examining whether or not evolutionary conservatism exists in Eltonian niches. Our findings offer novel insights to interpret which niche parameters are highly divergent or evolutionary conserved through speciation in mammals and the roles that Grinnellian and Eltonian niche conservatism may have played on the diversification and ecological differentiation of this clade. Contrary to our initial predictions, Eltonian trophic niches do not seem to show the same high levels of evolutionary conservatism consistently displayed by Grinnellian niches (Wiens \& Graham, 2005; Soberón, 2007). This provides evidence that PNC is not ubiquitous. The cold tolerances of most tropical mammals appears to be niche-limiting as they are physiologically constrained to survive in warmer areas, but 
trophic specialization does not seem to be subject to the same levels of stabilizing selection.

Although few quantitative data exist, conducting comparative studies at greater phylogenetic scales including entire clades does not always lead to detection of stronger phylogenetic signals (Losos 2008). Among-clade convergence can decrease evidence of PNC, thus analyses should be conducted considering both broad and narrow phylogenetic scales. Lack of a relationship between niche similarity and phylogenetic relatedness among species may also be due to an early burst of evolutionary divergence. Weak levels of phylogenetic signal would be expected if mammal species radiated adaptively with a burst of speciation early in the clade's history followed by slowdown evolutionary rates (Kamilar \& Muldoon, 2010). There are numerous examples of adaptive radiations in which trophic niches were not evolutionary conserved but Grinnellian climatic niches were (Cooper et al., 2010; Wiens et al., 2010). The ecomorphological diversification of early Cenozoic mammals is a paradigmatic example of adaptive radiation driven by ecological opportunity that led to the exploitation of diverse niches vacated after the extinction of non-avian dinosaurs (Luo, 2007). The evolution of key innovations in trophic strategies, in combination with other biological traits such as body size, is thought to be critical for the diversification of mammals (Price et al., 2012).

To conclude, we calculated different metrics of dietary specialization in extant mammal species and found that the detection of phylogenetic patterns for this Eltonian trait depended on the definition of trophic niche and on underlying data quality. The degree of similarity in trophic niches varied among different taxonomic groups and, importantly, even within the same group was contingent on the metric of dietary preferences used. Phylogenetic imprints on trophic niches cannot be safely inferred using only qualitative data regarding food items consumed and require more precise, quantitative or semi-quantitative descriptions of diet. Characterizing trophic niches requires capturing, or at least acknowledging, spatio-temporal variation in dietary preferences, ideally obtaining data from multiple studies and ensuring field data are not biased by methodological limitations (Martínez-Gutiérrez et al., 2015). Going beyond verbal or categorical descriptions is a 
first step towards this goal which, as we show here, can also bring interesting insights. Nearly all large carnivores eat mammals, but the proportion of their diets comprised by mammals varies such that related species are more likely to have similar proportions. Further assessments of phylogenetic imprints on dietary specialization would benefit from using well-resolved phylogenies jointly with detailed dietary information and diversity indices that enable analyses of quantitative, or at least semi-quantitative, dietary data. These analyses should also explore alternative evolutionary models to evaluate the different processes that underlie niche conservatism.

Acknowledgements: MAOT was funded by a Jose Castillejo Visiting Fellowship (CAS14/00369) from the Spanish Ministry of Education, Culture \& Sports, MGS by the European Community's Seventh Framework Programme (FP7/2007-2013) under grant agreement nº 235897 and a Juan de la Cierva post-doctoral fellowship (JCI-2011-09158), ER by the Spanish Ministry of Economy and Competitiveness (CGL2009-07301/BOS and CGL2012-35931/BOS co-funded by FEDER), RB-M by BES-2013-065753, and FV by CNPq (“Science without Borders” BJT 301540/2014-4). 


\section{References}

Ackerly, D.D., Schwilk, D.W. \& Webb, C.O. (2006) Niche evolution and adaptive radiation: testing the order of trait divergence. Ecology, 87, S50-S61.

Bininda-Emonds, O.R.P., Cardillo, M., Jones, K.E., MacPhee, R.D.E., Beck, R.M.D., Grenyer, R., Price, S.A., Vos, R.A., Gittleman, J.L. \& Purvis, A. (2007) The delayed rise of present-day mammals. Nature, 446, 507-512.

Blomberg, S.P., Garland, T. \& Ives, A. R. (2003) Testing for phylogenetic signal in comparative data: Behavioral traits are more labile. Evolution, 57, 717-745.

Böhning-Gaese, K. \& Oberrath, R. (1999) Phylogenetic effects on morphological, life-history, behavioural and ecological traits of birds. Evolutionary Ecology Research, 1, 347-364.

Brändle, R., Prinzing, A., Pfeifer, R. \& Brandl, R. (2002) Dietary niche breadth for Central European birds: correlations with species-specific traits. Evolutionary Ecology Research, 4, 643-657.

Buckley, L.B., Davies, T.J., Ackerly, D.D., Kraft, N.J., Harrison, S.P., Anacker, B.L., Cornell, H.V., Damschen, E.I., Grytnes, J.A., Hawkins, B.A., McCain, C.M., Stephens, P.R. \& Wiens, J.J. (2010) Phylogeny, niche conservatism and the latitudinal diversity gradient in mammals. Proceedings of the Royal Society B: Biological Sciences, 277, 2131-2138.

Cantalapiedra, J. L., Fitzjohn, R.G., Kuhn, T.S., Fernández, M.H., Demiguel, D., Azanza, B., Morales, J. \& Mooers, A.Ø. (2014) Dietary innovations spurred the diversification of ruminants during the Caenozoic. Proceedings of the Royal Society B: Biological Sciences, 281, 20132746. 
Cardillo, M. (2011) Phylogenetic structure of mammal assemblages at large geographical scales: linking phylogenetic community ecology with macroecology. Philosophical Transactions of the Royal Society B: Biological Sciences, 366, 2545-2553.

Cooper, N., Jetz, W. \& Freckleton, R. P. (2010) Phylogenetic comparative approaches for studying niche conservatism. Journal of Evolutionary Biology, 23, 2529-2539.

Cooper, N., Freckleton, R.P. \& Jetz, W. (2011) Phylogenetic conservatism of environmental niches in mammals. Proceedings of the Royal Society B: Biological Sciences, 278, 2384-2391.

Cooper, N., Thomas G.H., Venditti C., Meade, A. \& Freckleton, R.P. (2016) A cautionary note on the use of Ornstein Uhlenbeck models in macroevolutionary studies. Biological Journal of the Linnean Society, 118, 64-77.

Davies, T.J., Kraft, N.J., Salamin, N. \& Wolkovich, E.M. (2012) Incompletely resolved phylogenetic trees inflate estimates of phylogenetic conservatism. Ecology, 93, 242-247.

Diniz-Filho, J.A.F., Rodríguez, M.Á., Bini, L.M., Olalla-Tárraga, M.Á., Cardillo, M., Nabout, J.C., Hortal, J. \& Hawkins, B.A. (2009) Climate history, human impacts and global body size of Carnivora (Mammalia: Eutheria) at multiple evolutionary scales. Journal of Biogeography, 36, 2222-2236.

Fritz, S.A., Bininda-Emonds, O.R.P. \& Purvis, A. (2009) Geographical variation in predictors of mammalian extinction risk: big is bad, but only in the tropics. Ecology Letters, 12, 538-549.

Fritz, S.A. \& Purvis, A. (2010) Selectivity in mammalian extinction risk and threat types: a new measure of phylogenetic signal strength in binary traits. Conservation Biology, 24, 10421051. 
Jones, K.E., Bielby, J., Cardillo, M. et al. (2009) PanTHERIA: a species-level database of life history, ecology, and geography of extant and recently extinct mammals. Ecology, 90, 26482648.

Kamilar, J.M. \& Muldoon, K.M. (2010) The climatic niche diversity of Malagasy primates: A phylogenetic approach. PLoS ONE 5, e11073.

Kamilar, J.M. \& Cooper, N. (2013) Phylogenetic signal in primate behaviour, ecology and life history. Philosophical Transactions of the Royal Society B: Biological Sciences, 368, 20120341.

Khaliq, I., Fritz, S.A., Prinzinger, R., Pfenninger, M., Böhning-Gaese, K. \& Hof, C. (2015) Global variation in thermal physiology of birds and mammals: evidence for phylogenetic niche conservatism only in the tropics. Journal of Biogeography, 42, 2187-2196.

Kissling, W.D., Dalby, L., Fløjgaard, C., Lenoir, J., Sandel, B., Sandom, C., Trøjelsgaard, K. \& Svenning, J.-C. (2014) Establishing macroecological trait datasets: digitalization, extrapolation, and validation of diet preferences in terrestrial mammals worldwide. Ecology and Evolution, 4, 2913-2930.

Kelt, D.A. \& Van Vuren, D. (2001) The ecology and macroecology of mammalian home range. The American Naturalist, 157, 637-645.

Larson, E.R., Olden, J.D. \& Usio, N. (2010) Decoupled conservatism of Grinnellian and Eltonian niches in an invasive arthropod. Ecosphere, 1, 1-13.

Litsios, G., Pellissier, L., Forest, F., Lexer, C., Pearman, P.B., Zimmermann, N.E. \& Salamin, N. (2012) Trophic specialization influences the rate of environmental niche evolution in damselfishes (Pomacentridae). Proceedings of the Royal Society of London B: Biological Sciences, 279, 3662-3669. 
Losos, J.B. (2008) Phylogenetic niche conservatism, phylogenetic signal and the relationship between phylogenetic relatedness and ecological similarity among species. Ecology Letters, 11, 995-1003.

Luo, Z.X. (2007) Transformation and diversification in early mammal evolution. Nature, 450, 1011-1019.

Martínez-Gutiérrez, P.G., Palomares, F. \& Fernández, N. (2015) Predator identification methods in diet studies: uncertain assignment produces biased results? Ecography, 38, 922-929.

Morales-Castilla, I., Olalla-Tárraga, M.Á., Purvis A., Hawkins, B.A. \& Rodríguez, M.Á. (2012) The imprint of Cenozoic migrations and evolutionary history on the biogeographic gradient of body size in New World mammals. The American Naturalist, 180, 246-256

Olalla-Tárraga, M.A., Mcinnes, L., Bini, L.M., Diniz-Filho, J.A.F., Fritz, S.A., Hawkins, B.A., Hortal, J., Orme, C.D.L., Rahbek, C., Rodríguez, M.Á. \& Purvis, A. (2011) Climatic niche conservatism and the evolutionary dynamics in species range boundaries: global congruence across mammals and amphibians. Journal of Biogeography, 38, 2237-2247.

Orme, D., Freckleton, R.; Thomas, G.; Petzoldt, T.; Fritz, S.; Isaac, N. \& Pearse, W. (2013) caper: Comparative Analyses of Phylogenetics and Evolution in R. R package version 0.5.2. http://CRAN.R-project.org/package=caper

Ossi, K.M. \& Kamilar, J.M. (2006) Environmental and phylogenetic correlates of Eulemur behavior and ecology (Primates: Lemuridae). Behavioral Ecology and Sociobiology, 61, 53-64.

Pearman, P.B., Guisan, A., Broennimann, O. \& Randin, C.F. (2008) Niche dynamics in space and time. Trends in Ecology and Evolution, 23, 149-158. 
Pearman, P.B., Lavergne, S., Roquet, C., Wüest, R., Zimmermann, N.E. \& Thuiller, W. (2014) Phylogenetic patterns of climatic, habitat and trophic niches in a European avian assemblage. Global Ecology and Biogeography, 23, 414-424

Peterson, A.T. (2011) Ecological niche conservatism: a time-structured review of evidence. Journal of Biogeography, 38, 817-827.

Pineda-Munoz, S. \& Alroy, J. (2014) Dietary characterization of terrestrial mammals. Proceedings of the Royal Society B: Biological Sciences, 281, 20141173.

Price, S.A., Hopkins, S.S.B., Smith, K.K. \& Roth, V.L. (2012) Tempo of trophic evolution and its impact on mammalian diversification. Proceedings of the National Academy of Sciences USA, 109, 7008-7012.

R Core Team. 2014. R: A language and environment for statistical computing. R Foundation for Statistical Computing, Vienna, Austria. http://www.R-project.org/ (Last accessed date 03/06/2016).

Revell, L.J., Harmon, L.J. \& Collar, D.C. (2008) Phylogenetic signal, evolutionary process, and rate. Systematic Biology, 57, 591-601.

Revell, L.J. (2012) phytools: an R package for phylogenetic comparative biology (and other things). Methods in Ecology and Evolution, 3, 217-223.

Safi, K., Cianciaruso, M.V., Loyola, R.D., Brito, D., Armour-Marshall, K. \& Diniz-Filho, J.A.F. (2011) Understanding global patterns of mammalian functional and phylogenetic diversity. Philosophical Transactions of the Royal Society B: Biological Sciences, 366, 2536-2544.

Soberón, J. (2007) Grinnellian and Eltonian niches and geographic distributions of species. Ecology Letters, 10, 1115-1123. 
Tsirogiannis, C. \& Sandel, B. (2015) PhyloMeasures: Fast and Exact Algorithms for Computing Phylogenetic Biodiversity Measures. R package version 1.1. http://CRAN.Rproject.org/package $=$ PhyloMeasures

Tucker, M.A., Ord, T.J. \& Rogers, T.L. (2014) Evolutionary predictors of mammalian home range size: body mass, diet and the environment. Global Ecology and Biogeography, 23, 11051114

Webb, C.O., Ackerly, D.D., McPeek, M.A. \& Donoghue, M.J. (2002) Phylogenies and community ecology. Annual Review of Ecology, Evolution and Systematics, 33, 475-505.

Wiens, J.J. (2008) Commentary on Losos (2008): niche conservatism déjà vu. Ecology Letters, 11, 1004-1005.

Wiens, J.J. (2011) The niche, large-scale biogeography, and species interactions. Philosophical Transactions of the Royal Society B: Biological Sciences, 366, 2336-2350.

Wiens, J.J. \& Graham, C.H. (2005). Niche conservatism: integrating evolution, ecology, and conservation biology. Annual Review of Ecology, Evolution and Systematics, 36, 516-539.

Wiens, J.J., Ackerly, D.D., Allen, A.P., Anacker, B.L., Buckley, L.B., Cornell, H.V., Damschen E.I., Davies T.J., Grytnes J.-A., Harrison, S.P., Hawkins, B.A., Holt R.D., McCain, C.M. \& Stephens, P.R. (2010) Niche conservatism as an emerging principle in ecology and conservation biology. Ecology Letters, 13, 1310-1324.

Wilman, H., Belmaker, J., Simpson, J., de la Rosa, C., Rivadeneira, M.M. \& Jetz, W. (2014) EltonTraits 1.0: Species-level foraging attributes of the world's birds and mammals. Ecology, 95, 2027-2027.

Wilson, D. E. \& Reeder, D.A.M (2005) Mammal Species of the World. A Taxonomic and Geographic Reference, Johns Hopkins University Press, Baltimore. 


\section{SUPPORTING INFORMATION}

Additional Supporting Information may be found in the online version of this article:

Appendix S1 Data sources for the CUFdiet database.

Appendix S2 Complete R script used to generate reported results.

Appendix S3. Supplementary tables and figure.

BIOSKETCH: Miguel Ángel Olalla Tárraga is an associate professor interested in the macroecology, macroevolution and conservation biogeography of terrestrial vertebrates and Manuela González-Suárez is a lecturer in ecological modelling interested in population dynamics, macroecology and conservation biology, working primarily on mammalian species.

Author contributions: MAOT conceived the study and drafted a first version of the manuscript. MAOT and MGS designed the study. MGS and ER compiled the CUFDiet database. MGS and RBM processed the data. MGS helped draft the manuscript and analysed the data with contributions from FV. All authors revised the manuscript and gave final approval for publication.

Editor: Peter Linder 
Table 1. Phylogenetic signal (Blomberg's K) detected in the dietary breadth (total number of food categories consumed) of species from different mammalian orders. Dietary data obtained from MammalDIET and EltonTraits. We report $P_{R}$ as the $P$-values against a randomization test (N=1000) to determine if estimates significantly departed from expectations if there was no phylogenetic signal; and $P_{B M}$ as the probability of the observed value being greater or smaller than the expected under a Brownian model of evolution (1000 simulated datasets). We also report the mean dietary breadth for each order/group and associated standard deviation (SD). $N_{p}$ is the number of species with available data for each trait. Small orders includes mammalian orders with $\leq 20$ species with diet data: Cingulata, Dermoptera, Hyracoidea, Macroscelidea, Microbiotheria, Monotremata, Notoryctemorphia, Paucituberculata, Peramelemorphia, Perissodactyla, Pholidota, Pilosa, Proboscidea, Scandentia and Tubulidentata.

\begin{tabular}{|c|c|c|c|c|c|c|c|c|c|c|c|c|}
\hline \multirow[t]{2}{*}{ Order } & \multicolumn{6}{|c|}{ MammalDiet $(N=1921)$} & \multicolumn{6}{|c|}{ EltonTraits $(N=4246)$} \\
\hline & $N_{p}$ & $\bar{K}$ & $\overline{P_{R}}$ & $P_{B M}$ & mean & $S D$ & $\overline{N_{p}}$ & $\bar{K}$ & $\overline{P_{R}}$ & $P_{B M}$ & mean & $S D$ \\
\hline Afrosoricida & 14 & 1.22 & 0.009 & 0.728 & 1.71 & 1.267 & 41 & 2.81 & 0.001 & 0.026 & 1.29 & 0.642 \\
\hline Didelphimorphia & 38 & 0.66 & 0.046 & 0.258 & 2.24 & 1.261 & 70 & 1.81 & 0.001 & 0.026 & 3.66 & 1.328 \\
\hline Erinaceomorpha & 8 & 0.72 & 0.106 & 0.668 & 2.50 & 1.414 & 20 & 1.71 & 0.001 & 0.454 & 3.80 & 1.765 \\
\hline Lagomorpha & 44 & 0.44 & 0.003 & 0.389 & 1.18 & 1.206 & 79 & 0.11 & 0.708 & 0.001 & 1.03 & 0.158 \\
\hline Dasyuromorphia & 16 & 0.46 & 0.475 & 0.170 & 1.25 & 0.577 & 61 & 0.39 & 0.137 & 0.001 & 2.49 & 0.698 \\
\hline Diprotodontia & 39 & 0.36 & 0.608 & 0.006 & 1.69 & 1.217 & 117 & 0.60 & 0.001 & 0.543 & 2.13 & 1.236 \\
\hline Chiroptera & 424 & 0.32 & 0.001 & 0.027 & 1.51 & 0.984 & 877 & 1.01 & 0.001 & 0.998 & 1.27 & 0.650 \\
\hline Soricomorpha & 85 & 0.30 & 0.206 & 0.008 & 1.29 & 0.737 & 298 & 1.93 & 0.001 & 0.369 & 2.49 & 0.744 \\
\hline
\end{tabular}




\begin{tabular}{|c|c|c|c|c|c|c|c|c|c|c|c|c|}
\hline Primates & 218 & 0.25 & 0.001 & 0.059 & 3.02 & 1.672 & 310 & 0.53 & 0.001 & 0.370 & 3.10 & 1.257 \\
\hline Small_Orders & 58 & 0.23 & 0.014 & 0.003 & 1.62 & 1.057 & 125 & 0.29 & 0.001 & 0.058 & 1.68 & 0.930 \\
\hline Artiodactyla & 149 & 0.17 & 0.035 & 0.001 & 2.01 & 1.297 & 216 & 0.49 & 0.001 & 0.528 & 1.70 & 1.081 \\
\hline Rodentia & 626 & 0.15 & 0.001 & 0.001 & 1.84 & 1.237 & 1678 & 1.13 & 0.001 & 0.804 & 2.72 & 1.103 \\
\hline Carnivora & 202 & 0.13 & 0.208 & 0.001 & 3.08 & 1.788 & 272 & 0.20 & 0.001 & 0.001 & 2.90 & 1.318 \\
\hline Cetacea & - & - & - & - & - & - & 82 & 0.88 & 0.001 & 0.760 & 1.84 & 0.429 \\
\hline
\end{tabular}

Table 2. Phylogenetic signal detected in quantitative descriptors of mammalian dietary composition. Descriptors included: ranked presence/importance for the MammalDIET database, and numerical frequency (proportion of the items found in a sample belonging to that food category) and frequency of occurrence (proportion of the samples that contained at least one item from that food category) for the CUFdiet database. Phylogenetic signal is estimated using Blomberg's K. We report $P_{R}$ as the $P$-values against a randomization test $(\mathrm{N}=1000)$ to test if estimates significantly departed from the expected if there was no phylogenetic signal; and $P_{B M}$ as the probability of the observed value being greater or smaller than expected under a Brownian model of evolution (1000 simulated datasets). $N_{f 0}$ is the number of species with presence or frequency $=0$ for each dietary category.

\begin{tabular}{|c|c|c|c|}
\hline \multirow[t]{3}{*}{ Dietary category } & MammalDiet & EltonTraits & CUFdiet \\
\hline & Numerical importance $(N=1921)$ & Numerical freq. $(N=4246)$ & Numerical freq. $(N=53) \quad$ Freq. occurrence $(N=50)$ \\
\hline & $P_{B M}$ & $P_{B M}$ & $P_{B M} \quad \boldsymbol{N}_{f 0}$ \\
\hline
\end{tabular}




\begin{tabular}{|c|c|c|c|c|c|c|c|c|c|c|c|c|c|c|c|c|}
\hline Vert & - & - & - & - & 3898 & 0.24 & 0.001 & 0.022 & - & - & - & - & - & $\overline{-}$ & - & - \\
\hline Vend & - & - & - & - & 3860 & 0.37 & 0.001 & 0.313 & 2 & 0.11 & 0.054 & 0.064 & - & - & - & - \\
\hline Mammal & 1739 & 0.21 & 0.001 & 0.002 & - & - & - & - & 2 & 0.10 & 0.090 & 0.015 & 4 & 0.12 & 0.025 & 0.124 \\
\hline Bird & 1797 & 0.10 & 0.003 & 0.001 & - & - & - & - & 7 & 0.17 & 0.023 & 0.041 & 7 & 0.17 & 0.012 & 0.041 \\
\hline Herptile & 1766 & 0.13 & 0.001 & 0.001 & 3849 & 0.27 & 0.001 & 0.059 & 14 & 0.10 & 0.266 & 0.001 & 16 & 0.13 & 0.092 & 0.005 \\
\hline Fish & 1840 & 0.16 & 0.001 & 0.001 & 4056 & 0.32 & 0.001 & 0.118 & 40 & 0.08 & 0.666 & 0.001 & 40 & 0.13 & 0.187 & 0.004 \\
\hline Invertebrate & 866 & 0.21 & 0.001 & $>0.999$ & 1476 & 0.57 & 0.001 & $>0.999$ & 12 & 0.09 & 0.393 & 0.001 & 14 & 0.08 & 0.304 & 0.001 \\
\hline Fruit & 1198 & 0.14 & 0.001 & 0.941 & 2585 & 0.43 & 0.001 & $>0.999$ & 32 & 0.32 & 0.001 & 0.378 & 31 & 0.05 & 0.858 & 0.001 \\
\hline Nectar & 1818 & 0.18 & 0.001 & 0.001 & 4040 & 0.31 & 0.001 & 0.095 & 51 & 1.66 & 0.005 & 0.765 & 50 & - & - & - \\
\hline Woody & 1749 & 0.11 & 0.002 & 0.001 & - & - & - & - & 48 & 1.76 & 0.003 & 0.757 & 42 & 0.33 & 0.051 & 0.420 \\
\hline Grass & 1637 & 0.14 & 0.001 & 0.001 & - & - & - & - & 36 & 0.06 & 0.731 & 0.001 & 34 & 0.07 & 0.641 & 0.001 \\
\hline Seed & 1523 & 0.16 & 0.001 & 0.188 & 2932 & 0.49 & 0.001 & $>0.999$ & 46 & 0.50 & 0.013 & 0.691 & 43 & 0.02 & 0.908 & 0.001 \\
\hline Root & 1792 & 0.12 & 0.001 & 0.001 & - & - & - & - & 53 & - & - & - & 50 & - & - & - \\
\hline Plant & - & - & - & - & 2098 & 0.71 & 0.001 & $>0.999$ & - & - & - & - & - & - & - & - \\
\hline Carrion & - & - & - & - & 3895 & 0.48 & 0.001 & 0.590 & 43 & 0.07 & 0.655 & 0.001 & 44 & 0.08 & 0.69 & 0.001 \\
\hline Other & 1565 & 0.10 & 0.001 & 0.001 & - & - & - & - & - & - & - & - & - & - & - & - \\
\hline
\end{tabular}




\section{Figure Legends}

Figure 1. Available dietary data for all mammalian taxonomic orders from the two global databases (MammalDIET, N=1921; EltonTraits, $\mathrm{N}=4246)$ compared with taxonomic diversity $(\mathrm{N}=5020)$ represented by the mammalian phylogeny of Fritz et al. (2009). The CUFdiet dataset includes data for 73 species, all of them in the Order Carnivora.

Figure 2. Estimates of phylogenetic signal (Blomberg's K) detected in diverse mammal species' traits including dietary breadth (the total number of food categories consumed) as described by each dataset (MammalDIET, EltonTraits and CUFdiet) and the standardized Levin's diet index based on numerical frequency data from the EltonTraits and CUFdiet databases. Asterisks indicate significant $(<0.05)$ values for $P_{R}$ (estimates were significantly different from those expected if there was no phylogenetic signal) and for $P_{B M}$ (estimates were significantly different from those expected under a Brownian model of evolution). A point indicates marginal significance $(\mathrm{P}<0.10)$.

Figure 3. Phylogenetic signal (Blomberg's K) detected in dietary breadth (total number of food categories consumed) of species from distinct mammalian orders. Dietary data obtained from MammalDIET and EltonTraits, including only species with data in both datasets to compare estimates. Small orders include mammalian orders with $\leq 20$ species: Cingulata, Dermoptera, Hyracoidea, Macroscelidea, Microbiotheria, Monotremata, Notoryctemorphia, Paucituberculata, Peramelemorphia, Perissodactyla, Pholidota, Pilosa, Proboscidea, Scandentia and Tubulidentata. $P_{R}$ and $\mathrm{P}_{\mathrm{BM}}$ represented as in figure 2.

Figure 4. Phylogenetic signal detected in qualitative descriptors (presence/absence) of mammalian dietary composition. Phylogenetic signal is estimated using Fritz \& Purvis D ( $D=1$ when there is no phylogenetic structure). Asterisks indicate significant values for $P_{R}$ (estimates were significantly different those expected if there was no phylogenetic signal) and for $P_{B M}$ (estimates were significantly different from those expected under a Brownian model of evolution). A point indicates marginal significance. 


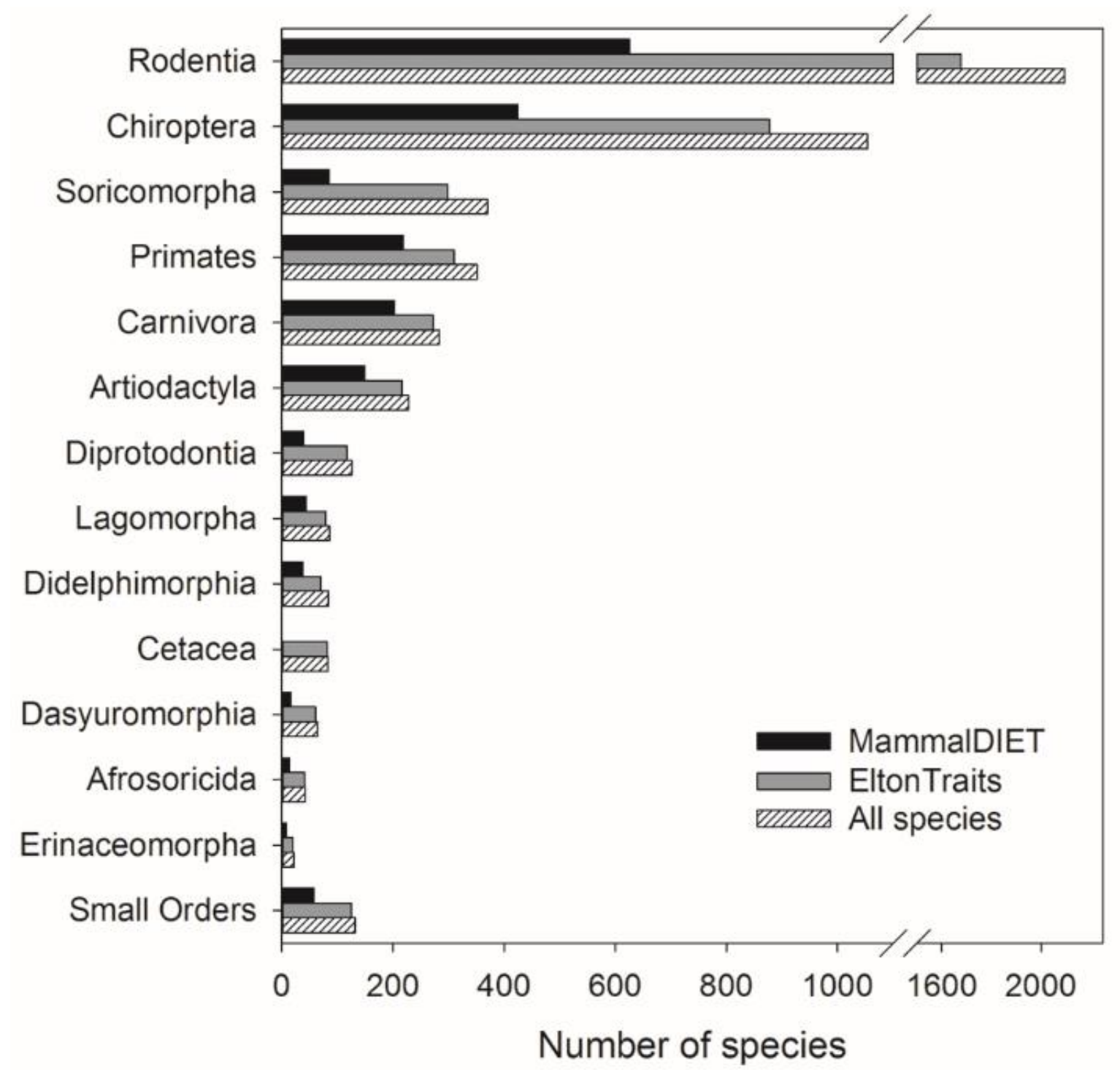

Figure 1 


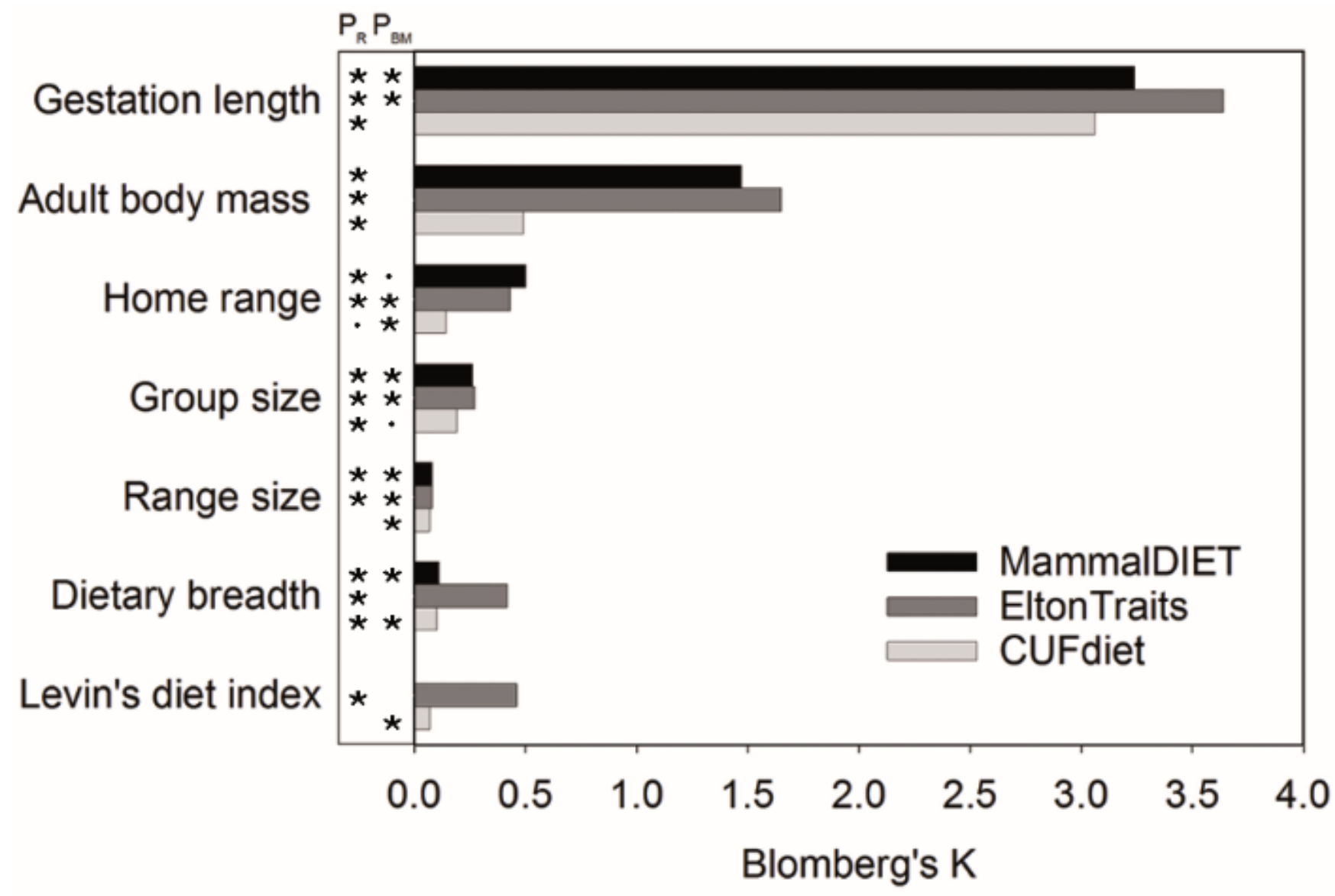

Figure 2 


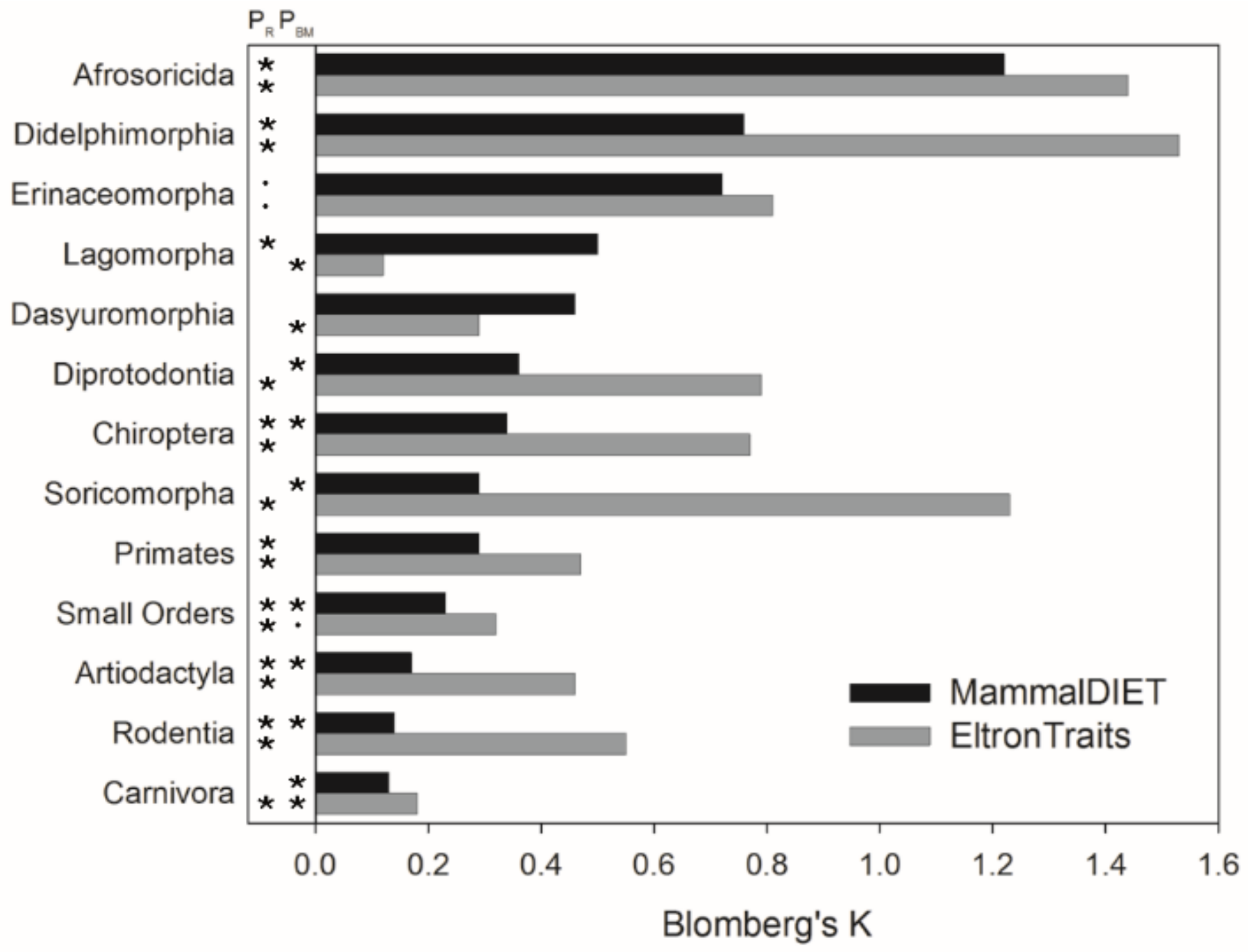

Figure 3 


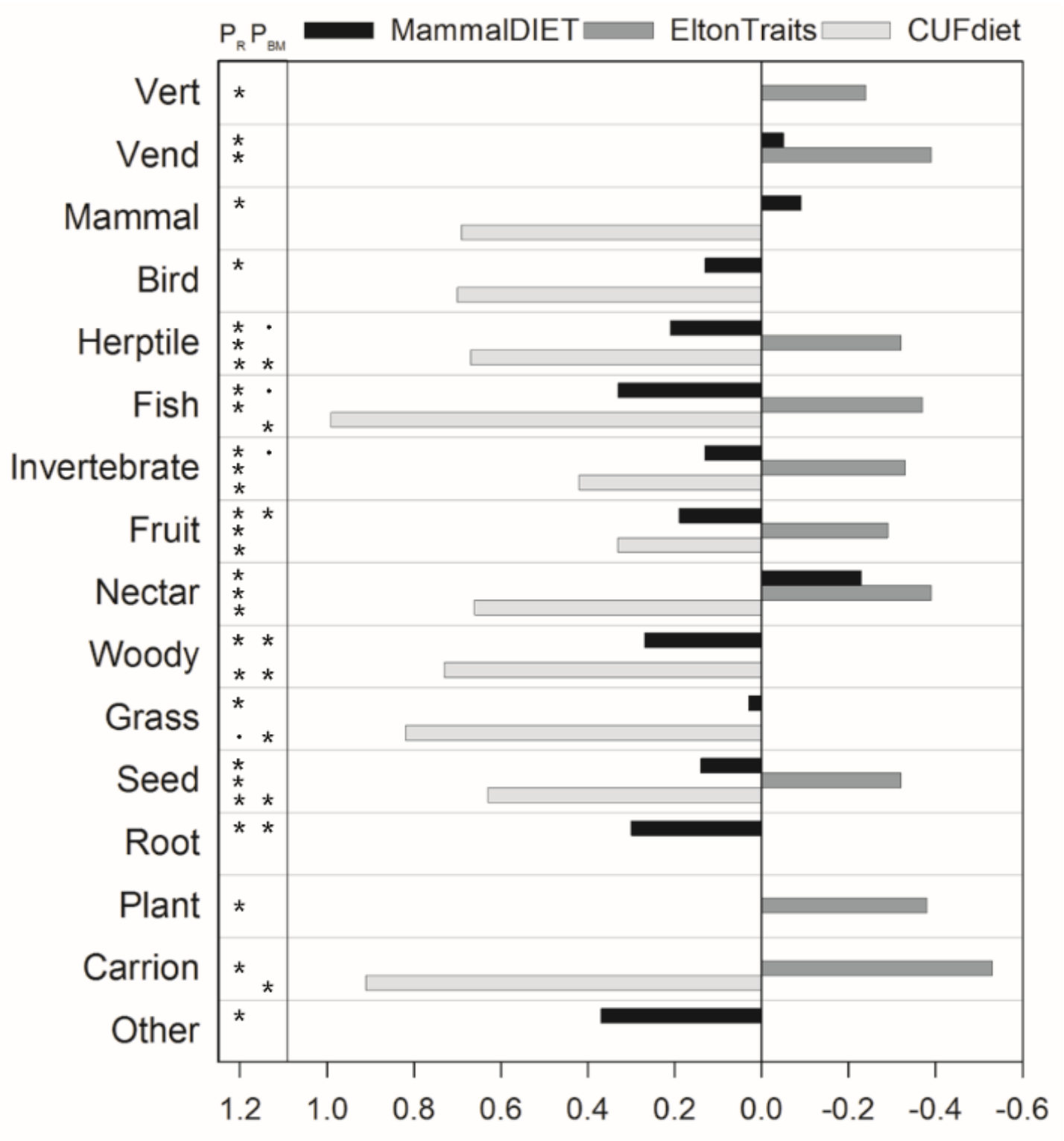

Fritz \& Purvis' D

Figure 4 


\section{SUPPORTING INFORMATION}

Appendix S1. Data sources for the CUFdiet database.

Abreu, K.C., Moro-Rios, R.F., Silva-Pereira, J.E., Miranda, J.M.D., Jablonski, E.F. \& Passos, F.C. (2008) Feeding habits of ocelot (Leopardus pardalis) in Southern Brazil. Mammalian Biology, 73, 407-411.

Acosta, G. \& Lucherini, M. (2008) Leopardus guigna. In: IUCN 2010. IUCN Red List of Threatened Species. Version 2010.4. <www.iucnredlist.org>

Alvarez-Castaneda, S.T. \& Gonzalez-Quintero, P. (2005) Winter-spring food habits of an island population of coyote Canis latrans in Baja California, Mexico. Journal of Arid Environments, 60, 397-404.

Amroun, M., Giraudoux, P. \& Delattre, P. (2006) A comparative study of the diets of two sympatric carnivores - the golden jackal (Canis aureus) and the common genet (Genetta genetta) - in Kabylia, Algeria. Mammalia, 70, 247-254.

Andheria, A.P., Karanth, K.U. \& Kumar, N.S. (2007) Diet and prey profiles of three sympatric large carnivores in Bandipur Tiger Reserve, India. Journal of Zoology, 273, 169-175.

Angerbjorn, A., Tannerfeldt, M. \& Erlinge, S. (1999) Predator-prey relationships: arctic foxes and lemmings. Journal of Animal Ecology, 68, 34-49.

Ansorge, H., Kluth, G. \& Hahne, S. (2006) Feeding ecology of wolves Canis lupus returning to Germany. Acta Theriologica, 51, 99-106.

Anthony, R.M., Barten, N.L. \& Seiser, P.E. (2000) Foods of arctic foxes (Alopex lagopus) during winter and spring in western Alaska. Journal of Mammalogy, 81, 820-828.

Apps, C.D. (2000) Space-use, diet, demographics, and topographic associations of lynx in the southern Canadian Rocky Mountains: a study. Ecology and conservation of lynx in the United States (ed. by L.F. Ruggiero, K.B. Aubry, S.W. Buskirk, G.M. Koehler, C.J. Krebs, K.S. Mckelvey and J.R. Squires). University Press of Colorado, Boulder, Colorado.

Aragona, M. \& Setz, E.Z.F. (2001) Diet of the maned wolf, Chrysocyon brachyurus (Mammalia : Canidae), during wet and dry seasons at Ibitipoca State Park, Brazil. Journal of Zoology, 254, 131136.

Arruda-Bueno, D. \& Motta-Junior, C. (2004) Food habits of two syntopic canids, the maned wolf (Chrysocyon brachyurus) and the crab-eating fox (Cerdocyon thous), in southeastern Brazil. Revista Chilena De Historia Natural, 77, 5-14.

Aryal, A. \& Kreigenhofer, B. (2009) Summer diet composition of the common leopard Panthera pardus (Carnivora: Felidae) in Nepal. Journal of Threatened Taxa, 1, 562-566.

Ashenafi, Z.T., Coulson, T., Sillero-Zubiri, C. \& Leader-Williams, N. (2005) Behaviour and ecology of the Ethiopian wolf (Canis simensis) in a human-dominated landscape outside protected areas. Animal Conservation, 8, 113-121. 
Atkinson, K.T. \& Shackleton, D.M. (1991) Coyote, Canis latrans, ecology in a rural-urban environment. Canadian Field-Naturalist, 105, 49-54.

Atkinson, R.P.D., Macdonald, D.W. \& Kamizola, R. (2002) Dietary opportunism in side-striped jackals Canis adustus Sundevall. Journal of Zoology, 257, 129-139.

Aubry, K.B., Koehler, G.M. \& Squires, J.R. (2000) Ecology of Canada lynx in southern boreal forests. Ecology and conservation of lynx in the United States., pp. 373-396.

Austin, S.C., Tewes, M.E., Grassman, L.I., Jr. \& Silvy, N.J. (2007) Ecology and conservation of the leopard cat Prionailurus bengalensis and clouded leopard Neofelis nebulosa in Khao Yai National Park, Thailand. Acta Zoologica Sinica, 53, 1-14.

Avenant, N.L. \& Nel, J.A.J. (1997) Prey use by four syntopic carnivores in a strandveld ecosystem. South African Journal of Wildlife Research, 27, 86-93.

Avenant, N.L. \& Nel, J.A.J. (2002) Among habitat variation in prey availability and use by caracal Felis caracal. Mammalian Biology, 67, 18-33.

Avery, G., Avery, D.M., Braine, S. \& Loutit, R. (1987) Prey of coastal black-backed jackal Canis mesomelas (Mammalia: Canidae) in the Skeleton Coast Park, Namibia. Journal of Zoology, 213, 81-94.

Bagchi, S., Goyal, S.P. \& Sankar, K. (2003) Prey abundance and prey selection by tigers (Panthera tigris) in a semi-arid, dry deciduous forest in western India. Journal of Zoology, 260, 285-290.

Baker, L.A., Warren, R.J., Diefenbach, D.R. \& James, W.E. (2001) Prey selection by reintroduced bobcats (Lynx rufus) on Cumberland Island, Georgia. American Midland Naturalist, 145, 80-93.

Baldwin, R.A. \& Bender, L.C. (2009) Foods and nutritional components of diets of black bear in Rocky Mountain National Park, Colorado. Canadian Journal of Zoology-Revue Canadienne De Zoologie, 87, 1000-1008.

Balestrieri, A., Remonti, L. \& Prigioni, C. (2011) Assessing carnivore diet by faecal samples and stomach contents: a case study with Alpine red foxes. Central European Journal of Biology, 6, 283292.

Baltrunaite, L. (2002) Diet composition of the red fox (Vulpes vulpes L.), pine marten (Martes martes L.) and raccoon dog (Nyctereutes procyonoides Gray) in clay plain landscape, Lithuania. Acta Zoologica Lituanica, 12, 362-368.

Bantle, J.L. \& Alisauskas, R.T. (1998) Spatial and temporal patterns in arctic fox diets at a large goose colony. Arctic, 51, 231-236.

Bargali, H.S., Akhtar, N. \& Chauhan, N.P.S. (2004) Feeding ecology of sloth bears in a disturbed area in central India. Ursus, 15, 212-217.

Barja, I. (2009) Prey and prey-age preference by the Iberian wolf Canis lupus signatus in a multiple-prey ecosystem. Wildlife Biology, 15, 147-154.

Beltran, J.F. \& Delibes, M. (1991) Ecología trófica del lince ibérico en Doñana durante un periodo seco. Doñana, Acta vertebrata, 18, 113-122. 
Benson, J.F. \& Chamberlain, M.J. (2006) Food habits of Louisiana black bears (Ursus americanus luteolus) in two subpopulations of the Tensas River Basin. American Midland Naturalist, 156, 118127.

Berry, M.P.S. (1981) Stomach contents of bat-eared foxes, Otocyon megalotis, from the Northern Transvaal. South African Journal of Wildlife Research, 11, 28-30.

Bianchi, R.C. \& Mendes, S.L. (2007) Ocelot (Leopardus pardalis) predation on primates in Caratinga Biological Station, Southeast Brazil. American Journal of Primatology, 69, 1173-1178.

Bianchi, R.D., Rosa, A.F., Gatti, A. \& Mendes, S.L. (2011) Diet of margay, Leopardus wiedii, and jaguarundi, Puma yagouaroundi, (Carnivora: Felidae) in Atlantic Rainforest, Brazil. Zoologia, 28, 127-132.

Biro, Z., Lanszki, J., Szemethy, L., Heltai, M. \& Randi, E. (2005) Feeding habits of feral domestic cats (Felis catus), wild cats (Felis silvestris) and their hybrids: trophic niche overlap among cat groups in Hungary. Journal of Zoology, 266, 187-196.

Bisbal E, F.J. (1986) Food habits of some neotropical carnivores in Venezuela (Mammalia, Carnivora). Mammalia, 50, 329-339.

Bisceglia, S.B.C., Pereira, J.A., Teta, P. \& Quintana, R.D. (2008) Food habits of Geoffroy's cat (Leopardus geoffroyi) in the central Monte desert of Argentina. Journal of Arid Environments, 72, $1120-1126$.

Bissett, C. \& Bernard, R.T.F. (2007) Habitat selection and feeding ecology of the cheetah (Acinonyx jubatus) in thicket vegetation: is the cheetah a savanna specialist? Journal of Zoology, 271, 310317.

Biswas, S. \& Sankar, K. (2002) Prey abundance and food habit of tigers (Panthera tigris tigris) in Pench National Park, Madhya Pradesh, India. Journal of Zoology, 256, 411-420.

Blumstein, D.T. \& Robertson, M. (1995) Summer diets of tibetan red foxes in Khunjerab NationalPark, Pakistan. Zeitschrift Fur Saugetierkunde-International Journal of Mammalian Biology, 60, 243-245.

Bodendorfer, T., Hoppe-Dominik, B., Fischer, F. \& Linsenmair, K.E. (2006) Prey of the leopard (Panthera pardus) and the lion (Panthera leo) in the Comoe and Marahoue National Parks, Cote d'lvoire, West Africa. Mammalia, 70, 231-246.

Boileau, F., Crete, M. \& Huot, J. (1994) Food-habits of the black bear, Ursus americanus, and habitat use in Gaspesie Park, Eastern Quebec. Canadian Field-Naturalist, 108, 162-169.

Boisjoly, D., Ouellet, J.P. \& Courtois, R. (2010) Coyote habitat selection and management implications for the Gaspesie caribou. Journal of Wildlife Management, 74, 3-11.

Borah, J., Deka, K., Dookia, S. \& Gupta, R.P. (2009) Food habits of dholes (Cuon alpinus) in Satpura Tiger Reserve, Madhya Pradesh, India. Mammalia, 73, 85-88.

Borkowski, J. (1994) Food composition of red fox in the Tatra National Park. Acta Theriologica, 39, 209-214.

Bothma, J.D. \& Leriche, E.A.N. (1994) Scat analysis and aspects of defecation in Northern Cape leopards. South African Journal of Wildlife Research, 24, 21-25. 
Bothma, J.d.P. (1966) Notes on the stomach contents of certain Carnivora (Mammalia) from the Kalahari Gemsbok Park. Koedoe, No. 9, 37-39.

Bothma, J.d.P. (1971) Food habits of some Carnivora (Mammalia) from southern Africa. Annals of the Transvaal Museum, 27, 15-26.

Bothma, J.D.P., Nel, J.A.J. \& Macdonald, A. (1984) Food niche separation between four sympatric Namib Desert carnivores. Journal of Zoology, 202, 327-340.

Bueno, A.D. \& Motta, J.C. (2009) Feeding habits of the maned wolf, Chrysocyon brachyurus (Carnivora: Canidae), in southeast Brazil. Studies on Neotropical Fauna and Environment, 44, 6775.

Bull, E.L., Torgersen, T.R. \& Wertz, T.L. (2001) The importance of vegetation, insects, and neonate ungulates in black bear diet in northeastern Oregon. Northwest Science, 75, 244-253.

Burns, R.D. (1960) Stomach contents of a kit fox. Ecology, 41, 365-365.

Calisti, M., Ciampalini, B., Lovari, S. \& Lucherini, M. (1990) Food-habits and trophic niche variation of the red fox Vulpes vulpes $(1,1758)$ in a Mediterranean coastal area. Revue D EcologieLa Terre Et La Vie, 45, 309-320.

Canepuccia, A.D., Martinez, M.M. \& Vassallo, A.I. (2007) Selection of waterbirds by Geoffroy's cat: Effects of prey abundance, size, and distance. Mammalian Biology, 72, 163-173.

Carrera, R., Ballard, W., Gipson, P., Kelly, B.T., Krausman, P.R., Wallace, M.C., Villalobos, C. \& Wester, D.B. (2008) Comparison of Mexican wolf and coyote diets in Arizona and New Mexico. Journal of Wildlife Management, 72, 376-381.

Cavalcanti, S.M.C. \& Gese, E.M. (2010) Kill rates and predation patterns of jaguars (Panthera onca) in the southern Pantanal, Brazil. Journal of Mammalogy, 91, 722-736.

Cavallini, P. \& Volpi, T. (1996) Variation in the diet of the red fox in a Mediterranean area. Revue D Ecologie-La Terre Et La Vie, 51, 173-189.

Cepek, J.D. (2004) Diet composition of coyotes in the Cuyahoga Valley National Park, Ohio. Ohio Journal of Science, 104, 60-64.

Chamberlain, M.J. \& Leopold, B.D. (1999) Dietary patterns of sympatric bobcats and coyotes in central Mississippi.

Chinchilla, F.A. (1997) Diets of Panthera onca, Felis concolor and Felis pardalis (Carnivora:

Felidae) in Parque Nacional Corcovado, Costa Rica. Revista de Biologia Tropical, 45, 1223-1229.

Clevenger, A.P. \& Purroy, F.J. (1991) Ecología del oso pardo en España. Museo Nacional de Ciencias Naturales, Consejo Superior de Investigaciones Científicas.

Clevenger, A.P., Purroy, F.J. \& Pelton, M.R. (1992) Food-habits of brown bears (Ursus arctos) in the Cantabrian mountains, Spain. Journal of Mammalogy, 73, 415-421.

Cohen, J.A. (1978) Cuon alpinus. Mammalian Species, 100, 1-3. 
Contesse, P., Hegglin, D., Gloor, S., Bontadina, F. \& Deplazes, P. (2004) The diet of urban foxes (Vulpes vulpes) and the availability of anthropogenic food in the city of Zurich, Switzerland. Mammalian Biology, 69, 81-95.

Cordero Rodriguez, G.A. \& Nassar H, J.M. (1999) Ecological data on Cerdocyon thous in Barlovento region, state of Miranda, Venezuela. Acta Biologica Venezuelica, 19, 21-26.

Correa, P. \& Roa, A. (2005) Nutritional relations between Oncifelis guigna, Lycalopex culpaeus, Lycalopex griseus and Tyto alba in a fragmented ambience of the central area of Chile.

Mastozoologia Neotropical, 12, 57-60.

Cossios, E.D. (2010) Lycalopex sechurae (Carnivora: Canidae). Mammalian Species, 848, 1-6.

Courtenay, O., Macdonald, D.W., Gillingham, S., Almeida, G. \& Dias, R. (2006) First observations on South America's largely insectivorous canid: the hoary fox (Pseudaloplex vetulus). Journal of Zoology, 268, 45-54.

Creel, S. \& Creel, N.M. (1995) Communal hunting and pack size in African wild dogs, Lycaon pictus. Animal Behaviour, 50, 1325-1339.

Croft, J.D. \& Hone, L.J. (1978) Stomach contents of foxes, Vulpes vulpes, collected in New South Wales. Australian Wildlife Research, 5, 85-92.

Crooks, K.R. \& Van Vuren, D. (1995) Resource utilization by two insular endemic mammalian carnivores, the island fox and island spotted skunk. Oecologia, 104, 301-307.

Cuesta, L., Barcena, F., Palacios, F. \& Reig, S. (1991) The trophic ecology of the Iberian wolf (Canis lupus signatus Cabrera, 1907): a new analysis of stomachs data. Mammalia, 55, 239-254.

Cunningham, P.L. \& Howarth, B. (2002) Notes on the distribution and diet of Blanford's Fox, Vulpes cana Blanford, 1877 from the United Arab Emirates. Zoology in the Middle East, 27, 21-28.

Cunningham, S.C., Gustavson, C.R. \& Ballard, W.B. (1999) Diet selection of mountain lions in southeastern Arizona. Journal of Range Management, 52, 202-207.

Cunningham, S.C., Kirkendall, L. \& Ballard, W. (2006) Gray fox and coyote abundance and diet responses after a wildfire in central Arizona. Western North American Naturalist, 66, 169-180.

Cupples, J.B., Crowther, M.S., Story, G. \& Letnic, M. (2011) Dietary overlap and prey selectivity among sympatric carnivores: could dingoes suppress foxes through competition for prey? Journal of Mammalogy, 92, 590-600.

Cutter, W.L. (1958) Food habits of the swift fox in northern Texas. Journal of Mammalogy, 39, $527-532$.

Cypher, B.L., Warrick, G.D., Otten, M.R.M., O'Farrell, T.P., Berry, H., Harris, C.E., Kato, T.T., McCue, P.M., Scrivner, J.H. \& Zoellick, B.W. (2000) Population dynamics of San Joaquin kit foxes at the Naval Petroleum Reserves in California. Wildlife Monographs, 145, 1-43.

Dalerum, F. \& Angerbjorn, A. (2000) Arctic fox (Alopex lagopus) diet in Karupelv valley, East Greenland, during a summer with low lemming density. Arctic, 53, 1-8.

de Azevedo, F.C.C. (2008) Food habits and livestock depredation of sympatric jaguars and pumas in the Iguacu National Park area, south Brazil. Biotropica, 40, 494-500. 
de Azevedo, F.C.C. \& Murray, D.L. (2007) Spatial organization and food habits of jaguars (Panthera onca) in a floodplain forest. Biological Conservation, 137, 391-402.

de Oliveira, T., Eizirik, E., Schipper, J., Valderrama, C., Leite-Pitman, R. \& Payan, E. (2008) Leopardus tigrinus. In: IUCN 2010. IUCN Red List of Threatened Species. Version 2010.2. <www.iucnredlist.org>

de Villa Meza, A., Martinez Meyer, E. \& Lopez Gonzalez, C.A. (2002) Ocelot (Leopardus pardalis) food habits in a tropical deciduous forest of Jalisco, Mexico. American Midland Naturalist, 148, 146-154.

Delgado-V, C.A. (2002) Food habits and habitat of the crab-eating fox Cerdocyon thous in the highlands of eastern Antioquia, Cordillera Central, Colombia. Mammalia, 66, 599-602.

Delibes, M. (1980) Feeding ecology of the Spanish lynx in the Coto Doñana. Acta Theriologica, 25, 309-324.

Delibes, M. \& Hiraldo, F. (1987) Food habits of the bobcat in two habitats of the southern Chihuahuan desert, Mexico. Southwestern Naturalist, 32, 457-462.

Delibes, M., Blazquez, M.C., Rodriguez-Estrella, R. \& Zapata, S.C. (1997) Seasonal food habits of bobcats (Lynx rufus) in subtropical Baja California Sur, Mexico. Canadian Journal of ZoologyRevue Canadienne De Zoologie, 75, 478-483.

DeMaster, D.P. \& Stirling, I. (1981) Ursus maritimus. Mammalian Species, 145, 1-7.

Derocher, A.E., Andriashek, D. \& Stirling, I. (1993) Terrestrial foraging by polar bears during the ice-free period in western Hudson Bay. Arctic, 46, 251-254.

Derocher, A.E., Wiig, O. \& Andersen, M. (2002) Diet composition of polar bears in Svalbard and the western Barents Sea. Polar Biology, 25, 448-452.

Dibello, F.J., Arthur, S.M. \& Krohn, W.B. (1990) Food habits of sympatric coyotes, Canis latrans, red foxes, Vulpes vulpes, and bobcats, Lynx rufus, in Maine. Canadian Field-Naturalist, 104, 403408.

Dietz, J.M. (1984) Ecology and social organization of the maned wolf (Chrysocyon brachyurus). Smithsonian Contributions to Zoology, 392, 1-51.

Dobey, S., Masters, D.V., Scheick, B.K., Clark, J.D., Pelton, M.R. \& Sunquist, M.E. (2005) Ecology of Florida black bears in the Okefenokee-Osceola ecosystem. Wildlife Monographs, 1-41.

Drygala, F., Zoller, H., Stier, N., Mix, H. \& Roth, M. (2008) Ranging and parental care of the raccoon dog Nyctereutes procyonoides during pup rearing. Acta Theriologica, 53, 111-119.

Duckworth, J.W., Steinmetz, R., Sanderson, J. \& Mukherjee, S. (2008) Felis chaus. In: IUCN 2010. IUCN Red List of Threatened Species. Version 2010.2. <www.iucnredlist.org>

Dumond, M., Villard, M.A. \& Tremblay, E. (2001) Does coyote diet vary seasonally between a protected and an unprotected forest landscape? Ecoscience, 8, 301-310.

Dunstone, N., Durbin, L., Wylie, I., Freer, R., Jamett, G.A., Mazzolli, M. \& Rose, S. (2002) Spatial organization, ranging behaviour and habitat use of the kodkod (Oncifelis guigna) in southern Chile. Journal of Zoology, 257, 1-11. 
Ebensperger, L.A., Mella, J.E. \& Simonetti, J.A. (1991) Trophic niche relationships among Galictis cuya, Dusicyon culpaeus and Tyto alba in central Chile. Journal of Mammalogy, 72, 820-823.

Edgaonkar, A. \& Chellam, R. (2002) Food habit of the leopard, Panthera pardus, in the Sanjay Gandhi National Park, Maharashtra, India. Mammalia, 66, 353-360.

Eide, N.E., Eid, P.M., Prestrud, P. \& Swenson, J.E. (2005) Dietary responses of arctic foxes Alopex lagopus to changing prey availability across an Arctic landscape. Wildlife Biology, 11, 109-121.

Elgueta, E.I., Valenzuela, J. \& Rau, J.R. (2007) New insights into the prey spectrum of Darwin's fox (Pseudalopex fulvipes Martin, 1837) on Chiloe Island, Chile. Mammalian Biology, 72, 179-185.

Elmhagen, B., Tannerfeldt, M. \& Angerbjorn, A. (2002) Food-niche overlap between arctic and red foxes. Canadian Journal of Zoology-Revue Canadienne De Zoologie, 80, 1274-1285.

Elmhagen, B., Tannerfeldt, M., Verucci, P. \& Angerbjorn, A. (2000) The arctic fox (Alopex lagopus): an opportunistic specialist. Journal of Zoology, 251, 139-149.

Emmons, L.H. (1987) Comparative feeding ecology of felids in a Neotropical rainforest. Behavioral Ecology and Sociobiology, 20, 271-283.

Facure, K.G. \& Giaretta, A.A. (1996) Food habits of carnivores in a coastal Atlantic forest of southeastern Brazil. Mammalia, 60, 499-502.

Facure, K.G. \& Monteiro-Filho, E.L.A. (1996) Feeding habits of the crab-eating fox, Cerdocyon thous (Carnivora, Canidae), in a suburban area of southeastern Brazil. Mammalia, 60, 147-149.

Facure, K.G., Giaretta, A.A. \& Monteiro-Filho, E.L.A. (2003) Food habits of the crab-eating-fox, Cerdocyon thous, in an altitudinal forest of the Mantiqueira Range, southeastern Brazil. Mammalia, 67, 503-511.

Farias, A.A. \& Kittlein, M.J. (2008) Small-scale spatial variability in the diet of pampas foxes (Pseudalopex gymnocercus) and human-induced changes in prey base. Ecological Research, 23, 543-550.

Fedriani, J.M. \& Travaini, A. (2000) Predator trophic guild assignment: the importance of the method of diet quantification. Revue D Ecologie-La Terre Et La Vie, 55, 129-139.

Fedriani, J.M., Fuller, T.K. \& Sauvajot, R.M. (2001) Does availability of anthropogenic food enhance densities of omnivorous mammals? An example with coyotes in southern California. Ecography, 24, 325-331.

Ferrari, N. \& Weber, J.M. (1995) Influence of the abundance of food resources on the feeding habits of the red fox, Vulpes vulpes, in Western Switzerland. Journal of Zoology, 236, 117-129.

Foster, R.J., Harmsen, B.J., Valdes, B., Pomilla, C. \& Doncaster, C.P. (2010) Food habits of sympatric jaguars and pumas across a gradient of human disturbance. Journal of Zoology, 280, 309318.

Fox, J.L. (1989) A review of the status and ecology of the snow leopard. International Snow Leopard Trust.

Frackowiak, W. \& Gula, R. (1992) The autumn and spring diet of brown bear Ursus arctos in the Bieszczady mountains of Poland. Acta Theriologica, 37, 339-344. 
Frafjord, K. (1993) Food habits of arctic foxes (Alopex lagopus) on the western coast of Svalbard. Arctic, 46, 49-54.

Frafjord, K. (2000) Do arctic and red foxes compete for food? Zeitschrift Fur SaugetierkundeInternational Journal of Mammalian Biology, 65, 350-359.

Fredriksson, G.M., Wich, S.A. \& Trisno (2006) Frugivory in sun bears (Helarctos malayanus) is linked to El Nino related fluctuations in fruiting phenology, East Kalimantan, Indonesia. Biological Journal of the Linnean Society, 89, 489-508.

Fuller, T.K. (1989) Population dynamics of wolves in north-central Minnesota. Wildlife Monographs, 105, 1-41.

Fuller, T.K., Nicholls, T.H. \& Kat, P.W. (1995) Prey and estimated food consumption of African wild dogs in Kenya. South African Journal of Wildlife Research, 25, 106-110.

Garcia Esponda, C.M., Carrera, J.D., Moreira, G.J., Cazon, A.V. \& de Santis, L.J.M. (2009) Microvertebrates preyed by Leopardus pajeros (Carnivora: Felidae) in southern Mendoza Province, Argentina. Mastozoologia Neotropical, 16, 455-457.

Garcia, V.B. \& Kittein, M.J. (2005) Diet, habitat use, and relative abundance of pampas fox (Pseudalopex gymnocercus) in northern Patagonia, Argentina. Mammalian Biology, 70, 218-226.

Gardner, A.L. (1971) Notes on the little spotted cat, Felis tigrina oncilla Thomas, in Costa Rica. Journal of Mammalogy, 52, 464-465.

Garla, R.C., Setz, E.Z.F. \& Gobbi, N. (2001) Jaguar (Panthera onca) food habits in Atlantic rain forest of southeastern Brazil. Biotropica, 33, 691-696.

Garshelis, D.L. (2009) Family Ursidae (bears). Handbook of the mammals of the World. Vol. 1. Carnivores (ed. by D.E. Wilson and R.A. Mittermeier). Lynx editions, Barcelona.

Gatti, A., Bianchi, R., Rosa, C.R.X. \& Mendes, S.L. (2006a) Diet of two sympatric carnivores, Cerdocyon thous and Procyon cancrivorus, in a restinga area of Espirito Santo State, Brazil. Journal of Tropical Ecology, 22, 227-230.

Gatti, A., Bianchi, R., Xavier Rosa, C.R. \& Mendes, S.L. (2006b) Diet of the crab-eating fox, Cerdocyon thous (Carnivora, Canidae) in Paulo Cesar Vinha State Park, Espirito Santo State, Brazil. Mammalia, 70, 153-155.

Gau, R.J., Case, R., Penner, D.F. \& McLoughlin, P.D. (2002) Feeding patterns of barren-ground grizzly bears in the central Canadian Arctic. Arctic, 55, 339-344.

Gazzola, A., Bertelli, I., Avanzinelli, E., Tolosano, A., Bertotto, P. \& Apollonio, M. (2005) Predation by wolves (Canis lupus) on wild and domestic ungulates of the western Alps, Italy. Journal of Zoology, 266, 205-213.

Geertsema, A.A. (1985) Aspects of the ecology of the serval Leptailurus serval in the Ngorongoro crater, Tanzania. Netherlands Journal of Zoology, 35, 527-610.

Geffen, E., Hefner, R., Macdonald, D.W. \& Ucko, M. (1992a) Diet and foraging behavior of the Blanford's foxes Vulpes cana in Israel. Journal of Mammalogy, 73, 395-402. 
Geffen, E., Degen, A.A., Kam, M., Hefner, R. \& Nagy, K.A. (1992b) Daily energy expenditure and water flux of free-living Blanford's foxes (Vulpes cana), a small desert carnivore. Journal of Animal Ecology, 61, 611-617.

Germain, E., Ruette, S. \& Poulle, M.L. (2009) Likeness between the food habits of European wildcats, domestic cats and their hybrids in France. Mammalian Biology, 74, 412-417.

Giannatos, G., Karypidou, A., Legakis, A. \& Polymeni, R. (2010) Golden jackal (Canis aureus L.) diet in Southern Greece. Mammalian Biology, 75, 227-232.

Gil-Sanchez, J.M., Ballesteros-Duperon, E. \& Bueno-Segura, J.F. (2006) Feeding ecology of the Iberian lynx Lynx pardinus in eastern Sierra Morena (Southern spain). Acta Theriologica, 51, 8590 .

Glen, A.S., Fay, A.R. \& Dickman, C.R. (2006) Diets of sympatric red foxes Vulpes vulpes and wild dogs Canis lupus in the northern rivers region, New South Wales. Australian Mammalogy, 28, 101104.

Goldyn, B., Hromada, M., Surmacki, A. \& Tryjanowski, P. (2003) Habitat use and diet of the red fox Vulpes vulpes in an agricultural landscape in Poland. Zeitschrift Fur Jagdwissenschaft, 49, 191200.

Grassman, L. (1999) Ecology and behaviour of the Indochinese leopard in Kaeng Krachan National Park, Thailand. Natural History Bulletin of the Siam Society, 47, 77-93.

Grassman, L.I. (2000) Movements and diet of the leopard cat Prionailurus bengalensis in a seasonal evergreen forest in south-central Thailand. Acta Theriologica, 45, 421-426.

Grassman, L.I., Tewes, M.E., Silvy, N.J. \& Kreetiyutanont, K. (2005a) Spatial ecology and diet of the dhole Cuon alpinus (Canidae, Carnivora) in north central Thailand. Mammalia, 69, 11-20.

Grassman, L.I., Tewes, M.E., Silvy, N.J. \& Kreetiyutanont, K. (2005b) Spatial organization and diet of the leopard cat (Prionailurus bengalensis) in north-central Thailand. Journal of Zoology, 266, 45-54.

Green, K. (2003) Altitudinal and temporal differences in the food of foxes (Vulpes vulpes) at alpine and subalpine altitudes in the Snowy Mountains. Wildlife Research, 30, 245-253.

Green, K. \& Osborne, W.S. (1981) The diet of foxes, Vulpes vulpes (L), in relation to abundance of prey above the winter snowline in New South Wales. Australian Wildlife Research, 8, 349-360.

Greenleaf, S.S., Matthews, S.M., Wright, R.G., Beecham, J.J. \& Leithead, H.M. (2009) Food habits of American black bears as a metric for direct management of human-bear conflict in Yosemite Valley, Yosemite National Park, California. Ursus, 20, 94-101.

Grobler, J.H. (1981) Feeding behavior of the caracal Caracal caracal Schreber 1776 in the Mountain Zebra National Park. South African Journal of Zoology, 16, 259-262.

Guerrero, S., Badii, M.H., Zalapa, S.S. \& Flores, A.E. (2002) Diet and feeding niche of coyote, grey fox, racoon and jaguarundi in a tropical deciduous forest on the south coast of Jalisco state, Mexico. Acta Zoologica Mexicana Nueva Serie, 86, 119-137.

Guzman-Sandoval, J., Sielfeld, W. \& Ferru, M. (2007) Diet of Lycalopex culpaeus (Mammalia: Canidae) in northernmost Chile (Tarapaca region). Gayana, 71, 1-7. 
Hamer, D., Herrero, S. \& Brady, K. (1991) Food and habitat used by grizzly bears, Ursus arctos, along the continental divide in Waterton Lakes National Park, Alberta. Canadian Field-Naturalist, 105, 325-329.

Haque, N. \& Vijayan, V. (1995) Food of fishing cat in Keoladeo National Park, India. Cat News, 22, 19.

Harrison, R.L. (1997) A comparison of gray fox ecology between residential and undeveloped rural landscapes. Journal of Wildlife Management, 61, 112-122.

Harrison, R.L. (2003) Swift fox demography, movements, denning, and diet in New Mexico. Southwestern Naturalist, 48, 261-273.

Hart, J.A., Katembo, M. \& Punga, K. (1996) Diet, prey selection and ecological relations of leopard and golden cat in the Ituri Forest, Zaire. African Journal of Ecology, 34, 364-379.

Hartova-Nentvichova, M., Salek, M., Cerveny, J. \& Koubek, P. (2010) Variation in the diet of the red fox (Vulpes vulpes) in mountain habitats: Effects of altitude and season. Mammalian Biology, 75, 334-340.

Hashimoto, Y. (2002) Seasonal food habits of the Asiatic black bear (Ursus thibetanus) in the Chichibu Mountains, Japan. Mammal Study, 27, 65-72.

Hashimoto, Y., Kaji, M., Sawada, H. \& Takatsuki, S. (2003) Five-year study on the autumn food habits of the Asiatic black bear in relation to nut production. Ecological Research, 18, 485-492.

Hass, C.C. (2009) Competition and coexistence in sympatric bobcats and pumas. Journal of Zoology, 278, 174-180.

Hawbecker, A.C. (1943) Food of the San Joaquin Kit Fox. Journal of Mammalogy, 24, 499.

Hayward, M.W., Hofmeyr, M., O'Brien, J. \& Kerley, G.I.H. (2006) Prey preferences of the cheetah (Acinonyx jubatus) (Felidae : Carnivora): morphological limitations or the need to capture rapidly consumable prey before kleptoparasites arrive? Journal of Zoology, 270, 615-627.

Henschel, P., Abernethy, K.A. \& White, L.J.T. (2005) Leopard food habits in the Lope National Park, Gabon, Central Africa. African Journal of Ecology, 43, 21-28.

Herbst, M. \& Mills, M.G.L. (2010) The feeding habits of the Southern African wildcat, a facultative trophic specialist, in the southern Kalahari (Kgalagadi Transfrontier Park, South Africa/Botswana). Journal of Zoology, 280, 403-413.

Hersteinsson, P. \& Macdonald, D.W. (1996) Diet of arctic foxes (Alopex lagopus) in Iceland. Journal of Zoology, 240, 457-474.

Hewson, R. (1983) The food of wild cats (Felis silvestris) and red foxes (Vulpes vulpes) in the west and northeast Scotland. Journal of Zoology, 200, 283-289.

Hiscocks, K. \& Perrin, M.R. (1987) Feeding observations and diet of black-bakced jackals in an arid coastal environment. South African Journal of Wildlife Research, 17, 55-58.

Hockman, J.G. \& Chapman, J.A. (1983) Comparative feeding habits of red foxes (Vulpes vulpes) and gray foxes (Urocyon cineroargenteus) in Maryland. American Midland Naturalist, 110, 276285. 
Holcroft, A.C. \& Herrero, S. (1991) Black bear, Ursus americanus, food-habits in Southwestern Alberta. Canadian Field-Naturalist, 105, 335-345.

Home, C. \& Jhala, Y.V. (2009) Food habits of the Indian fox (Vulpes bengalensis) in Kutch, Gujarat, India. Mammalian Biology, 74, 403-411.

Hoppedominik, B. (1984) Prey frequency of the leopard, Panthera pardus, in the Tai National Park of the Ivory Coast. Mammalia, 48, 477-487.

Hovens, J.P.M. \& Tungalaktuja, K. (2005) Seasonal fluctuations of the wolf diet in the Hustai National Park (Mongolia). Mammalian Biology, 70, 210-217.

Huey, R.B. (1969) Winter diet of the Peruvian desert fox. Ecology, 50, 1089-1091.

Hunter, J.S., Durant, S.M. \& Caro, T.M. (2007) To flee or not to flee: predator avoidance by cheetahs at kills. Behavioral Ecology and Sociobiology, 61, 1033-1042.

Iriarte, J.A., Jimenez, J.E., Contreras, L.C. \& Jaksic, F.M. (1989) Small mammal availability and consumption by the fox Dusicyon culpaeus in central Chile scrublands. Journal of Mammalogy, $\mathbf{7 0}$, 641-645.

Jacomo, A.T.d.A., Silveira, L. \& Diniz, J.A.F. (2004) Niche separation between the maned wolf (Chrysocyon brachyurus), the crab-eating fox (Dusicyon thous) and the hoary fox (Dusicyon vetulus) in central Brazil. Journal of Zoology, 262, 99-106.

Jaeger, M.M., Haque, E., Sultana, P. \& Bruggers, R.L. (2007) Daytime cover, diet and space-use of golden jackals (Canis aureus) in agro-ecosystems of Bangladesh. Mammalia, 71, 1-10.

Jaksic, F.M., Schlatter, R.P. \& Yanez, J.L. (1980) Feeding ecology of central Chilean foxes Dusicyon culpaeus and Dusicyon griseus. Journal of Mammalogy, 61, 254-260.

Jaksic, F.M., Yanez, J.L. \& Rau, J.R. (1983) Trophic relations of the southernmost populations of Dusicyon in Chile. Journal of Mammalogy, 64, 693-697.

Jaksic, F.M., Jimenez, J.E., Medel, R.G. \& Marquet, P.A. (1990) Habitat and diet of the Darwin fox (Pseudalopex fulvipes) on the Chilean mainland. Journal of Mammalogy, 71, 246-248.

Jedrzejewski, W. \& Jedrzejewska, B. (1992) Foraging and diet of the red fox Vulpes vulpes in relation to variable food resources in Bialowieza National Park, Poland. Ecography, 15, 212-220.

Jedrzejewski, W., Schmidt, K., Milkowski, L., Jedrzejewska, B. \& Okarma, H. (1993) Foraging by lynx and its role in ungulate mortality - the local (Bialowieza Forest) and the palearctic viewpoints. Acta Theriologica, 38, 385-403.

Jimenez, J.E. (2007) Ecology of a coastal population of the critically endangered Darwin's fox (Pseudalopex fulvipes) on Chiloe Island, southern Chile. Journal of Zoology, 271, 63-77.

Jimenez, J.E., Marquet, P.A., Medel, R.G. \& Jaksic, F.M. (1990) Comparative ecology of Darwin fox (Pseudalopex fulvipes) in mainland and island settings of southern Chile. Revista Chilena De Historia Natural, 63, 177-186.

Jobin, A., Molinari, P. \& Breitenmoser, U. (2000) Prey spectrum, prey preference and consumption rates of Eurasian lynx in the Swiss Jura Mountains. Acta Theriologica, 45, 243-252. 
Johnsingh, A.J.T. (1992) Prey selection in three large sympatric carnivores in Bandipur. Mammalia, 56, 517-526.

Johnson, K.G., Wang, W., Reid, D.G. \& Hu, J.C. (1993) Food-habits of asiatic leopards (Panthera pardus fusea) in Wolong Reserve, Sichuan, China. Journal of Mammalogy, 74, 646-650.

Johnson, W.E. \& Franklin, W.L. (1991) Feeding and spatial ecology of Felis geoffroyi in southern Patagonia. Journal of Mammalogy, 72, 815-820.

Johnson, W.E. \& Franklin, W.L. (1994) Role of body size in the diets of sympatric gray and culpeo foxes. Journal of Mammalogy, 75, 163-174.

Jones, D.M. \& Theberge, J.B. (1983) Variation in red fox, Vulpes vulpes, summer diets in Northwest British Columbia and Southwest Yukon. Canadian Field-Naturalist, 97, 311-314.

Joseph, S., Thomas, A.P., Satheesh, R. \& Sugathan, R. (2007) Foraging ecology and relative abundance of large carnivores in Parambikulam Wildlife Sanctuary, southern India. Zoos' Print Journal, 22, 2667-2670.

Joshi, A.R., Garshelis, D.L. \& Smith, J.L.D. (1997) Seasonal and habitat-related diets of sloth bears in Nepal. Journal of Mammalogy, 78, 584-597.

Kaikusalo, A. \& Angerbjorn, A. (1995) The arctic fox population in finnish Lapland during 30 years, 1964-93. Annales Zoologici Fennici, 32, 69-77.

Kamler, J.F., Ballard, W.B., Wallace, M.C. \& Gipson, P.S. (2007) Diets of swift foxes (Vulpes velox) in continuous and fragmented prairie in northwestern Texas. Southwestern Naturalist, $\mathbf{5 2}$, 504-510.

Kapel, C.M.O. (1999) Diet of arctic foxes (Alopex lagopus) in Greenland. Arctic, 52, 289-293.

Karanth, K.U. \& Sunquist, M.E. (1995) Prey selection by tiger, leopard and dhole in tropical forests. Journal of Animal Ecology, 64, 439-450.

Karwanishi, K. \& Sunquist, M.E. (2008) Food habits and activity patterns of the Asiatic golden cat (Catopuma temminckii) and dhole (Cuon alpinus) in a primary rainforest of Peninsular Malaysia. Mammal Study, 33, 173-177.

Kauhala, K. (1996) Reproductive strategies of the raccoon dog and the red fox in Finland. Acta Theriologica, 41, 51-58.

Kauhala, K. \& Auniola, M. (2001) Diet of raccoon dogs in summer in the Finnish archipelago. Ecography, 24, 151-156.

Kauhala, K., Laukkanen, P. \& Von ReÌ• ge, I. (1998) Summer food composition and food niche overlap of the raccoon dog, red fox and badger in Finland. Ecography, 21, 457-463.

Kaunda, S.K.K. \& Skinner, J.D. (2003) Black-backed jackal diet at Mokolodi Nature Reserve, Botswana. African Journal of Ecology, 41, 39-46.

Khan, M.M.H. (2004) Food habit of the leopard cat Prionailurus bengalensis (Kerr, 1792) in the Sundarbans East Wildlife Sanctuary, Bangladesh. Zoos' Print Journal, 19, 1475-1476. 
Kidawa, D. \& Kowalczyk, R. (2011) The effects of sex, age, season and habitat on diet of the red fox Vulpes vulpes in northeastern Poland. Acta Theriologica, 56, 209-218.

Kilgore, D.L. (1969) An ecological study of swift fox (Vulpes velox) in Oklahoma panhandle. American Midland Naturalist, 81, 512-534.

Kitchen, A.M., Gese, E.M. \& Schauster, E.R. (1999) Resource partitioning between coyotes and swift foxes: space, time, and diet. Canadian Journal of Zoology-Revue Canadienne De Zoologie, 77, 1645-1656.

Kitchener, A. (1991) The natural history of the wild cats. Comstock Pub. Associates, Ithaca, N.Y.

Klare, U., Kamler, J.F., Stenkewitz, U. \& Macdonald, D.W. (2010) Diet, prey selection, and predation impact of black-backed jackals in South Africa. Journal of Wildlife Management, 74, 1030-1042.

Knopff, K.H., Knopff, A.A., Kortello, A. \& Boyce, M.S. (2010) Cougar kill rate and prey composition in a multiprey system. Journal of Wildlife Management, 74, 1435-1447.

Koehler, G.M. \& Hornocker, M.G. (1991) Seasonal resource use among mountain lions, bobcats, and coyotes. Journal of Mammalogy, 72, 391-396.

Koike, S. (2010) Long-term trends in food habits of Asiatic black bears in the Misaka Mountains on the Pacific coast of central Japan. Mammalian Biology, 75, 17-28.

Kok, O.B. \& Nel, J.A.J. (1992) Diet of the bat-eared fox in the Orange Free State and Northern Cape Province. South African Journal of Wildlife Research, 22, 36-39.

Kok, O.B. \& Nel, J.A.J. (2004) Convergence and divergence in prey of sympatric canids and felids: opportunism or phylogenetic constraint? Biological Journal of the Linnean Society, 83, 527-538.

Konecny, M.J. (1989) Movement patterns and food habits of four sympatric carnivore species in Belize, Central America. In: Advances in Neotropical Mammalogy eds. K.H. Redford and J.F. Eisenberg), pp. 243-264. Sandhill Crane Press, Gainesville, Florida.

Kowalski, K. (1988) The food of the sand fox Vulpes rueppelli Schinz, 1825 in the Egyptian Sahara. Folia Biologica (Cracow), 36, 89-94.

Kozlowski, J., Gese, E.M. \& Arjo, W.M. (2008) Niche overlap and resorce partitioning between sympatric kit foxes and coyotes in the Great Basin Desert of Western Utah. American Midland Naturalist, 160, 191-208.

Kruger, S.C., Lawes, M.J. \& Maddock, A.H. (1999) Diet choice and capture success of wild dog (Lycaon pictus) in Hluhluwe-Umfolozi Park, South Africa. Journal of Zoology, 248, 543-551.

Kubarsepp, M. \& Valdmann, H. (2003) Winter diet and movements of wolf (Canis lupus) in Alampedja Nature Reserve, Estonia. Acta Zoologica Lituanica, 13, 28-33.

Kunkel, K.E., Ruth, T.K., Pletscher, D.H. \& Hornocker, M.G. (1999) Winter prey selection by wolves and cougars in and near Glacier National Park, Montana. Journal of Wildlife Management, 63, 901-910.

Kuntzsch, V. \& Nel, J.A.J. (1992) Diet of bat-eared foxes Otocyon megalotis in the Karoo. Koedoe, 35, 37-48. 
Lanszki, J. (2005) Diet composition of red fox during rearing in a moor: a case study. Folia Zoologica, 54, 213-216.

Lanszki, J. \& Heltai, M. (2002) Feeding habits of golden jackal and red fox in south-western Hungary during winter and spring. Mammalian Biology, 67, 129-136.

Lanszki, J., Heltai, M. \& Szabo, L. (2006) Feeding habits and trophic niche overlap between sympatric golden jackal (Canis aureus) and red fox (Vulpes vulpes) in the Pannonian ecoregion (Hungary). Canadian Journal of Zoology-Revue Canadienne De Zoologie, 84, 1647-1656.

Lanszki, J., Zalewski, A. \& Horvath, G. (2007) Comparison of red fox Vulpes vulpes and pine marten Martes martes food habits in a deciduous forest in Hungary. Wildlife Biology, 13, 258-271.

Lanszki, J., Kormendi, S., Hancz, C. \& Zalewski, A. (1999) Feeding habits and trophic niche overlap in a Carnivora community of Hungary. Acta Theriologica, 44, 429-442.

Laurie, A. \& Seidensticker, J. (1977) Behavioral ecology of sloth bear (Melursus ursinus). Journal of Zoology, 182, 187-204.

Leberg, P.L., Carloss, M.R., Dugas, L.J., Pilgrim, K.L., Mills, L.S., Green, M.C. \& Scognamillo, D. (2004) Recent record of a cougar (Puma concolor) in Louisiana, with notes on diet, based on analysis of fecal materials. Southeastern Naturalist, 3, 653-658.

Leckie, F.M., Thirgood, S.J., May, R. \& Redpath, S.M. (1998) Variation in the diet of red foxes on Scottish moorland in relation to prey abundance. Ecography, 21, 599-604.

Leite Pitman, M.R.P. \& Williams, R.S.R. (2004) Short-eared dog Atelocynus microtis. Canids: foxes, wolves, jackals and dogs. Status survey and conservation action plan (ed. by C. SilleroZubiri, M. Hoffmann and D.W. Macdonald). IUCN/SSC Canid Specialist Group, Gland, Switzerland.

Lenain, D.M., Olfermann, E. \& Warrington, S. (2004) Ecology, diet and behaviour of two fox species in a large, fenced protected area in central Saudi Arabia. Journal of Arid Environments, 57, 45-60.

Leroux, P.G. \& Skinner, J.D. (1989) A note on the ecology of the leopard (Panthera pardus linnaeus) in the Londolozi Game Reserve, South Africa. African Journal of Ecology, 27, 167-171.

Lima, E.D., Jorge, R.S.P. \& Dalponte, J.C. (2009) Habitat use and diet of bush dogs, Speothos venaticus, in the Northern Pantanal, Mato Grosso, Brazil. Mammalia, 73, 13-19.

Lindsay, I.M. \& Macdonald, D.W. (1986) Behaviour and ecology of the Ruppell's fox, Vulpes ruppelli in Oman. Mammalia, 50, 461-474.

Liu, B.W. \& Jiang, Z.G. (2003) Diet composition of wolves Canis lupus in the northeastern Qinghai-Tibet Plateau, China. Acta Theriologica, 48, 255-263.

Liu, Q.X., Harris, R.B. \& Wang, X.M. (2010) Food habits of the Tibetan fox (Vulpes ferrilata) in the Kunlun Mountains, Qinghai Province, China. Mammalian Biology, 75, 283-286.

Loveridge, A.J. \& Macdonald, D.W. (2003) Niche separation in sympatric jackals (Canis mesomelas and Canis adustus). Journal of Zoology, 259, 143-153. 
Lu, Z., Wang, D. \& Garshelis, D.L. (2008) Ailuropoda melanoleuca. In: IUCN 2010. IUCN Red List of Threatened Species. Version 2010.2. <www.iucnredlist.org>

Lucherini, M. \& Crema, G. (1994) Seasonal-variation in diet and trophic niche of the red fox in an alpine habitat. Zeitschrift Fur Saugetierkunde-International Journal of Mammalian Biology, 59, 18.

Ludwig, G., Aguiar, L.M., Miranda, J.M.D., Teixeira, G.M., Svoboda, W.K., Malanski, L.S., Shiozawa, M.M., Hilst, C.L.S., Navarro, I.T. \& Passos, F.C. (2007) Cougar predation on black-andgold howlers on Mutum Island, southern Brazil. International Journal of Primatology, 28, 39-46.

Macdonald, D.W. \& Courtenay, O. (1996) Enduring social relationships in a population of crabeating zorros, Cerdocyon thous, in Amazonian Brazil (Carnivora, Canidae). Journal of Zoology, 239, 329-355.

Macdonald, D.W. \& Loveridge, A.J. (2010) Biology and conservation of wild felids. Oxford University Press, Oxford; New York.

MacDonald, J.T. \& Nel, J.A.J. (1986) Comparative diets of sympatric small carnivores. South African Journal of Wildlife Research, 16, 115-121.

Macfadem-Juarez, K. \& Marinho-Filho, J. (2002) Diet, habitat use, and home ranges of sympatric canids in central Brazil. Journal of Mammalogy, 83, 925-933.

Maehr, D.S. \& Brady, J.R. (1986) Food habits of bobcats Lynx rufus in Florida. Journal of Mammalogy, 67, 133-138.

Malcolm, J. (1997) The diet of the Ethiopian wolf (Canis simensis Ruppell) from a grassland area of the Bale Mountains, Ethiopia. African Journal of Ecology, 35, 162-164.

Malcolm, J.R. (1986) Socio-ecology of bat-eared foxes (Otocyon megalotis). Journal of Zoology, 208, $457-467$.

Mallon, D.P., Sliwa, A. \& Strauss, M. (2008) Felis margarita. In: IUCN 2010. IUCN Red List of Threatened Species. Version 2010.2. <www.iucnredlist.org>

Malo, A.F., Lozano, J., Huertas, D.L. \& Virgos, E. (2004) A change of diet from rodents to rabbits (Oryctolagus cuniculus). Is the wildcat (Felis silvestris) a specialist predator? Journal of Zoology, 263, 401-407.

Manfredi, C., Lucherini, M., Canepuccia, A.D. \& Casanave, E.B. (2004) Geographical variation in the diet of Geoffroy's cat (Oncifelis geoffroyi) in Pampas grassland of Argentina. Journal of Mammalogy, 85, 1111-1115.

Manzani, P.R. \& Filho, E. (1989) Notes on the food-habits of the jaguarundi, Felis yagouaroundi (Mammalia, Carnivora). Mammalia, 53, 659-660.

Marino, J., Mitchell, R. \& Johnson, P.J. (2010) Dietary specialization and climatic-linked variations in extant populations of Ethiopian wolves. African Journal of Ecology, 48, 517-525.

Marker, L.L., Muntifering, J.R., Dickman, A.J., Mills, M.G.L. \& Macdonald, D.W. (2003)

Quantifying prey preferences of free-ranging Namibian cheetahs. South African Journal of Wildlife Research, 33, 43-53. 
Marquet, P.A., Contreras, L.C., Torres-Mura, J.C., Silva, S.I. \& Jaksic, F.M. (1993) Food habits of Pseudalopex foxes in the Atacama desert, pre-Andean ranges, and the high-Andean plateau of northernmost Chile. Mammalia, 57, 130-135.

Martins, Q., Horsnell, W.G.C., Titus, W., Rautenbach, T. \& Harris, S. (2011) Diet determination of the Cape Mountain leopards using global positioning system location clusters and scat analysis. Journal of Zoology, 283, 81-87.

Martins, R., Quadros, J. \& Mazzolli, M. (2008) Food habits and anthropic interference on the territorial marking activity of Puma concolor and Leopardus pardalis (Carnivora: Felidae) and other carnivores in the Jureia-Itatins Ecological Station, Sao Paulo, Brazil. Revista Brasileira De Zoologia, 25, 427-435.

Matlack, C.R. \& Evans, A.J. (1992) Diet and condition of bobcats, Lynx rufus, in Nova Scotia during autumn and winter. Canadian Journal of Zoology-Revue Canadienne De Zoologie, 70, 11141119.

Matsuo, R. \& Ochiai, K. (2009) Dietary overlap among two introduced and one native sympatric carnivore species, the raccoon, the masked palm civet, and the raccoon dog, in Chiba prefecture, Japan. Mammal Study, 34, 187-194.

Mattson, D.J., Blanchard, B.M. \& Knight, R.R. (1991) Food-habits of Yellowstone grizzly bears, 1977-1987. Canadian Journal of Zoology-Revue Canadienne De Zoologie, 69, 1619-1629.

McBride, R., Giordano, A. \& Ballard, W.B. (2010) Note on the winter diet of jaguars Panthera onca in the paraguayan transitional Chaco. Bellbird, 4

McKinney, T. \& Smith, T.W. (2007) Diets of sympatric bobcats and coyotes during years of varying rainfall in central Arizona. Western North American Naturalist, 67, 8-15.

McLean, M.L., McCay, T.S. \& Lovallo, M.J. (2005) Influence of age, sex and time of year on diet of the bobcat (Lynx rufus) in Pennsylvania. American Midland Naturalist, 153, 450-453.

McShane, T.O. \& Grettenberger, J.F. (1984) Food of the golden jackal (Canis aureus) in central Niger. African Journal of Ecology, 22, 49-53.

Medel, R.G. \& Jaksic, F.M. (1988) Ecology of South American canids: a review. Revista Chilena de Historia Natural, 61, 67-80.

Medel, R.G., Jimenez, J.E., Jaksic, F.M., Yanez, J.L. \& Armesto, J.J. (1990) Discovery of a continental population of the rare Darwin fox, Dusicyon fulvipes (Martin, 1837) in Chile. Biological Conservation, 51, 71-77.

Melville, H., Bothma, J.D. \& Mills, M.G.L. (2004) Prey selection by caracal in the Kgalagadi Transfrontier Park. South African Journal of Wildlife Research, 34, 67-75.

Meriggi, A., Rosa, P., Brangi, A. \& Matteucci, C. (1991) Habitat use and diet of the wolf in northern Italy. Acta Theriologica, 36, 141-151.

Merkle, J.A., Krausman, P.R., Stark, D.W., Oakleaf, J.K. \& Ballard, W.B. (2009) Summer diet of the Mexican gray wolf (Canis lupus baileyi). Southwestern Naturalist, 54, 480-485.

Meserve, P.L., Shadrick, E.J. \& Kelt, D.A. (1987) Diets and selectivity of two Chilean predators in the northern semi-arid zone. Revista Chilena de Historia Natural, 60, 93-100. 
Mills, J.K. (1984) Food habits of bobcats, Lynx rufus, in Nova Scotia. Canadian Field-Naturalist, 98, 50-51.

Mills, M.G.L. \& Gorman, M.L. (1997) Factors affecting the density and distribution of wold dogs in the Kruger National Park. Conservation Biology, 11, 1397-1406.

Mills, M.G.L., Broomhall, L.S. \& du Toit, J.T. (2004) Cheetah Acinonyx jubatus feeding ecology in the Kruger National Park and a comparison across African savanna habitats: is the cheetah only a successful hunter on open grassland plains? Wildlife Biology, 10, 177-186.

Moleon, M. \& Gil-Sanchez, J.M. (2003) Food habits of the wildcat (Felis silvestris) in a peculiar habitat: the Mediterranean high mountain. Journal of Zoology, 260, 17-22.

Molsher, R.L., Gifford, E.J. \& McIlroy, J.C. (2000) Temporal, spatial and individual variation in the diet of red foxes (Vulpes vulpes) in central New South Wales. Wildlife Research, 27, 593-601.

Moreno, R.S., Kays, R.W. \& Samudio, R. (2006) Competitive release in diets of ocelot (Leopardus pardalis) and puma (Puma concolor) after jaguar (Panthera onca) decline. Journal of Mammalogy, 87, 808-816.

Morey, P.S., Gese, E.M. \& Gehrt, S. (2007) Spatial and temporal variation in the diet of coyotes in the Chicago metropolitan area. American Midland Naturalist, 158, 147-161.

MottaJunior, J.C., Talamoni, S.A., Lombardi, J.A. \& Simokomaki, K. (1996) Diet of the maned wolf, Chrysocyon brachyurus, in central Brazil. Journal of Zoology, 240, 277-284.

Mukherjee, S., Goyal, S.P., Johnsingh, A.J.T. \& Pitman, M. (2004) The importance of rodents in the diet of jungle cat (Felis chaus), caracal (Caracal caracal) and golden jackal (Canis aureus) in Sariska Tiger Reserve, Rajasthan, India. Journal of Zoology, 262, 405-411.

Murdoch, J.D., Munkhzul, T., Buyandelger, S., Reading, R.P. \& Sillero-Zubiri, C. (2010) Seasonal food habits of corsac and red foxes in Mongolia and the potential for competition. Mammalian Biology, 75, 36-44.

Napolitano, C., Bennett, M., Johnson, W.E., O'Brien, S.J., Marquet, P.A., Barria, I., Poulin, E. \& Iriarte, A. (2008) Ecological and biogeographical inferences on two sympatric and enigmatic Andean cat species using genetic identification of faecal samples. Molecular Ecology, 17, 678-690.

Naves, J., Fernandez-Gil, A., Rodriguez, C. \& Delibes, M. (2006) Brown bear food habits at the border of its range: A long-term study. Journal of Mammalogy, 87, 899-908.

Neale, J.C.C. \& Sacks, B.N. (2001) Food habits and space use of gray foxes in relation to sympatric coyotes and bobcats. Canadian Journal of Zoology-Revue Canadienne De Zoologie, 79, 1794-1800.

Nel, J.A.J. (1990) Foraging and feeding by bat-eared foxes Otocyon megalotis in the southwestern Kalahari. Koedoe, 33, 9-16.

Nel, J.A.J., Loutit, R. \& Bothma, J.D. (1997) Prey use by black-backed jackals along a desert coast. South African Journal of Wildlife Research, 27, 100-104.

Nelson, J.L., Cypher, B.L., Bjurlin, C.D. \& Creel, S. (2007) Effects of habitat on competition between kit foxes and coyotes. Journal of Wildlife Management, 71, 1467-1475. 
Novack, A.J., Main, M.B., Sunquist, M.E. \& Labisky, R.F. (2005) Foraging ecology of jaguar (Panthera onca) and puma (Puma concolor) in hunted and non-hunted sites within the Maya Biosphere Reserve, Guatemala. Journal of Zoology, 267, 167-178.

Novaro, A.J., Walker, R.S. \& Suarez, M. (1995) Dry-season food habits of the gray fox (Urocyon cinereoargenteus fraterculus) in the Belizean Peten. Mammalia, 59, 19-24.

Novaro, A.J., Funes, M.C. \& Walker, R.S. (2000) Ecological extinction of native prey of a carnivore assemblage in Argentine Patagonia. Biological Conservation, 92, 25-33.

Nowak, R.M. (1999) Walker's mammals of the world, 6th edn. Johns Hopkins University Press, Baltimore.

Nowell, K. \& Jackson, P. (1996a) Asiatic golden cat, Catopuma temmincki (Vigors and Horsfield, 1827). Wild Cats. Status survey and conservation action plan (ed. by K. Nowell and P. Jackson). IUCN/SSC Cat Specialist Group, Gland, Switzerland.

Nowell, K. \& Jackson, P. (1996b) Black-footed cat, Felis nigripes Burchell, 1824. Wild Cats. Status survey and conservation action plan (ed. by K. Nowell and P. Jackson). IUCN/SSC Cat Specialist Group, Gland, Switzerland.

Nowell, K. \& Jackson, P. (1996c) Chinese mountain cat, Felis bieti Milne-Edwards, 1892. Wild Cats. Status survey and conservation action plan (ed. by K. Nowell and P. Jackson). IUCN/SSC Cat Specialist Group, Gland, Switzerland.

Nowell, K. \& Jackson, P. (1996d) Flat-headed cat, Prionailurus planiceps (Vigors and Horsfield, 1827). Wild Cats. Status survey and conservation action plan (ed. by K. Nowell and P. Jackson), Gland, Switzerland.

Nowell, K. \& Jackson, P. (1996e) Jungle cat, Felis chaus Schreber, 1777. Wild Cats. Status survey and conservation action plan (ed. by K. Nowell and P. Jackson). IUCN/SSC Cat Specialist Group, Gland, Switzerland.

Nowell, K. \& Jackson, P. (1996f) Manul, Otocolobus manul (Pallas, 1776). Wild Cats. Status survey and conservation action plan (ed. by K. Nowell and P. Jackson). IUCN/SSC Cat Specialist Group, Gland, Switzerland.

Nowell, K. \& Jackson, P. (1996g) Oncilla, Leopardus tigrinus (Schreber, 1775). Wild Cats. Status survey and conservation action plan (ed. by K. Nowell and P. Jackson). IUCN/SSC Cat Specialist Group, Gland, Switzerland.

Nunez, R., Miller, B. \& Lindzey, F. (2000) Food habits of jaguars and pumas in Jalisco, Mexico. Journal of Zoology, 252, 373-379.

Odden, J., Linnell, J.D.C. \& Andersen, R. (2006) Diet of Eurasian lynx, Lynx lynx, in the boreal forest of southeastern Norway: the relative importance of livestock and hares at low roe deer density. European Journal of Wildlife Research, 52, 237-244.

Okarma, H., Jedrzejewski, W., Schmidt, K., Kowalczyk, R. \& Jedrzejewska, B. (1997) Predation of Eurasian lynx on roe deer and red deer in Bialowieza Primeval Forest, Poland. Acta Theriologica, 42, 203-224.

Oli, M.K., Taylor, I.R. \& Rogers, M.E. (1993) Diet of the snow leopard (Panthera uncia) in the Annapurna Conservation Area, Nepal. Journal of Zoology, 231, 365-370. 
Olmos, F. (1993) Notes on the food habits of Brazilian 'Caatinga' carnivores. Mammalia, 57, 126130 .

Ott, T., Kerley, G.I.H. \& Boshoff, A.F. (2007) Preliminary observations on the diet of leopards (Panthera pardus) from a conservation area and adjacent rangelands in the Baviaanskloof region, South Africa. African Zoology, 42, 31-37.

Padial, J.M., Avila, E. \& Gil-Sanchez, J.M. (2002) Feeding habits and overlap among red fox (Vulpes vulpes) and stone marten (Martes foina) in two Mediterranean mountain habitats. Mammalian Biology, 67, 137-146.

Pagh, S. \& Hersteinsson, P. (2008) Difference in diet and age structure of blue and white Arctic foxes (Vulpes lagopus) in the Disko Bay area, West Greenland. Polar Research, 27, 44-51.

Palmer, R. \& Fairall, N. (1988) Caracal and African wild cat diet in the Karoo National Park and the implications thereof for hyrax. South African Journal of Wildlife Research, 18, 30-34.

Palomares, F., Delibes, M., Revilla, E., Calzada, J. \& Fedriani, J.M. (2001) Spatial ecology of Iberian lynx and abundance of European rabbits in southwestern Spain. Wildlife Monographs, 1-36.

Paralikidis, N.P., Papageorgiou, N.K., Kontsiotis, V.J. \& Tsiompanoudis, A.C. (2010) The dietary habits of the Brown bear (Ursus arctos) in western Greece. Mammalian Biology, 75, 29-35.

Parker, G.R. (1986) The seasonal diet of coyotes, Canis latrans, in northern New Brunswick. Canadian Field-Naturalist, 100, 74-77.

Parker, G.R. \& Smith, G.E.J. (1983) Sex specific and age specific reproductive and physical parameters of the bobcat (Lynx rufus) on Cape Breton island, Nova Scotia Canadian Journal of Zoology-Revue Canadienne De Zoologie, 61, 1771-1782.

Parker, G.R., Maxwell, J.W., Morton, L.D. \& Smith, G.E.J. (1983) The ecology of the lynx (Lynx canadensis) on Cape Breton Island. Canadian Journal of Zoology-Revue Canadienne De Zoologie, 61, 770-786.

Pechacek, P., Lindzey, F.G. \& Anderson, S.H. (2000) Autumn and winter diet of the swift fox (Vulpes velox) in south-eastern Wyoming. Hystrix, 11, 83-87.

Pedo, E., Tomazzoni, A.C., Hartz, S.M. \& Christoff, A.U. (2006) Diet of crab-eating fox, Cerdocyon thous (Linnaeus) (Carnivora, Canidae), in a suburban area of southern Brazil. Revista Brasileira De Zoologia, 23, 637-641.

Persson, I.L., Wikan, S., Swenson, J.E. \& Mysterud, I. (2001) The diet of the brown bear Ursus arctos in the Pasvik Valley, northeastern Norway. Wildlife Biology, 7, 27-37.

Peyton, B. (1980) Ecology, distribution, and food-habits of spectacled bears, Tremarctos ornatus, in Peru. Journal of Mammalogy, 61, 639-652.

Phillips, R.B., Winchell, C.S. \& Schmidt, R.H. (2007) Dietary overlap of an alien and native carnivore on San Clemente Island, California. Journal of Mammalogy, 88, 173-180.

Pia, M.V., Lopez, M.S. \& Novaro, A.J. (2003) Effects of livestock on the feeding ecology of endemic culpeo foxes (Pseudalopex culpaeus smithersi) in central Argentina. Revista Chilena de Historia Natural, 76, 313-321. 
Purchase, G.K. \& du Toit, J.T. (2000) The use of space and prey by cheetahs in Matusadona National Park, Zimbabwe. South African Journal of Wildlife Research, 30, 139-144.

Queirolo, D. \& Motta-Junior, J.C. (2007) Prey availability and diet of maned wolf in Serra da Canastra National Park, southeastern Brazil. Acta Theriologica, 52, 391-402.

Quinn, T. (1997) Coyote (Canis latrans) food habits in three urban habitat types of western Washington. Northwest Science, 71, 1-5.

Rabinowitz, A. (1990) Notes on the behavior and movements of leopard cats, Felis bengalensis, in a dry tropical forest mosaic in Thailand. Biotropica, 22, 397-403.

Rabinowitz, A.R. \& Nottingham, B.G. (1986) Ecology and behavior of the jaguar (Panthera onca) in Belize, Central America. Journal of Zoology, 210, 149-159.

Rajaratnam, R., Sunquist, M., Rajaratnam, L. \& Ambu, L. (2007) Diet and habitat selection of the leopard cat (Prionailurus bengalensis borneoensis) in an agricultural landscape in Sabah, Malaysian Borneo. Journal of Tropical Ecology, 23, 209-217.

Rau, J. \& Jimenez, J.E. (2002) Dieta otoño-invernal del zorro de Darwin: una comparación entre dos hábitats de Chiloé, Chile. Gestion Ambiental, 8, 57-62.

Rau, J.R., Martinez, D.R., Low, J.R. \& Tilleria, M.S. (1995) Depredacion por zorros chillas (Pseudalopex griseus) sobre micromamiferos cursoriales, escansoriales y arboricolas en un area silvestre protegida del sur de Chile. Revista Chilena de Historia Natural, 68, 333-340.

Reddy, H.S., Srinivasulu, C. \& Rao, K.T. (2004) Prey selection by the Indian tiger (Panthera tigris tigris) in Nagarjunasagar Srisailam Tiger Reserve, India. Mammalian Biology, 69, 384-391.

Reed, J.E., Ballard, W.B., Gipson, P.S., Kelly, B.T., Krausman, P.R., Wallace, M.C. \& Wester, D.B. (2006) Diets of free-ranging Mexican gray wolves in Arizona and New Mexico. Wildlife Society Bulletin, 34, 1127-1133.

Reichel, J.D. (1991) Relationships among coyote food habits, prey populations, and habitat use. Northwest Science, 65, 133-137.

Reid, D., Jiang, M., Teng, Q., Qin, Z. \& Hu, J. (1991) Ecology of the asiatic black bear (Ursus thibetanus) in Sichuan, China. Mammalia, 55, 221-237.

Richards, D.F. (1977) Observations on the diet of the Red fox (Vulpes vulpes) in South Devon. Journal of Zoology, 183, 495-504.

Rios-Uzeda, B., Villalpando, G., Palabral, O. \& Alvarez, O. (2009) Spectacled bear diet in the Apolobamba and Madidi highlands in Northern of La Paz, Bolivia. Ecologia en Bolivia, 44, 50-55.

Rivadeneira-Canedo, C. (2008) Study of the Andean bear (Tremarctos ornatus) as a legitimate seed disperser and elements of its diet in the region of Apolobamba-Bolivia. Ecologia en Bolivia, 43, 2939.

Roberts, M.W., Dexter, N., Meek, P.D., Hudson, M. \& Buttemer, W.A. (2006) Does baiting influence the relative composition of the diet of foxes? Wildlife Research, 33, 481-488.

Robertson, P.A. \& Whelan, J. (1987) The food of the red fox (Vulpes vulpes) in Co Kildare, Ireland. Journal of Zoology, 213, 740-743. 
Rocha-Mendes, F., Mikich, S.B., Quadros, J. \& Wagner, A.P. (2010) Feeding ecology of carnivores (Mammalia, Carnivora) in Atlantic Forest remnants, Southern Brazil. Biota Neotropica, 10, 21-30.

Rocha, V.J., Aguiar, L.M., Silva-Pereira, J.E., Moro-Rios, R.F. \& Passo, F.C. (2008) Feeding habits of the crab-eating fox, Cerdocyon thous (Carnivora: Canidae), in a mosaic area with native and exotic vegetation in Southern Brazil. Revista Brasileira De Zoologia, 25, 594-600.

Rodel, H.G., Scholze, W.W.A. \& Paulsch, A. (2004) Notes on the feeding habits of the leopard in the alpine zone of Mount Kenya. Mammalia, 68, 61-63.

Romo, M.C. (1995) Food habits of the Andean fox (Pseudalopex culpaeus) and notes on the mountain cat (Felis colocolo) and puma (Felis concolor) in the Rio Abiseo National Park, Peru. Mammalia, 59, 335-343.

Rosas-Rosas, O.C., Valdez, R., Bender, L.C. \& Daniel, D. (2003) Food hahits of pumas in northwestern Sonora, Mexico. Wildlife Society Bulletin, 31, 528-535.

Rose, M.D. \& Polis, G.A. (1998) The distribution and abundance of coyotes: The effects of allochthonous food subsidies from the sea. Ecology, 79, 998-1007.

Ross, S., Munkhtsog, B. \& Harris, S. (2010) Dietary composition, plasticity, and prey selection of Pallas's cats. Journal of Mammalogy, 91, 811-817.

Ross, S., Murdoch, J., Mallon, D., Sanderson, J. \& Barashkova, A. (2008) Otocolobus manul. In: IUCN 2010. IUCN Red List of Threatened Species. Version 2010.2. <www.iucnredlist.org>

Rowe-Rowe, D.T. (1983) Black-backed jackal diet in relation to food availability in the Natal Drakensberg. South African Journal of Wildlife Research, 13, 17-23.

Russell, A.J.M. \& Storch, I. (2004) Summer food of sympatric red fox and pine marten in the German Alps. European Journal of Wildlife Research, 50, 53-58.

Sakaguchi, N. \& Ono, Y. (1994) Seasonal change in the food-habits of the iriomote cat Felis iriomotensis. Ecological Research, 9, 167-174.

Salvador, A. \& Abad, P.L. (1987) Food habits of a wolf population (Canis lupus) in Leon province, Spain. Mammalia, 51, 45-52.

Samson, C. \& Crete, M. (1997) Summer food habits and population density of Coyotes, Canis latrans, in boreal forests of southeastern Quebec. Canadian Field-Naturalist, 111, 227-233.

Sanderson, J., Sunquist, M.E. \& Iriarte, A.W. (2002) Natural history and landscape-use of guignas (Oncifelis guigna) on Isla Grande de Chiloe, Chile. Journal of Mammalogy, 83, 608-613.

Sankar, K. \& Johnsingh, A.J.T. (2002) Food habits of Tiger (Panthera tigris) and Leopard (Panthera pardus) in Sariska Tiger Reserve, Rajasthan, India, as shown by scat analysis. Mammalia, 66, 285-289.

Santos, E.F., Setz, E.Z.F. \& Gobbi, N. (2003) Diet of the maned wolf (Chrysocyon brachyurus) and its role in seed dispersal on a cattle ranch in Brazil. Journal of Zoology, 260, 203-208.

Sarmento, P. (1996) Feeding ecology of the European wildcat Felis silvestris in Portugal. Acta Theriologica, 41, 409-414. 
Sato, Y., Mano, T. \& Takatsuki, S. (2005) Stomach contents of brown bears Ursus arctos in Hokkaido, Japan. Wildlife Biology, 11, 133-144.

Saunders, G., Berghout, M., Kay, B., Triggs, B., van de Ven, R. \& Winstanley, R. (2004) The diet of foxes (Vulpes vulpes) in south-eastern Australia and the potential effects of rabbit haemorrhagic disease. Wildlife Research, 31, 13-18.

Schmidt, K. (2008) Behavioural and spatial adaptation of the Eurasian lynx to a decline in prey availability. Acta Theriologica, 53, 1-16.

Scognamillo, D., Maxit, I.E., Sunquist, M. \& Polisar, J. (2003) Coexistence of jaguar (Panthera onca) and puma (Puma concolor) in a mosaic landscape in the Venezuelan llanos. Journal of Zoology, 259, 269-279.

Serafini, P. \& Lovari, S. (1993) Food-habits and trophic niche overlap of the red fox and the stone marten in a Mediterranean rural area. Acta Theriologica, 38, 233-244.

Servheen, C. (1983) Grizzly bear food-habits, movements, and habitat selection in the Mission Mountains, Montana. Journal of Wildlife Management, 47, 1026-1035.

Sidorovich, V.E., Sidorovich, A.A. \& Izotova, I.V. (2006) Variations in the diet and population density of the red fox Vulpes vulpes in the mixed woodlands of northern Belarus. Mammalian Biology, 71, 74-89.

Sidorovich, V.E., Solovej, I.A., Sidorovich, A.A. \& Dyman, A.A. (2008) Seasonal and annual variation in the diet of the raccoon dog Nyctereutes procyonoides in northern Belarus: The role of habitat type and family group. Acta Theriologica, 53, 27-38.

Sillero-Zubiri, C. (2009) Family Canidae (dogs). Handbook of the mammals of the World. Vol. 1. Carnivores (ed. by D.E. Wilson and R.A. Mittermeier). Lynx editions, Barcelona.

Sillero-Zubiri, C. \& Gottelli, D. (1995) Diet and feeding behavior of Ethiopian wolves (Canis simensis). Journal of Mammalogy, 76, 531-541.

Silva-Rodriguez, E.A., Ortega-Solis, G.R. \& Jimenez, J.E. (2010) Conservation and ecological implications of the use of space by chilla foxes and free-ranging dogs in a human-dominated landscape in southern Chile. Austral Ecology, 35, 765-777.

Silva, S.I., Bozinovic, F. \& Jaksic, F.M. (2005) Frugivory and seed dispersal by foxes in relation to mammalian prey abundance in a semiarid thornscrub. Austral Ecology, 30, 739-746.

Sliwa, A. (1994) Black-footed cat studies in South Africa. Cat News, 20, 15-19.

Sliwa, A. (2006) Seasonal and sex-specific prey composition of black-footed cats Felis nigripes. Acta Theriologica, 51, 195-204.

Smith, R.M. (1978) Movement patterns and feeding behaviour of the leopard in the Rhodes Matopos National Park, Rhodesia. Carnivore (Seattle), 1, 58-69.

Smithers, R.H.N. (1978) Serval Felis serval, Schreber, 1776. South African Journal of Wildlife Research, 8, 29-37. 
Smits, C.M.M., Slough, B.G. \& Yasui, C.A. (1989) Summer food-habits of sympatric arctic foxes, Alopex lagopus, and red foxes, Vulpes vulpes, in the Northern Yukon Territory. Canadian FieldNaturalist, 103, 363-367.

Sousa, K.S. \& Bager, A. (2008) Feeding habits of Geoffroy's cat (Leopardus geoffroyi) in southern Brazil. Mammalian Biology, 73, 303-308.

Southern, H.N. \& Watson, J.S. (1941) Summer food of the red fox (Vulpes vulpes) in Great Britain: A preliminary report. Journal of Animal Ecology, 10, 1-11.

Sovada, M.A., Roy, C.C. \& Telesco, D.J. (2001) Seasonal food habits of swift fox (Vulpes velox) in cropland and rangeland landscapes in western Kansas. American Midland Naturalist, 145, 101-111.

Squires, J.R. \& Ruggiero, L.F. (2007) Winter prey selection of Canada lynx in northwestern Montana. Journal of Wildlife Management, 71, 310-315.

Sreekumar, P.G. \& Balakrishnan, M. (2002) Seed dispersal by the sloth bear (Melursus ursinus) in South India. Biotropica, 34, 474-477.

Stoen, O.G. \& Wegge, P. (1996) Prey selection and prey removal by tiger (Panthera tigris) during the dry season in lowland Nepal. Mammalia, 60, 363-373.

Stuart, C. \& Stuart, M. (2007) Diet of leopard and caracal in the northern United Arab Emirates and adjoining Oman Territory. Cat News, 46, 30-31.

Stuart, C.T. \& Shaughnessy, P.D. (1984) Contents of Hyaena brunnea and Canis mesomelas scats from souther coastal Namibia. Mammalia, 48, 611-612.

Sunde, P. \& Kvam, T. (1997) Diet patterns of Eurasian lynx Lynx lynx: What causes sexually determined prey size segregation? Acta Theriologica, 42, 189-201.

Sunquist, M.E. \& Sunquist, F.C. (2009) Family Felidae (cats). Handbook of the mammals of the World. Vol. 1. Carnivores (ed. by D.E. Wilson and R.A. Mittermeier). Lynx editions, Barcelona.

Sutor, A., Kauhala, K. \& Ansorge, H. (2010) Diet of the raccoon dog Nyctereutes procyonoides -A canid with an opportunistic foraging strategy. Acta Theriologica, 55, 165-176.

Thompson, D.J., Fecske, D.M., Jenks, J.A. \& Jarding, A.R. (2009) Food habits of recolonizing cougars in the Dakotas: prey obtained from prairie and agricultural habitats. American Midland Naturalist, 161, 69-75.

Thornton, D.H., Sunquist, M.E. \& Main, M.B. (2004) Ecological separation within newly sympatric populations of coyotes and bobcats in south-central Florida. Journal of Mammalogy, 85, 973-982.

Thurber, J.M. \& Peterson, R.O. (1993) Effects of population density and pack size on the foraging ecology of gray wolves. Journal of Mammalogy, 74, 879-889.

Thurber, J.M., Peterson, R.O., Woolington, J.D. \& Vucetich, J.A. (1992) Coyote coexistence with wolves on the Kenai Peninsula, Alaska. Canadian Journal of Zoology-Revue Canadienne De Zoologie, 70, 2494-2498.

Tofoli, C.F., Rohe, F. \& Setz, E.Z.F. (2009) Jaguarundi (Puma yagouaroundi) (Geoffroy, 1803) (Carnivora, Felidae) food habits in a mosaic of Atlantic Rainforest and eucalypt plantations of southeastern Brazil. Brazilian Journal of Biology, 69, 871-877. 
Tortato, M.A. \& de Oliveira, T.G. (2005) Ecology of the oncilla (Leopardus tigrinus) at Serra do Tabuleiro State Park, southern Brazil. Cat News, 42, 28-30.

Tremblay, J.-P., Crete, M. \& Huot, J. (1998) Summer foraging behaviour of eastern coyotes in rural versus forest landscape: a possible mechanism of source-sink dynamics. Ecoscience, 5, 172-182.

Trovati, R.G., de Campos, C.B. \& de Brito, B.A. (2008) Notes on convergence and divergence feed of canids and felids (Mammalia: Carnivora) sympatric in the Brazilian Cerrado. Neotropical Biology and Conservation, 3, 95-100.

Troya, V., Cuesta, F. \& Peralvo, M. (2004) Food habits of Andean bears in the Oyacachi River basin, Ecuador. Ursus, 15, 57-60.

Tryjanowski, P., Antczak, M., Hromada, M., Kuczynski, L. \& Skoracki, M. (2002) Winter feeding ecology of male and female European wildcats Felis silvestris in Slovakia. Zeitschrift Fur Jagdwissenschaft, 48, 49-54.

Uresk, D.W. \& Sharps, J.C. (1986) Denning habitat and diet of the swift fox in Western South Dakota. Great Basin Naturalist, 46, 249-253.

Valdmann, H., Andersone-Lilley, Z., Koppa, O., Ozolins, J. \& Bagrade, G. (2005) Winter diets of wolf Canis lupus and lynx Lynx lynx in Estonia and Latvia. Acta Theriologica, 50, 521-527.

Vanak, A.T. \& Gompper, M.E. (2009) Dietary niche separation between sympatric free-ranging domestic dogs and indian foxes in central India. Journal of Mammalogy, 90, 1058-1065.

Varela, O., Cormenzana-Mendez, A., Krapovickas, L. \& Bucher, E.H. (2008) Seasonal diet of the Pampas fox (Lycalopex gymnocercus) in the chaco dry woodland, northwestern Argentina. Journal of Mammalogy, 89, 1012-1019.

Venkataraman, A.B., Arumugam, R. \& Sukumar, R. (1995) The foraging ecology of dhole (Cuon alpinus) in Mudumalai Sanctuary, southern India. Journal of Zoology, 237, 543-561.

Vieira, E.M. \& Port, D. (2007) Niche overlap and resource partitioning between two sympatric fox species in southern Brazil. Journal of Zoology, 272, 57-63.

Vlachos, C.G., Bakaloudis, D.E., Dimitriou, M., Kritikou, K. \& Chouvardas, D. (2000) Seasonal food habits of the European brown bear (Ursus arctos) in the Pindos Mountains, Western Greece. Folia Zoologica, 49, 19-25.

Wachter, B., Jauernig, O. \& Breitenmoser, U. (2006) Determination of prey hair in faeces of freeranging Namibian cheetahs with a simple method. Cat News, 44, 8-9.

Walker, R.S., Novaro, A.J., Perovic, P., Palacios, R., Donadio, E., Lucherini, M., Pia, M. \& Lopez, M.S. (2007) Diets of three species of Andean carnivores in high-altitude deserts of Argentina. Journal of Mammalogy, 88, 519-525.

Wang, E. (2002) Diets of ocelots (Leopardus pardalis), margays (L. wiedii), and oncillas ( $L$. tigrinus) in the Atlantic rainforest in southeast Brazil. Studies on Neotropical Fauna and Environment, 37, 207-212.

Wang, S.W. \& Macdonald, D.W. (2009) Feeding habits and niche partitioning in a predator guild composed of tigers, leopards and dholes in a temperate ecosystem in central Bhutan. Journal of Zoology, 277, 275-283. 
Watanabe, S., Nakanishi, N. \& Izawa, M. (2003) Habitat and prey resource overlap between the Iriomote cat Prionailurus iriomotensis and introduced feral cat Felis catus based on assessment of scat content and distribution. Mammal Study, 28, 47-56.

Watson, A. (1976) Food remains in the droppings of foxes (Vulpes vulpes) in the Cairngorms. Journal of Zoology, 180, 495-496.

Weber, J.M. \& Weissbrodt, M. (1999) Feeding habits of the Eurasian lynx in the Swiss Jura Mountains determined by faecal analysis. Acta Theriologica, 44, 333-336.

Weckel, M., Giuliano, W. \& Silver, S. (2006) Cockscomb revisited: Jaguar diet in the Cockscomb Basin Wildlife Sanctuary, Belize. Biotropica, 38, 687-690.

Weisbein, Y. \& Mendelssohn, H. (1990) The biology and ecology of the Caracal Felis caracal in the northern Aravah Valley of Israel. Cat News, 12, 20-22.

White, P.J., Ralls, K. \& Vanderbilt White, C.A. (1995) Overlap in habitat and food use between coyotes and San Joaquin kit foxes. Southwestern Naturalist, 40

Wiebe, N., Samelius, G., Alisauskas, R.T., Bantle, J.L., Bergman, C., De Carle, R., Hendrickson, C.J., Lusignan, A., Phipps, K.J. \& Pitt, J. (2009) Foraging behaviours and diets of wolves in the Queen Maud Gulf Bird Sanctuary, Nunavut, Canada. Arctic, 62, 399-404.

Wilson, W.L. (1990) Changes in the diet of foxes (Vulpes vulpes) on the sands of Forvie National Nature Reserve, during the eider nesting period, 1974 to 1988. Journal of Zoology, 221, 305-308.

Wong, S.T., Servheen, C. \& Ambu, L. (2002) Food habits of Malayan sun bears in lowland tropical forests of Borneo. Ursus, 13, 127-136.

Xu, A.C., Jiang, Z.G., Li, C.W., Guo, J.X., Wu, G.S. \& Cai, P. (2006) Summer food habits of brown bears in Kekexili Nature Reserve, Qinghai-Tibetan Plateau, China. Ursus, 17, 132-137.

Young, J.K., Andelt, W.F., Terletzky, P.A. \& Shivik, J.A. (2006) A comparison of coyote ecology after 25 years: 1978 versus 2003. Canadian Journal of Zoology-Revue Canadienne De Zoologie, 84, 573-582.

Zapata, S.C., Travaini, A. \& Delibes, M. (1998) Neither large nor small: intermediate-sized food items for the cubs of the Patagonian gray fox (Pseudoalopex griseus). Canadian Journal of Zoology-Revue Canadienne De Zoologie, 76, 2281-2284.

Zapata, S.C., Travaini, A., Delibes, M. \& Martinez-Peck, R. (2005) Food habits and resource partitioning between grey and culpeo foxes in southeastern Argentine Patagonia. Studies on Neotropical Fauna and Environment, 40, 97-103.

Zapata, S.C., Travaini, A., Ferreras, P. \& Delibes, M. (2007) Analysis of trophic structure of two carnivore assemblages by means of guild identification. European Journal of Wildlife Research, 53, 276-286.

Zapata, S.C., Procopio, D.E., Martinez-Peck, R., Zanon, J.I. \& Travaini, A. (2008) External morphometry and resource partitioning of sympatric foxes (Pseudalopex culpaeus and P. griseus) in southeastern Argentine Patagonia. Mastozoologia Neotropical, 15, 103-111.

Zhang, H.-H., Liu, X.-P., Dou, H.-S., Zhang, C.-D. \& Ren, Y. (2009) Food composition and food niche overlap of three kinds of Canidae. Acta Ecologica Sinica, 29, 347-350. 
Zuberbuhler, K. \& Jenny, D. (2002) Leopard predation and primate evolution. Journal of Human Evolution, 43, 873-886.

Zuercher, G.L., Gipson, P.S. \& Carrillo, O. (2005) Diet and habitat associations of bush dogs Speothos venaticus in the Interior Atlantic Forest of eastern Paraguay. Oryx, 39, 86-89.

Zuñiga, A., Quintana, V. \& Fierro, A. (2005) Trophic relations among predators in a fragmented environment in southern Chile. Gestion Ambiental, 11, 31-42.

Zuñiga, A., Munoz-Pedreros, A. \& Fierro, A. (2008) Diet of Lycalopex griseus (Gray, 1837) (Mammalia : Canidae) in the intermediate depression of southern Chile. Gayana, 72, 113-116.

Zunna, A., Ozolins, J. \& Pupila, A. (2009) Food habits of the wolf Canis lupus in Latvia based on stomach analyses. Estonian Journal of Ecology, 58, 141-152. 


\section{Appendix S2. Complete R script used to generate reported results.}

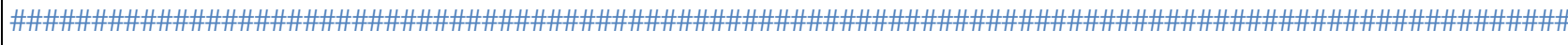
\#\#\#\#\#\#\#\#\#\#\#

\#\#Supporting Appendix S2 for the following publication:

\#\#Title: Contrasting evidence of phylogenetic trophic niche conservatism in mammals worldwide

\#\#Authors: Miguel Á. Olalla-Tárraga, Manuela González-Suárez, Rubén Bernardo-Madrid, Eloy Revilla, Fabricio

Villalobos

\#\#Journal: Journal of Biogeography

\#\#

\#\#This is the complete $\mathrm{R}$ script used to generate reported results byt his publication

\#\#

\#\#CONTACT PERSON: Manuela Gonzalez Suarez, manuela.gonzalez.suarez@ gmail.com

\#\#All data are freely available for download at [FIGSHARE DOI]

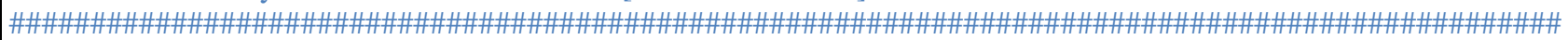
\#\#\#\#\#\#\#\#\#\#\#

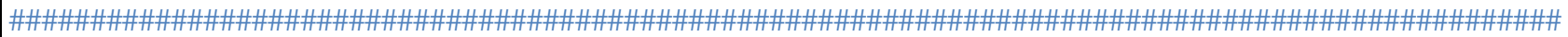

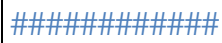

\#\#Read data and define data subsets\#\#\#\#

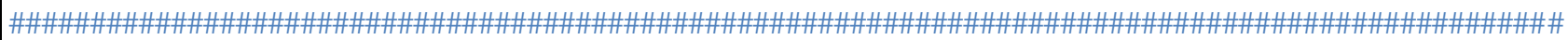

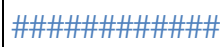

\#\#phylogeny

library(caper)

library(phytools)

tree=read.nexus("Fritz_tree.nex")

\#\#\#diet and life-history data

data<- read.table("Olalla-Tarraga_et_al_Mammalian_Diet_Data.csv",sep=",", header=T )

names(data)

data\$orders_analysis<-as.character(data\$Order)

data\$orders_analysis[data\$SMALL_ORDERS==1] <- "Small_orders"

orders<-unique(data\$orders_analysis)

MammalDIET_sub<-subset(data,MammalDIET==1)

EltonTraits_sub<-subset(data,EltonTraits==1)

CUFdiet_sub $<-$ subset(data, CUFdiet $==1$ )

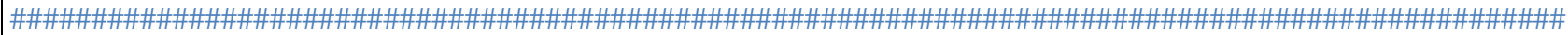

\#\#\#\#\#\#\#\#\#\#\#

\#\#\#\#\#\#\#PHYLOGENETIC SIGNAL IN GENERAL QUANTITATIVE DIET DESCRIPTORS AND OTHER

TRAITS\#\#\#\#\#\#\#\#\#\#\#\#\#\#\#

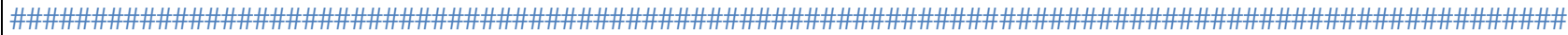
\#\#\#\#\#\#\#\#\#\#\#

\#\#REPRODUCES RESULTS DISPLAY IN FIGURE 2 AND TABLE S1 (NOTE THAT BECAUSE P-VALUES ARE BASED ON SIMULATIONS AND RANDOMIZATIONS VALUES WILL CHANGE EACH TIME)

\#\#Function K_P0_P1_function gives:

\#\# empirical $\mathrm{K}$ value

\#\# P0 is the P-value for the null hypothesis that there is no phylogenetic signal in the data based on a randomization test

\#\# P1 is the P-value for the null hypothesis that $\mathrm{K}$ is consistent with a Brownian model of evolution based on simulations

\#\#Simulation approach is based on code provided by Liam Revell http://blog.phytools.org/2011/12/testing-forphylogenetic-signal-k.html

\#\#Using fastBM we can simulate the values of a trait along our phylogenetic tree if evolution followed a Brownian model with the value of the root taxa (parameter a) set to be the mean value of the trait in the observed data, the variance (sig2) set as the variance in the data.

\#\#to estimate these parameters from the data the tree needs to have no polytomies, so we apply a random break of the polytomies using the function multi2di from package ape to break polytomies 
\#\#For each trait we set bounds to the minimum and maximum possible values:

\#\#[1,12] for the diet breadth of MammalDIET and CUFdiet and $[1,10]$ for EltonTraits, these bounds are defined by the

food categories possible

\#\#[0,Inf] for $\log 10$ of gestation length, assuming due to metabolic constrains gestation lenghts $<1$ day would not

evolve.

\#\#[0,Inf] for $\log 10$ of adult body mass, assuming due to metabolic constrains mammals weighting $<1$ gr would not

evolve.

\#\#[-Inf,Inf] for $\log 10$ of home range size, assuming home range size can take any value.

\#\#[0,Inf] for $\log 10$ of group size, group size $<1$ are not possible

\#\#[0,Inf] for $\log 10$ of distribution range size, assuming species with global distribution areas $<1 \mathrm{~km} 2$ would not evolve.

\#\#P1 is calculated following Liam Revell's suggestion "that we do this by counting the number of times that the absolute value of the logarithm of our observed value for $\mathrm{K}$ is no smaller than the absolute values of our simulated values for $\mathrm{K}$. This just makes $\mathrm{K}=1.5$ \& $\mathrm{K}=0.6667$ equivalent departures from BM."

K_P0_P1_function<-function(data_subset, trait, N_sim, bounds_sim, log=FALSE) \{

if $(\log ==$ FALSE) \{

print("non-transformed variable")

row.names(data_subset)=data_subset\$binomial_tree

test $1=$ as.vector(as.matrix (subset(data_subset, select=trait)))

names(test1)=row.names(data_subset)

kappa<-phylosig(tree, test1, method="K",test=T)

sss<-which(names(data_subset) $==$ trait)

selection<-subset(data_subset, data_subset[,sss]>0)

tree $1<-$ multi2di(tree, random $=$ TRUE)

$\mathrm{C} 1<$ - comparative.data $($ phy $=$ tree 1, data $=$ selection, names.col = binomial_tree, warn.dropped = FALSE,

na.omit=F)

ss $<-$ which $($ names $(\mathrm{C} 1$ data $)==$ trait $)$

nullK<-apply(fastBM(C1\$phy, n=N_sim, sig2=mean(pic $\left.(\mathrm{C} 1 \$ \text { data[,ss],C1\$phy })^{\wedge} 2\right), \mathrm{a}=\operatorname{mean}(\mathrm{C} 1 \$ \mathrm{data}[, \mathrm{ss}])$,

bounds=bounds_sim), 2 , phylosig,tree $=\bar{C} 1 \$$ phy)

p1_value<-mean $(\operatorname{abs}(\log (\mathrm{c}(\operatorname{kappa} \$ \mathrm{~K}, \mathrm{nullK})))>=\operatorname{abs}(\log (\operatorname{kappa} \$ \mathrm{~K})))$

return(list(trait, length(na.omit $(\mathrm{C} 1 \$ \operatorname{data}[, \mathrm{ss}]))$,round(kappa $\$ \mathrm{~K}$, digits=2), round(kappa $\$ \mathrm{P}$, digits=3),round(p1_value, digits=3)))

\}

else \{

print("log-transformed variable")

row.names(data_subset)=data_subset\$binomial_tree

test $1=$ as.vector(as.matrix $(\operatorname{subset}($ data_subset, select=trait $)))$

test $1=\log 10$ (test 1$)$

names(test1) $=$ row.names (data_subset)

kappa<-phylosig(tree, test1, method="K",test=T)

sss<- which(names(data)==trait)

selection<-subset(data_subset, data_subset[,sss]>0)

tree $1<-$ multi2di(tree, random = TRUE)

$\mathrm{C} 1<-$ comparative.data $($ phy $=$ tree 1, data $=$ selection, names.col $=$ binomial tree, warn.dropped $=$ FALSE,

na.omit $=\mathrm{F})$

ss $<-$ which $($ names $(\mathrm{C} 1$ data $)==$ trait $)$

nullK<-apply(fastBM $\left(\mathrm{C} 1\right.$ \$phy, n=N_sim, sig2=mean(pic $\left.(\log 10(\mathrm{C} 1 \$ \text { data[,ss] }), \mathrm{C} 1 \text { \$phy })^{\wedge} 2\right)$,

$\mathrm{a}=$ mean $(\log 10(\mathrm{C} 1 \$$ data[,ss] $))$, bounds=bounds_sim $), 2$, phylosig,tree=C1\$phy $)$

p1_value<-mean $(\operatorname{abs}(\log (\mathrm{c}(\operatorname{kappa} \$ \mathrm{~K}, \mathrm{nullK})))>=\operatorname{abs}(\log (\operatorname{kappa} \$ \mathrm{~K})))$

return(list(trait, length(na.omit(C1\$data[,ss])),round(kappa $\$ K$, digits=2),round(kappa $\$ P$, digits=3),round(p1_value, digits=3)))

\}

\}

MD_diet<-K_P0_P1_function(MammalDIET_sub,"MD_Diet_breadth", 1000, c(1,12))

MD_ges<-K_P0_P1_function(MammalDIET_sub,"Gestation_length_days", 1000, c(-Inf,Inf), log=TRUE)

MD_mass<-K_P0_P1_function(MammalDIET_sub,"Adult_body_mass_g", 1000, c(-Inf,Inf), log=TRUE)

MD_home<-K_P0_P1_function(MammalDIET_sub,"Home_range_size_km2", 1000, c(-Inf,Inf), log=TRUE)

MD_group<-K_P0_P1_function(MammalDIET_sub,"Group_size_ind", 1000, c(-Inf,Inf), log=TRUE)

MD_dist<-K_P0_P1_function(MammalDIET_sub,"Distribution_range_area_km2", 1000, c(-Inf,Inf), log=TRUE) 
MD_results<-rbind(MD_ges, MD_mass, MD_home, MD_group, MD_dist,MD_diet,c("NA", "NA", "NA", "NA", "NA"))

ET_diet<-K_P0_P1_function(EltonTraits_sub,"ET_Diet_breadth", 1000, c(1,10))

ET_Levins<-K_P0_P1_function(EltonTraits_sub,"ET_Levins_stand", 1000, c $(0,1)$ )

ET_ges<-K_P0_P1_function(EltonTraits_sub,"Gestation_length_days", 1000, c(0,Inf), log=TRUE)

ET_mass<-K_P0_P1_function(EltonTraits_sub,"Adult_body_mass_g", 1000, c(0,Inf), log=TRUE)

ET_home<-K_P0_P1_function(EltonTraits_sub,"Home_range_size_km2", 1000, c(-Inf,Inf), log=TRUE)

ET_group<-K_P0_P1_function(EltonTraits_sub,"Group_size_ind", 1000, c(0,Inf), log=TRUE)

ET_dist<-K_P0_P1_function(EltonTraits_sub,"Distribution_range_area_km2", 1000, c(0,Inf), log=TRUE)

ET_results<-rbind(ET_ges, ET_mass, ET_home, ET_group, ET_dist,ET_diet, ET_Levins)

CUF_diet<-K_P0_P1_function(CUFdiet_sub,"CUF_Diet_breadth", 1000, c(1,12))

CUF_Levins<-K_P0_P1_function(CUFdiet_sub,"CUF_Levins_stand", 1000, c $(0,1)$ )

CUF_ges<-K_P0_P1_function(CUFdiet_sub,"Gestation_length_days", 1000, c(0,Inf), log=TRUE)

CUF_mass <-K_P0_P1_function(CUFdiet_sub,"Adult_body_mass_g", 1000, c(0,Inf), log=TRUE)

CUF_home<-K_P0_P1_function(CUFdiet_sub,"Home_range_size_km2", 1000, c(-Inf,Inf), log=TRUE)

CUF_group<-K_P0_P1_function(CUFdiet_sub,"Group_size_ind", 1000, c(0,Inf), log=TRUE)

CUF_dist<-K_P0_P1_function(CUFdiet_sub,"Distribution_range_area_km2", 1000, c(0,Inf), log=TRUE)

CUF_results<-rbind(CUF_ges, CUF_mass, CUF_home, CUF_group, CUF_dist,CUF_diet, CUF_Levins)

\#\#generating results for table $\mathrm{S} 1$

Table_S1_results<-cbind(c("Gestation_length_days", "Adult_body_mass_g","Home_range_size_km2",

"Group_size_ind", "Distribution_range_area_km2", "Diet_breadth", "Levin's index"),MD_results[,-1],ET_results[,-

1],CUF_results[,-1])

colnames(Table_S1_results)<-c("Variable","MD_sample_size", "MD_K", "MD_P0", "MD_P1","ET_sample_size",

"ET_K", "ET_P0", "ET_P1","CUF_sample_size", "CUF_K", "CUF_P0", "CUF_P1")

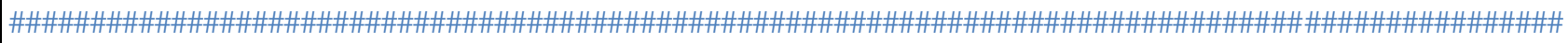

\#\#\#\#\#\#\#\#\#\#\#

\#\#\#\#\#\#\#PHYLOGENETIC SIGNAL IN DIET BREADTH FOR DISTINCT MAMMALIAN

ORDERS\#\#\#\#\#\#\#\#\#\#\#\#\#\#\#\#

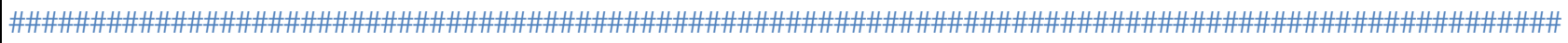

\#\#\#\#\#\#\#\#\#\#\#

\#\#REPRODUCES RESULTS FOR TABLE 1

\#\#Please note that there is no data on MammalDIET for Cetacea

results_orders<-list()

for (i in 1:length(orders)) \{

$\mathrm{j}<-$ noquote $($ toString $($ orders[i] $))$

if $(\mathrm{j} !=$ "Cetacea") \{

sub<-subset(MammalDIET_sub, orders_analysis==j)

compData_MD <- comparative.data $($ phy $=$ tree, data $=$ sub, names.col = binomial_tree, warn.dropped $=$ FALSE,

na.omit=F)

test1=as.vector(as.matrix(subset(compData_MD\$data, select=MD_Diet_breadth))

names(test1) $=$ compData_MD \$phy\$tip.label

kappa_MD<-phylosig(tree, test1, method="K",test=T)

compData_MD1 <- comparative.data(phy $=$ tree 1 , data $=$ sub, names.col $=$ binomial_tree, warn.dropped $=$ F,

na.omit=F)

nullK_MD<-apply(fastBM(compData_MD1\$phy, n=N_simulations,

sig2=mean(pic(compData_MD1\$data\$MD_Diet_breadth,compData_MD1\$phy $\left.)^{\wedge} 2\right)$,

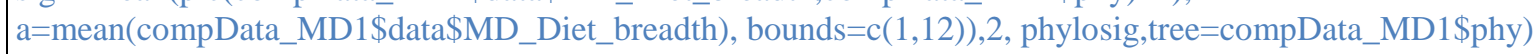

sub1<-subset(EltonTraits_sub, orders_analysis==j)

compData_ET<- comparative.data $($ phy $=$ tree, data $=$ sub1, names.col = binomial_tree, warn.dropped $=$ FALSE,

na.omit $=\mathrm{F}$ )

test2=as.vector(as.matrix(subset(compData_ET\$data, select=ET_Diet_breadth)))

names(test2)=compData_ET\$phy\$tip.label

kappa_ET<-phylosig(tree, test2, method="K",test=T) 


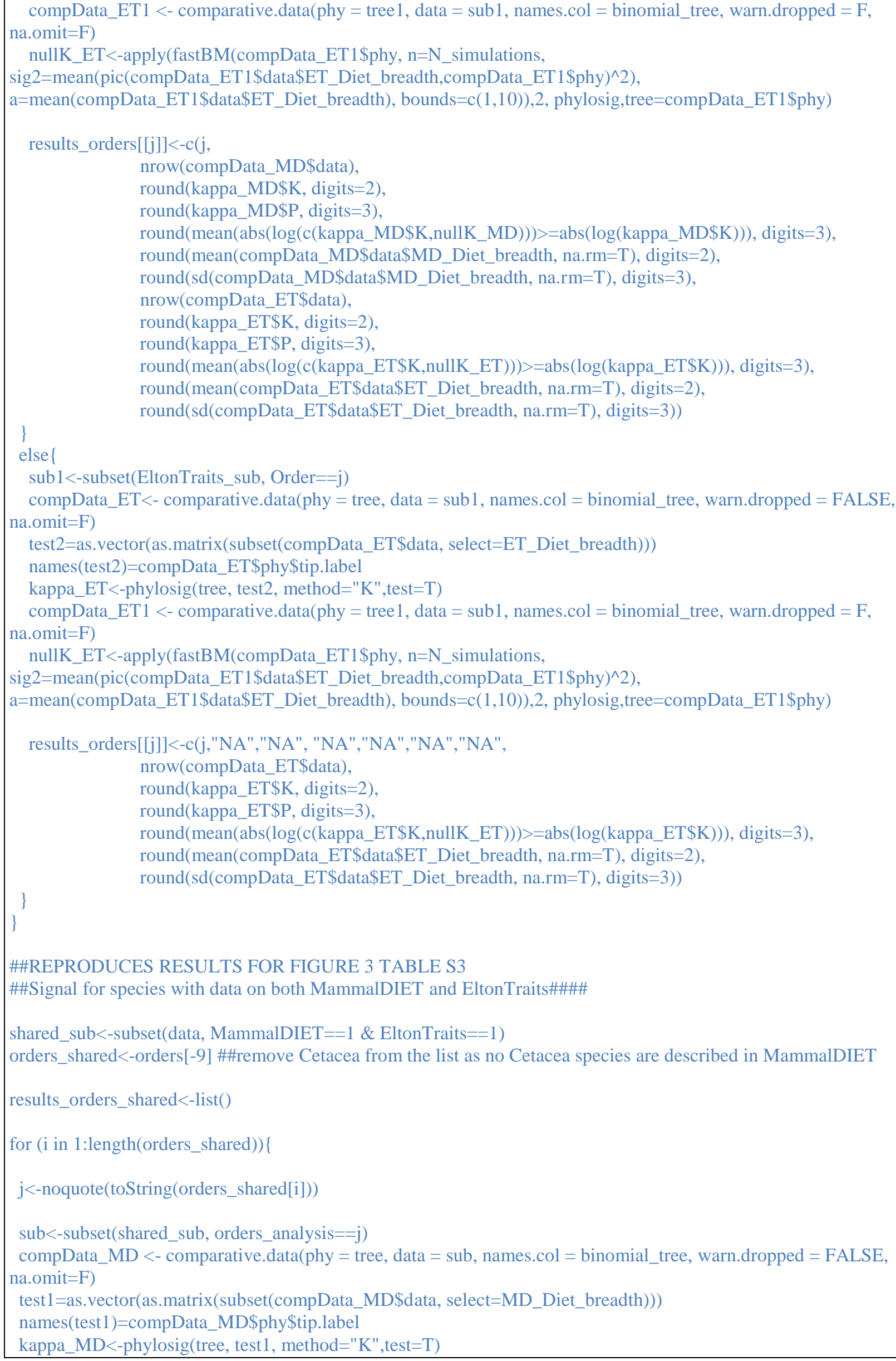


compData_MD1 <- comparative.data $($ phy $=$ tree1, data = sub, names.col = binomial_tree, warn.dropped = F, na.omit=F)

nullK_MD<-apply(fastBM(compData_MD1\$phy, $\mathrm{n}=\mathrm{N} \_$simulations,

sig2=mean (pic(compData_MD1\$data\$MD_Diet_breadth,compData_MD1\$phy)^2),

a=mean (compData_MD1\$data\$MD_Diet_breadth), bounds=c $(1,12)), 2$, phylosig,tree=compData_MD1\$phy)

sub1<-subset(shared_sub, orders_analysis==j)

compData_ET<- comparative.data $($ phy $=$ tree, data $=$ sub1, names.col $=$ binomial_tree, warn.dropped $=$ FALSE,

na.omit $=$ F)

test2=as.vector(as.matrix(subset(compData_ET\$data, select=ET_Diet_breadth))

names(test2)=compData_ET\$phy\$tip.label

kappa_ET<-phylosig(tree, test2, method="K",test=T)

compData_ET1 <- comparative.data $($ phy $=$ tree 1, data $=$ sub1, names.col $=$ binomial_tree, warn.dropped $=$ F,

na.omit $=\mathrm{F}$ )

nullK_ET<-apply(fastBM(compData_ET1\$phy, n=N_simulations,

sig2=mean (pic(compData_ET1\$data\$ET_Diet_breadth,compData_ET1\$phy)^2),

$\mathrm{a}=$ mean $($ compData_ET1\$data\$ET_Diet_breadth), bounds $=\mathrm{c}(1,10)), 2$, phylosig,tree=compData_ET1 $\$$ phy $)$

results_orders_shared[[j]]<-c(j,

nrow(compData_MD\$data),

round(kappa_MD\$K, digits=2),

round(kappa_MD\$P, digits=3),

$\operatorname{round}\left(\operatorname{mean}\left(\operatorname{abs}\left(\log \left(\mathrm{c}\left(\mathrm{kappa} \_\mathrm{MD} \$ \mathrm{~K}, \mathrm{nullK}\right.\right.\right.\right.\right.$ _MD $\left.\left.\left.)\right)\right)>=\operatorname{abs}(\log (\operatorname{kappa} \mathrm{MD} \$ \mathrm{~K}))\right)$, digits=3),

round(kappa_ET\$K, digits=2),

round(kappa_ET\$P, digits=3),

$\operatorname{round}\left(\operatorname{mean}\left(\operatorname{abs}\left(\log \left(\mathrm{c}\left(\mathrm{kappa}\right.\right.\right.\right.\right.$ ET $\left.\left.\left.\left.\$ \mathrm{~K}, \mathrm{nullK} \_\mathrm{ET}\right)\right)\right)>=\operatorname{abs}(\log (\operatorname{kappa} \mathrm{ET} \$ \mathrm{~K}))\right)$, digits=3))

\}

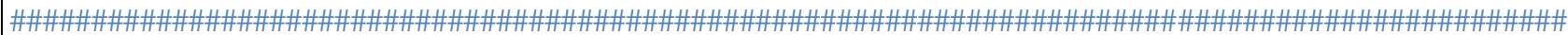
\#\#\#\#\#\#\#\#\#\#\#\#

\#\#\#\#\#\#\#\#PHYLOGENETIC SIGNAL IN BINARY PRESENCE DATA FOR DIFFERENT DIET

CATEGORIES\#\#\#\#\#\#\#\#\#\#\#\#\#\#\#

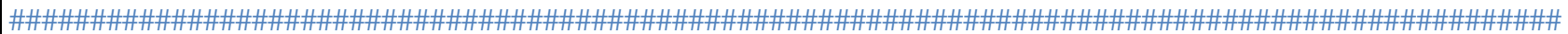

\#\#\#\#\#\#\#\#\#\#\#\#

\#\#REPRODUCES RESULTS FOR FIGURE 4 AND TABLE S4. P-VALUES ARE BASED ON PERMUTATION

TEST AND COULD CHANGE EACH TIME

N_permutations<-5000 \#\#defining the number of permutations to estimate P-values for D

compData_MD <- comparative.data $($ phy $=$ tree, data = MammalDIET_sub, names.col = binomial_tree, warn.dropped =

TRUE, na.omit=F)

dim(compData_MD\$data)

compData_ET $<-$ comparative.data $($ phy $=$ tree, data $=$ EltonTraits_sub, names.col $=$ binomial_tree, warn.dropped $=$ TRUE, na.omit=F)

dim(compData_ET\$data)

compData_CUF $<-$ comparative.data $($ phy $=$ tree, data $=$ CUFdiet_sub, names.col $=$ binomial_tree, warn.dropped $=$

TRUE, na.omit=F)

dim(compData_CUF\$data)

\#\#unclassified vertebrates is only a category in EltonTraits

ET_PhyloDvert_unc <-phylo.d(compData_ET, binvar=ET_vert_unclassified, permut = N_permutations)

vert_unc<-list("NA", "NA", "NA","NA",

sum(EltonTraits_sub\$ET_vert_unclassified), round(ET_PhyloDvert_unc\$DEstimate,digits=2),

round(ET_PhyloDvert_unc $\$$ Pval1, digits=3), round(ET_PhyloDvert_unc\$Pval0, digits=3),

"NA", "NA", "NA","NA")

\#\#Endotherm vertebrates (mammals and birds). In CUFdiet all species have presence for this category and those D

cannot be estimated

MD_PhyloDvend <- phylo.d(compData_MD, binvar=MD_vend, permut $=$ N_permutations $)$

ET_PhyloDvend <- phylo.d(compData_ET, binvar=ET_vend, permut $=$ N_permutations $)$

vend<-list(sum(MammalDIET_sub\$MD_vend), round(MD_PhyloDvend\$DEstimate, digits=2),

round(MD_PhyloDvend\$Pval1, digits=3), round(MD_PhyloDvend\$Pval0, digits=3), 
sum(EltonTraits_sub\$ET_vend), round(ET_PhyloDvend\$DEstimate,digits=2), round(ET_PhyloDvend\$Pval1, digits=3), round(ET_PhyloDvend\$Pval0, digits=3),

"NA", "NA", "NA", "NA")

\#\#Mammal category is only described in MammalDiet and CUFdiet

MD_PhyloDmammal <- phylo.d(compData_MD, binvar=MD_mammal, permut $=$ N_permutations)

CUF_PhyloDmammal <- phylo.d(compData_CUF, binvar=CUE_mammal, permut $=$ N_permutations $)$

mammal<-list(sum(MammalDIET_sub\$MD_mammal), round(MD_PhyloDmammal\$DEstimate, digits=2),

round(MD_PhyloDmammal\$Pval1, digits=3), round(MD_PhyloDmammal\$Pval0, digits=3),

"NA", "NA", "NA", "NA",

sum(CUFdiet_sub\$CUF_mammal), round(CUF_PhyloDmammal\$DEstimate,digits=2),

round(CUF_PhyloDmammal\$Pval1, digits=3), round(CUF_PhyloDmammal\$Pval0, digits=3))

\#\#Bird category is only described in MammalDiet and CUFdiet

MD_PhyloDbird <- phylo.d(compData_MD, binvar=MD_bird, permut $=$ N_permutations $)$

CUF_PhyloDbird <- phylo.d(compData_CUF, binvar=CUF_bird, permut $=$ N_permutations $)$

bird<-list(sum(MammalDIET_sub\$MD_bird), round(MD_PhyloDbird\$DEstimate, digits=2),

round(MD_PhyloDbird\$Pval1, digits=3), round(MD_PhyloDbird\$Pval0, digits=3),

"NA", "NA", "NA","NA",

sum(CUFdiet_sub\$CUF_bird), round(CUF_PhyloDbird\$DEstimate, digits=2), round(CUF_PhyloDbird\$Pval1, digits=3), round(CUF_PhyloDbird\$Pval0, digits=3))

MD_PhyloDherptile <- phylo.d(compData_MD, binvar=MD_herptile, permut $=$ N_permutations)

ET_PhyloDherptile <- phylo.d(compData_ET, binvar=ET_herptile, permut $=$ N_permutations)

CUF_PhyloDherptile $<-$ phylo.d (compData_CUF, binvar=CUF_herptile, permut $=$ N_permutations $)$

herptile<-list(sum(MammalDIET_sub\$MD_herptile), round(MD_PhyloDherptile\$DEstimate, digits=2),

round(MD_PhyloDherptile\$Pval1, digits=3), round(MD_PhyloDherptile\$Pval0, digits=3),

sum(EltonTraits_sub\$ET_herptile), round(ET_PhyloDherptile\$DEstimate,digits=2),

round(ET_PhyloDherptile\$Pval1, digits=3), round(ET_PhyloDherptile\$Pval0, digits=3),

sum(CUFdiet_sub\$CUF_herptile), round(CUF_PhyloDherptile\$DEstimate,digits=2),

round(CUF_PhyloDherptile\$Pval1, digits=3), round(CUF_PhyloDherptile $\$$ Pval0, digits=3))

MD_PhyloDfish <- phylo.d(compData_MD, binvar=MD_fish, permut $=$ N_permutations)

ET_PhyloDfish <- phylo.d(compData_ET, binvar=ET_fish, permut $=$ N_permutations $)$

CUF_PhyloDfish <- phylo.d(compData_CUF, binvar=CUF_fish, permut $=$ N_permutations $)$

fish<-list(sum(MammalDIET_sub\$MD_fish), round(MD_PhyloDfish\$DEstimate, digits=2),

round(MD_PhyloDfish\$Pval1, digits=3), round(MD_PhyloDfish\$Pval0, digits=3),

sum(EltonTraits_sub\$ET_fish), round(ET_PhyloDfish\$DEstimate,digits=2), round(ET_PhyloDfish\$Pval1,

digits=3), round(ET_PhyloDfish\$Pval0, digits=3),

sum(CUFdiet_sub\$CUF_fish), round(CUF_PhyloDfish\$DEstimate,digits=2), round(CUF_PhyloDfish\$Pval1,

digits=3), round(CUF_PhyloDfish\$Pval0, digits=3))

MD_PhyloDinvertebrate <- phylo.d(compData_MD, binvar=MD_invertebrate, permut $=$ N_permutations)

ET_PhyloDinvertebrate <- phylo.d(compData_ET, binvar=ET_invertebrate, permut = N_permutations)

CUF_PhyloDinvertebrate <- phylo.d(compData_CUF, binvar=CUF_invertebrate, permut = N_permutations)

invertebrate<-list(sum(MammalDIET_sub\$MD_invertebrate), round(MD_PhyloDinvertebrate\$DEstimate,digits=2),

round(MD_PhyloDinvertebrate\$Pval1, digits=3), round(MD_PhyloDinvertebrate\$Pval0, digits=3),

sum(EltonTraits_sub\$ET_invertebrate), round(ET_PhyloDinvertebrate\$DEstimate, digits=2),

round(ET_PhyloDinvertebrate\$Pval1, digits=3), round(ET_PhyloDinvertebrate\$Pval0, digits=3),

sum(CUFdiet_sub\$CUF_invertebrate), round(CUF_PhyloDinvertebrate\$DEstimate, digits=2),

round(CUF_PhyloDinvertebrate $\$$ Pval1, digits=3), round(CUF_PhyloDinvertebrate $\$$ Pval0, digits=3))

MD_PhyloDfruit <- phylo.d(compData_MD, binvar=MD_fruit, permut = N_permutations)

ET_PhyloDfruit <- phylo.d(compData_ET, binvar=ET_fruit, permut $=$ N_permutations)

CUF_PhyloDfruit <- phylo.d(compData_CUF, binvar=CUF_fruit, permut $=$ N_permutations)

fruit<-list(sum(MammalDIET_sub\$MD_fruit), round(MD_PhyloDfruit\$DEstimate,digits=2),

round(MD_PhyloDfruit\$Pval1, digits=3), round(MD_PhyloDfruit\$Pval0, digits=3),

sum(EltonTraits_sub\$ET_fruit), round(ET_PhyloDfruit\$DEstimate,digits=2), round(ET_PhyloDfruit\$Pval1,

digits=3), round(ET_PhyloDfruit\$Pval0, digits=3),

sum(CUFdiet_sub\$CUF_fruit), round(CUF_PhyloDfruit\$DEstimate, digits=2), round(CUF_PhyloDfruit\$Pval1,

digits=3), round(CUF_PhyloDfruit\$Pval0, digits=3)) 
MD_PhyloDnectar <- phylo.d(compData_MD, binvar=MD_nectar, permut = N_permutations)

ET_PhyloDnectar <- phylo.d(compData_ET, binvar=ET_nectar, permut = N_permutations $)$

CUF_PhyloDnectar $<-$ phylo.d(compData_CUF, binvar=CUF_nectar, permut $=$ N_permutations)

nectar<-list(sum(MammalDIET_sub\$MD_nectar), round(MD_PhyloDnectar\$DEstimate, digits=2),

round(MD_PhyloDnectar\$Pval1, digits=3), round(MD_PhyloDnectar\$Pval0, digits=3),

sum(EltonTraits_sub\$ET_nectar), round(ET_PhyloDnectar\$DEstimate,digits=2),

round(ET_PhyloDnectar\$Pval1, digits=3), round(ET_PhyloDnectar\$Pval0, digits=3),

sum(CUFdiet_sub\$CUF_nectar), round(CUF_PhyloDnectar\$DEstimate, digits=2),

round(CUF_PhyloDnectar\$Pval1, digits=3), round(CUF_PhyloDnectar $\$$ Pval0, digits=3))

\#\#Woody category is only described in MammalDiet and CUFdiet

MD_PhyloDwoody <- phylo.d(compData_MD, binvar=MD_woody, permut = N_permutations)

CUF_PhyloDwoody <- phylo.d(compData_CUF, binvar=CUF_woody, permut $=$ N_permutations)

woody<-list(sum(MammalDIET_sub\$MD_woody), round(MD_PhyloDwoody\$DEstimate, digits=2),

round(MD_PhyloDwoody\$Pval1, digits=3), round(MD_PhyloDwoody $\$$ Pval0, digits=3),

"NA", "NA", "NA","NA",

sum(CUFdiet_sub\$CUF_woody), round(CUF_PhyloDwoody\$DEstimate, digits=2),

round(CUF_PhyloDwoody $\$$ Pval1, digits=3), round $(\mathrm{CUF}$ _PhyloDwoody $\$$ Pval0, digits=3))

\#\#Grass category is only described in MammalDiet and CUFdiet

MD_PhyloDgrass <- phylo.d(compData_MD, binvar=MD_grass, permut = N_permutations)

CUF_PhyloDgrass <- phylo.d(compData_CUF, binvar=CUF_grass, permut $=$ N_permutations)

grass<-list(sum(MammalDIET_sub\$MD_grass), round(MD_PhyloDgrass\$DEstimate, digits=2),

round(MD_PhyloDgrass \$Pval1, digits=3), round(MD_PhyloDgrass\$Pval0, digits=3),

"NA", "NA", "NA","NA",

sum(CUFdiet_sub\$CUF_grass), round(CUF_PhyloDgrass\$DEstimate, digits=2),

round(CUF_PhyloDgrass $\$$ Pval1, digits=3), round(CUF_PhyloDgrass $\$$ Pval0, digits=3))

MD_PhyloDseed <- phylo.d(compData_MD, binvar=MD_seed, permut = N_permutations)

ET_PhyloDseed <- phylo.d (compData_ET, binvar=ET_seed, permut $=$ N_permutations)

CUF_PhyloDseed <- phylo.d (compData_CUF, binvar $=$ CUF_seed, permut $=$ N_permutations $)$

seed<-list(sum(MammalDIET_sub\$MD_seed), round(MD_PhyloDseed\$DEstimate, digits=2),

round(MD_PhyloDseed\$Pval1, digits=3), round(MD_PhyloDseed\$Pval0, digits=3),

sum(EltonTraits_sub\$ET_seed), round(ET_PhyloDseed\$DEstimate,digits=2), round(ET_PhyloDseed\$Pval1,

digits=3), round(ET_PhyloDseed $\$$ Pval0, digits=3),

sum(CUFdiet_sub\$CUF_seed), round(CUF_PhyloDseed\$DEstimate, digits=2), round(CUF_PhyloDseed\$Pval1,

digits=3), round(CUF_PhyloDseed\$Pval0, digits=3))

\#\#root category is only described in MammalDiet and CUFdiet, but in CUFdiet no species are listed as consuming roots

MD_PhyloDroot <- phylo.d(compData_MD, binvar=MD_root, permut = N_permutations)

root<-list(sum(MammalDIET_sub\$MD_root), round(MD_PhyloDroot\$DEstimate, digits=2),

round(MD_PhyloDroot\$Pval1, digits=3), round(MD_PhyloDroot\$Pval0, digits=3),

"NA", "NA", "NA", "NA",

"NA", "NA", "NA", "NA")

\#\#plant unclassified category is only described in EltonTraits

ET_PhyloDplant_unc <-phylo.d(compData_ET, binvar=ET_plant_unclassified, permut = N_permutations)

plant_unc<-list("NA", "NA", "NA", "NA", sum(EltonTraits_sub\$ET_plant_unclassified), round(ET_PhyloDplant_unc\$DEstimate, digits=2),

round(ET_PhyloDplant_unc\$Pval1, digits=3), round(ET_PhyloDplant_unc\$Pval0, digits=3), "NA", "NA", "NA", "NA")

\#\#carrion category is only described in EltonTraits and CUFdiet

ET_PhyloDcarrion $<-$ phylo.d(compData_ET, binvar=ET_carrion, permut $=$ N_permutations $)$

CUF_PhyloDcarrion <- phylo.d(compData_CUF, binvar=CUF_carrion, permut $=$ N_permutations)

carrion<-list("NA", "NA", "NA","NA",

sum(EltonTraits_sub\$ET_carrion), round(ET_PhyloDcarrion\$DEstimate, digits=2),

round(ET_PhyloDcarrion\$Pval1, digits=3), round(ET_PhyloDcarrion\$Pval0, digits=3), sum(CUFdiet_sub\$CUF_carrion), round(CUF_PhyloDcarrion\$DEstimate, digits=2),

round(CUF_PhyloDcarrion\$Pval1, digits=3), round(CUF_PhyloDcarrion\$Pval0, digits=3))

\#\#Other category is only described in MammalDiet 
MD_PhyloDother <- phylo.d(compData_MD, binvar=MD_other, permut = N_permutations)

other<-list(sum(MammalDIET_sub\$MD_other), round(MD_PhyloDother\$DEstimate,digits=2),

round(MD_PhyloDother\$Pval1, digits=3), round(MD_PhyloDother\$Pval0, digits=3),

"NA", "NA", "NA","NA",

"NA", "NA", "NA","NA")

\#\#generating results for table $\mathrm{S} 3$

table_PhyloD<-rbind(vert_unc,vend, mammal, bird, herptile, fish, invertebrate, fruit, nectar, woody, grass, seed, root,

plant_unc, carrion, other)

row.names(table_PhyloD)<-c("vert_unclassified","vend","mammal", "bird", "herptile", "fish", "invertebrate",

"fruit","nectar","woody", "grass", "seed", "root","plant_unclassified","carrion", "other")

colnames(table_PhyloD)<-

c("Np_MammalDiet","D_MammalDiet","P1_MammalDiet","P0_MammalDiet","Np_EltonTraits","D_EltonTraits","P1

_EltonTraits","P0_EltonTraits","Np_CUFdiet","D_CUFdiet","P1_CUFdiet","P0_CUFdiet")

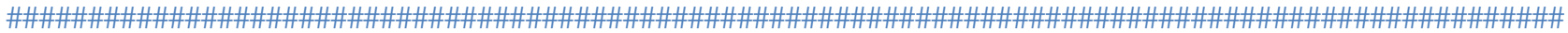
\#\#\#\#\#\#\#\#\#\#\#\#

\#\#\#\#\#\#\#\#PHYLOGENETIC SIGNAL IN QUANTITATIVE DATA FOR DIFFERENT DIET

CATEGORIES\#\#\#\#\#\#\#\#\#\#\#\#\#\#

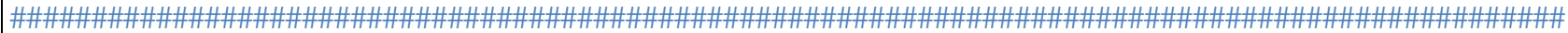

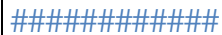

\#\#REPRODUCES RESULTS FOR TABLE 2

\#\#uses function K_P0_P1_function defined in lines 43-75

MD_Mammal_quant_K<-K_P0_P1_function(MammalDIET_sub,"MD_Mammal_quant", 2, c(1,4))

MD_Bird_quant_K<-K_P0_P1_function(MammalDIET_sub,"MD_Bird_quant", 2, c $(1,4)$ )

MD_Herptile_quant_K<-K_P0_P1_function(MammalDIET_sub,"MD_Herptile_quant", 2, c $(1,4)$ )

MD_Fish_quant_K<-K_P0_P1_function(MammalDIET_sub,"MD_Fish_quant", 2, c $(1,4)$ )

MD_Invertebrate_quant_K<-K_P0_P1_function(MammalDIET_sub,"MD_Invertebrate_quant", 2, c $(1,4)$ )

MD_Fruit_quant_K<-K_P0_P1_function(MammalDIET_sub,"MD_Fruit_quant", 2, c $(1,4)$ )

MD_Nectar_quant_K<-K_P0_P1_function(MammalDIET_sub,"MD_Nectar_quant", 2, c(1,4))

MD_Woody_quant_K<-K_P0_P1_function(MammalDIET_sub,"MD_Woody_quant", 2, c(1,4))

MD_Grass_quant_K<-K_P0_P1_function(MammalDIET_sub,"MD_Grass_quant", 2, c $(1,4)$ )

MD_Seed_quant_K<-K_P0_P1_function(MammalDIET_sub,"MD_Seed_quant", 2, c $(1,4)$ )

MD_Root_quant_K<-K_P0_P1_function(MammalDIET_sub,"MD_Root_quant", 2, c $(1,4)$ )

MD_Other_quant_K<-K_P0_P1_function(MammalDIET_sub,"MD_Other_quant", 2, c $(1,4)$ )

ET_Vert_uncl_quant_K<-K_P0_P1_function(EltonTraits_sub,"ET_Vert_uncl_quant", 2, c(0,100))

ET_Vend_quant_K<-K_P0_P1_function(EltonTraits_sub,"ET_Vend_quant", 2, c(0,100))

ET_Herptile_quant_K<-K_P0_P1_function(EltonTraits_sub,"ET_Herptile_quant", 2, c(0,100))

ET_Fish_quant_K<-K_P0_P1_function(EltonTraits_sub,"ET_Fish_quant", 2, c(0,100))

ET_Invertebrate_quant_K<-K_P0_P1_function(EltonTraits_sub,"ET_Invertebrate_quant", 2, c $(0,100))$

ET_Fruit_quant_K<-K_P0_P1_function(EltonTraits_sub,"ET_Fruit_quant", 2, c(0,100))

ET_Nectar_quant_K<-K_P0_P1_function(EltonTraits_sub,"ET_Nectar_quant", 2, c $(0,100)$ )

ET_Seed_quant_K<-K_P0_P1_function(EltonTraits_sub,"ET_Seed_quant", 2, c $(0,100)$ )

ET_Plant_unc_quant_K<-K_P0_P1_function(EltonTraits_sub,"ET_Plant_unc_quant", 2, c $(0,100)$ )

ET_Carrion_quant_K<-K_P0_P1_function(EltonTraits_sub,"ET_Carrion_quant", 2, c $(0,100))$

CUF_Vend_num_freq_K<-K_P0_P1_function(CUFdiet_sub,"CUF_Vend_num_freq", 2, c(0,1))

CUF_Mammal_num_freq_K<-K_P0_P1_function(CUFdiet_sub,"CUF_Mammal_num_freq", 2, c(0,1))

CUF_Bird_num_freq_K<-K_P0_P1_function(CUFdiet_sub,"CUF_Bird_num_freq", 2, c(0,1))

CUF_Herptile_num_freq_K<-K_P0_P1_function(CUFdiet_sub,"CUF_Herptile_num_freq", 2, c $(0,1)$ )

CUF_Fish_num_freq_K<-K_P0_P1_function(CUFdiet_sub,"CUF_Fish_num_freq", 2, c(0,1))

CUF_Invertebrate_num_freq_K<-K_P0_P1_function(CUFdiet_sub,"CUF_Invertebrate_num_freq", 2, c( $(0,1))$

CUF_Fruit_num_freq_K<-K_P0_P1_function(CUFdiet_sub,"CUF_Fruit_num_freq", 2, c $(0,1)$ )

CUF_Nectar_num_freq_K<-K_P0_P1_function(CUFdiet_sub,"CUF_Nectar_num_freq", 2, c $(0,1)$ )

CUF_Woody_num_freq_K<-K_P0_P1_function(CUFdiet_sub,"CUF_Woody_num_freq", 2, c(0,1))

CUF_Grass_num_freq_K<-K_P0_P1_function(CUFdiet_sub,"CUF_Grass_num_freq", 2, c $(0,1)$ )

CUF_Seed_num_freq_K<-K_P0_P1_function(CUFdiet_sub,"CUF_Seed_num_freq", 2, c $(0,1)$ )

CUF_Carrion_num_freq_K<-K_P0_P1_function(CUFdiet_sub,"CUF_Carrion_num_freq", 2, c(0,1)) 
CUF_Mammal_freq_occu_K<-K_P0_P1_function(CUFdiet_sub,"CUF_Mammal_freq_occu", 2, c $(0,1))$

CUF_Bird_freq_occu_K<-K_P0_P1_function(CUFdiet_sub,"CUF_Bird_freq_occu", 2, c $(0,1)$ )

CUF_Herptile_freq_occu_K<-K_P0_P1_function(CUFdiet_sub,"CUF_Herptile_freq_occu", 2, c $(0,1))$

CUF_Fish_freq_occu_K<-K_P0_P1_function(CUFdiet_sub,"CUF_Fish_freq_occu", 2, c(0,1))

CUF_Invertebrate_freq_occu_K<-K_P0_P1_function(CUFdiet_sub,"CUF_Invertebrate_freq_occu", 2, c(0,1))

CUF_Fruit_freq_occu_K<-K_P0_P1_function(CUFdiet_sub,"CUF_Fruit_freq_occu", 2, c $(0,1)$ )

CUF_Woody_freq_occu_K<-K_P0_P1_function(CUFdiet_sub,"CUF_Woody_freq_occu", 2, c(0,1))

CUF_Grass_freq_occu_K<-K_P0_P1_function(CUFdiet_sub,"CUF_Grass_freq_occu", 2, c(0,1))

CUF_Seed_freq_occu_K<-K_P0_P1_function(CUFdiet_sub,"CUF_Seed_freq_occu", 2, c $(0,1)$ )

CUF_Carrion_freq_occu_K<-K_P0_P1_function(CUFdiet_sub,"CUF_Carrion_freq_occu", 2, c(0,1))

\#\#generating table results

Table_2_results<-rbind(list("Vert_uncl","NA","NA", "NA", "NA",ET_Vert_uncl_quant_K,"NA","NA", "NA", "NA","NA","NA", "NA", "NA"),

"NA"), list("Vend", "NA","NA", "NA", "NA", ET_Vend_quant_K,CUF_Vend_quant_K, "NA","NA", "NA",

list("Mammal", MD_Mammal_quant_K, "NA","NA", "NA", "NA",CUF_Mammal_num_freq_K,

CUF_Mammal_freq_occu_K),

list("Bird", MD_Bird_quant_K,"NA","NA", "NA", "NA",CUF_Bird_num_freq_K,

CUF_Bird_freq_occu_K ),

list("Herptile", MD_Herptile_quant_K, ET_Herptile_quant_K, CUF_Herptile_num_freq_K,

CUF_Herptile_freq_occu_K),

list("Fish", MD_Fish_quant_K, ET_Fish_quant_K, CUF_Fish_num_freq_K, CUF_Fish_freq_occu_K), list("Invertebrate", MD_Invertebrate_quant_K, ET_Invertebrate_quant_K,

CUF_Invertebrate_num_freq_K, CUF_Invertebrate_freq_occu_K), list("Fruit", MD_Fruit_quant_K, ET_Fruit_quant_K, CUF_Fruit_num_freq_K,

CUF_Fruit_freq_occu_K),

list("Nectar", MD_Nectar_quant_K, ET_Nectar_quant_K, CUF_Nectar_num_freq_K,"NA","NA", "NA", "NA"),

CUF_Woody_freq_occu_K ), list("Woody", MD_Woody_quant_K,"NA","NA", "NA", "NA",CUF_Woody_num_freq_K,

list("Grass", MD_Grass_quant_K,"NA","NA", "NA", "NA", CUF_Grass_num_freq_K,

CUF_Grass_freq_occu_K), list("Seed", MD_Seed_quant_K, ET_Seed_quant_K, CUF_Seed_num_freq_K,

CUF_Seed_freq_occu_K), list("Root", MD_Root_quant_K,"NA","NA", "NA", "NA", "NA","NA", "NA", "NA" ), list("Plant", "NA","NA", "NA", "NA", ET_Plant_unc_quant_K, "NA","NA", "NA", "NA", "NA","NA", "NA", "NA"),

list("Carrion", "NA","NA", "NA", "NA", ET_Carrion_quant_K,CUF_Carrion_num_freq_K,

CUF_Carrion_freq_occu_K),

list("Other", MD_Other_quant_K, "NA","NA", "NA", "NA", "NA","NA", "NA", "NA", "NA","NA",

"NA", "NA" ))

colnames(Table_2_results)<-c("Food category","MD_sample_size", "MD_K", "MD_P0", "MD_P1","ET_sample_size", "ET_K", "ET_P0", "ET_P1","CUF_num_sample_size", "CUF_num_K", "CUF_num_P0",

"CUF_num_P1","CUF_freq_sample_size", "CUF_freq_K", "CUF_freq_P0", "CUF_freq_P1")

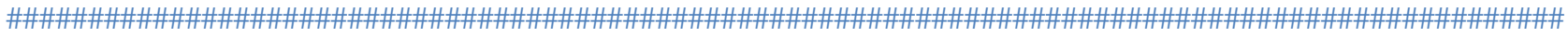

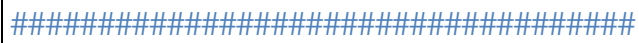

\#\#TESTING THE EFFECT OF POLYTOMIES IN THE RESULTS\#\#\#\#

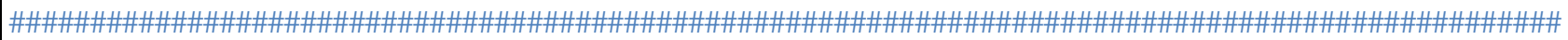

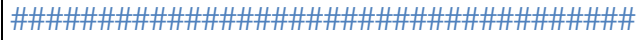

\#\# REPRODUCES RESULTS FOR TABLE S2

\#\# Code based on code written by Nathan Kraft-nkraft@ biodiversity.ubc.ca

\#\# available at http://www.esapubs.org/archive/ecol/E093/023/thin_terminal_polytomies.R

\#\# presented in publication "T. Jonathan Davies, Nathan J. B. Kraft, Nicolas Salamin, and Elizabeth M. Wolkovich

2012. Incompletely resolved phylogenetic trees inflate estimates of phylogenetic conservatism. Ecology 93:242-247.

http://dx.doi.org/10.1890/11-1360.1"

\#\# R-function to identify terminal polytomies, then randomly thin those 


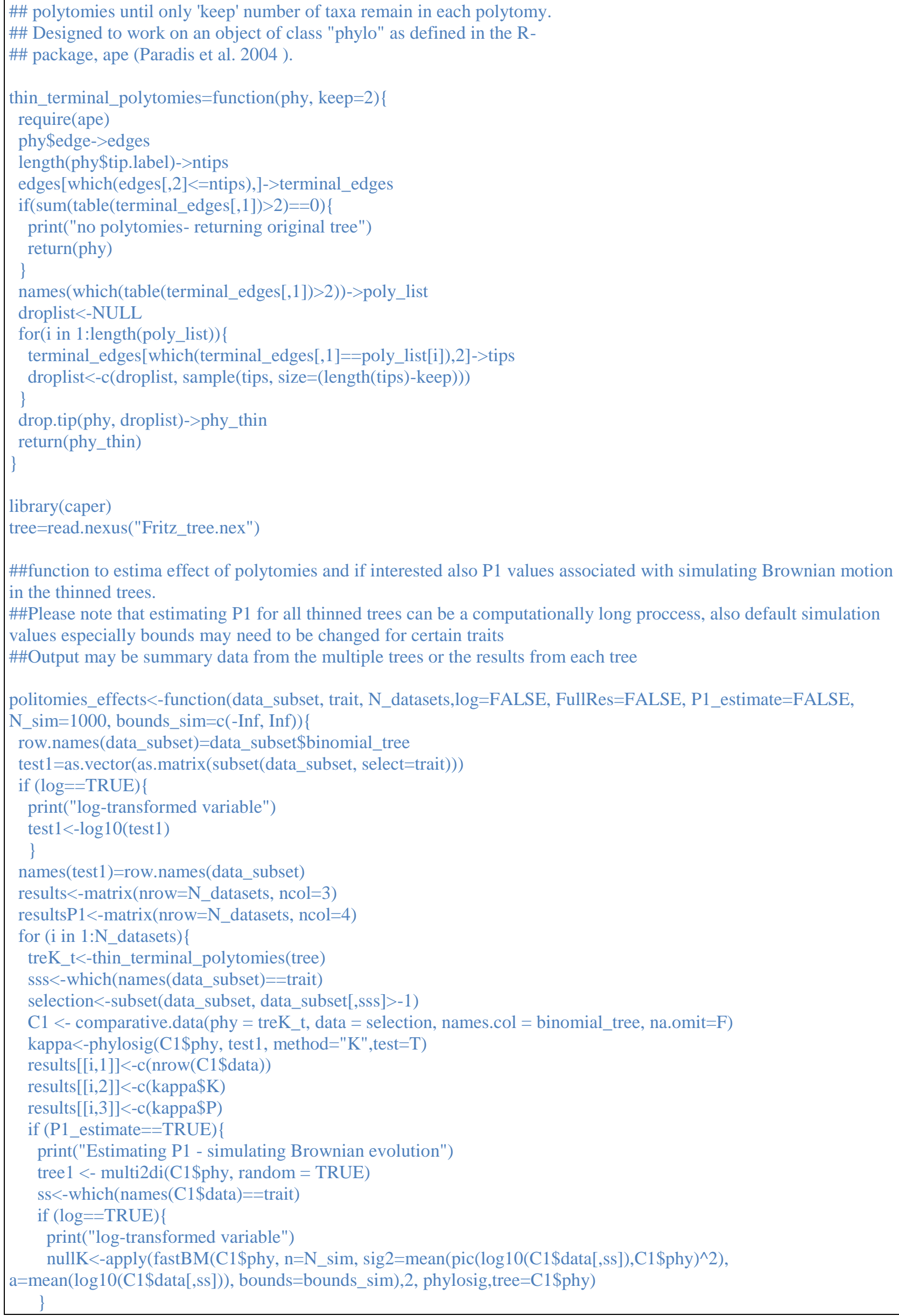




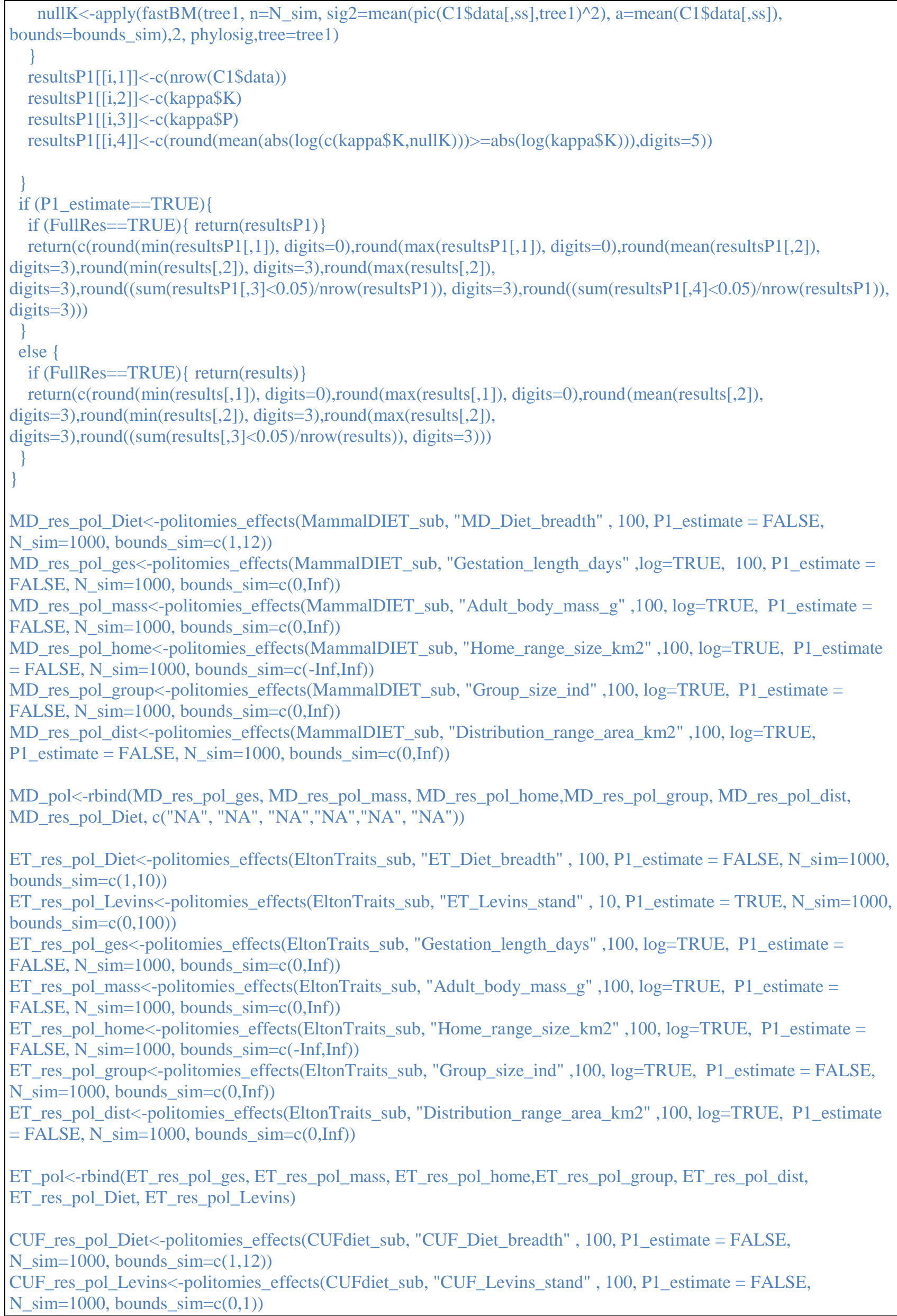


CUF_res_pol_ges<-politomies_effects(CUFdiet_sub, "Gestation_length_days" ,100, log=TRUE, P1_estimate = FALSE, N_sim $=1000$, bounds_sim $=\mathrm{c}(0$, Inf $))$

CUF_res_pol_mass<-politomies_effects(CUFdiet_sub, "Adult_body_mass_g" ,100, log=TRUE, P1_estimate = FALSE, N_sim $=1000$, bounds_sim $=\mathrm{c}(0$, Inf $))$

CUF_res_pol_home<-politomies_effects(CUFdiet_sub, "Home_range_size_km2" ,100, log=TRUE, P1_estimate = FALSE, N_sim=1000, bounds_sim=c(-Inf,Inf))

CUF_res_pol_group<-politomies_effects(CUFdiet_sub, "Group_size_ind" ,100, log=TRUE, P1_estimate = FALSE, N_sim $=1000$, bounds_sim $=c(0$, Inf $))$

CUF_res_pol_dist<-politomies_effects(CUFdiet_sub, "Distribution_range_area_km2" ,100, log=TRUE, P1_estimate = FALSE, N_sim $=1000$, bounds_sim $=\mathrm{c}(0$, Inf $))$

CUF_pol<-rbind(CUF_res_pol_ges, CUF_res_pol_mass, CUF_res_pol_home,CUF_res_pol_group, CUF_res_pol_dist, CUF_res_pol_Diet, CUF_res_pol_Levins)

\#\#Generating Table S2

Table_S2_results<-cbind(MD_pol, ET_pol, CUF_pol)

colnames(Table_S2_results)<-c("MD_min_N", "MD_max_N","MD_mean_K", "MD_min_K",

"MD_max_K","MD_P0",

"ET_min_N", "ET_max_N","ET_mean_K", "ET_min_K", "ET_max_K", "ET_P0",

"CUF_min_N", "CUF_max_N","CUF_mean_K", "CUF_min_K", "CUF_max_K","CUF_P0")

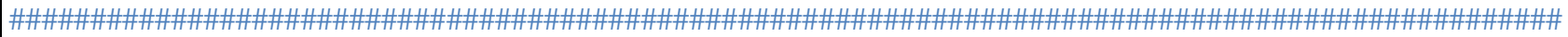

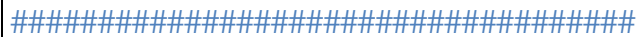

\#\#ESTIMATING THE NET RELATEDNESS INDEX\#\#\#\#

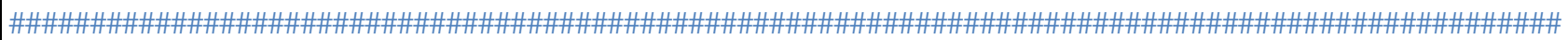

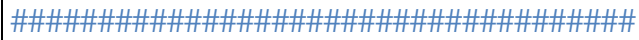

library(ape)

library(PhyloMeasures)

library(caper)

\#\#generate a database all species in the phylogeny with 0 indicating no data in the diet database and 1 indicating data available. Please note that because in the original dataset species that have no data for either global database were excluded we generated a new dataset with 5020 species (those in the phylogeny), as a result some species have zero for both MammalDIET and EltonTraits

diet_availability<-merge(as.data.frame(tree\$tip.label),(data[,c("binomial_tree","MammalDIET", "EltonTraits")]), by.x="tree\$tip.label", by.y="binomial_tree", all=T)

diet_availability[is.na(diet_availability) $]<-0$

colnames(diet_availability)<-c("binomial", "MammalDIET", "EltonTraits")

spp_matrix <-as.matrix (t(diet_availability[,2:3]))

colnames(spp_matrix) <- diet_availability\$binomial

\#\#\#\# MPD \#\#\#\# (NRI) Phylogenetic structure

\#get the standardized MPD values, NRI=-MPD

spp.mpd <- mpd.query(tree,spp_matrix,TRUE)

spp.mpd

\#check the result by using permutations as implemented in Picante's functions

library(picante)

spp.ses.mpd<-ses.mpd(samp = spp_matrix,dis=cophenetic $($ tree $)$, null.model $=$ "taxa.labels")

spp.ses.mpd 
Appendix S3 Supplementary tables and figure

Table S1. Phylogenetic signal (Blomberg's K) in species' traits. We report $P_{R}$ as the $P$-values against a randomization test $(N=1000)$ to determine if estimates significantly departed from those expected if traits vary randomly along the phylogeny; and $P_{B M}$ as probability of the observed value being greater or smaller than the expected under a Brownian model of evolution (1000 simulated datasets). $N_{p}$ is the number of species with available data for each trait.

\begin{tabular}{|c|c|c|c|c|c|c|c|c|c|c|c|c|}
\hline \multirow[t]{2}{*}{ Trait } & \multicolumn{4}{|c|}{ MammalDiet(N=1921) } & \multicolumn{4}{|c|}{ EltonTraits $(\mathrm{N}=4246)$} & \multicolumn{4}{|c|}{ CUFdiet (N=73) } \\
\hline & $N_{p}$ & $\mathrm{~K}$ & $\overline{P_{R}}$ & $P_{B M}$ & $\overline{N_{p}}$ & $\mathrm{~K}$ & $\overline{P_{R}}$ & $P P_{B M}$ & $N_{p}$ & $\mathrm{~K}$ & $\overline{P_{R}}$ & $P_{B M}$ \\
\hline Gestation length* & 793 & 3.24 & 0.001 & 0.007 & 1328 & 3.64 & 0.001 & 0.002 & 67 & 3.06 & 0.001 & 0.149 \\
\hline Adult body mass* & 1569 & 1.47 & 0.001 & 0.356 & 3584 & 1.65 & 0.001 & 0.229 & 72 & 0.49 & 0.001 & 0.380 \\
\hline Home range* & 473 & 0.50 & 0.001 & 0.082 & 698 & 0.43 & 0.001 & 0.023 & 51 & 0.14 & 0.097 & 0.001 \\
\hline Group size* & 453 & 0.26 & 0.001 & 0.002 & 735 & 0.27 & 0.001 & 0.002 & 61 & 0.19 & 0.001 & 0.072 \\
\hline Range size* & 1912 & 0.08 & 0.002 & 0.001 & 4193 & 0.08 & 0.001 & 0.001 & 71 & 0.07 & 0.564 & 0.001 \\
\hline Diet breadth & 1921 & 0.11 & 0.001 & 0.001 & 4246 & 0.42 & 0.001 & 0.247 & 73 & 0.10 & 0.031 & 0.001 \\
\hline Levin's diet index & - & - & - & - & 4246 & 0.46 & 0.001 & 0.352 & 53 & $\mathbf{0 . 0 7}$ & 0.601 & 0.001 \\
\hline
\end{tabular}

* $\log _{10}$-transformed 
Table S2. Unbiased estimates of phylogenetic signal (Blomberg's K) from diverse species' traits obtained from the rarefaction-based solution proposed by Davies et al. (2012). We report the mean and range (min-max) K calculated from 100 replicates. $N_{p}$ is the range for the number of species used in each replicate and $P_{0.05}$ is the proportion of the replicates in which $\mathrm{K}$ was significantly different from the expected in a randomization test $(N=1000)$. Because data were not available for all species in the tree, randomly selecting one species from existing polytomies changed the available sample size. The maximum number of species in a completely resolved phylogeny based on the mammalian supertree is 2716 (the tree includes information for 5020 species but many are reconstructed in polytomies).

\begin{tabular}{|c|c|c|c|c|c|c|c|c|c|}
\hline \multirow[t]{2}{*}{ Trait } & \multicolumn{2}{|c|}{ MammalDiet } & \multicolumn{3}{|c|}{ EltonTraits } & \multicolumn{4}{|c|}{ CUFdiet } \\
\hline & $N_{p}$ & $\bar{K}$ & $P_{0.05}$ & $N_{p}$ & $\bar{K}$ & $P_{0.05}$ & $N_{p}$ & $\bar{K}$ & $P_{0.05}$ \\
\hline Gestation length* & $626-654$ & $3.10(2.92-3.24)$ & 1.00 & $1001-1041$ & $3.57(3.39-3.75)$ & 1.00 & $59-62$ & $3.07(2.84-3.29)$ & 1.00 \\
\hline Adult body mass* & $1171-1214$ & $1.35(1.27-1.43)$ & 1.00 & $2319-2357$ & $1.42(1.31-1.57)$ & 1.00 & $63-65$ & $0.54(0.47-0.69)$ & 1.00 \\
\hline Home range* & $379-405$ & $0.48(0.45-0.52)$ & 1.00 & $546-580$ & $0.41(0.38-0.43)$ & 1.00 & $44-48$ & $0.16(0.14-0.19)$ & 0.31 \\
\hline Group size* & $364-387$ & $0.26(0.24-0.28)$ & 1.00 & $564-589$ & $0.26(0.24-0.27)$ & 1.00 & $53-55$ & $0.20(0.17-0.24)$ & 1.00 \\
\hline Range size* & $1402-1446$ & $0.09(0.08-0.10)$ & 1.00 & $2602-2632$ & $0.08(0.078-0.08)$ & 1.00 & $62-64$ & $0.08(0.07-0.09)$ & 0.00 \\
\hline Diet breadth & $1397-1447$ & $0.11(0.10-0.11)$ & 1.00 & $2640-2664$ & $0.31(0.30-0.32)$ & 1.00 & 64-66 & $0.11(0.10-0.12)$ & 0.79 \\
\hline Levin's diet index & - & - & & $2642-2665$ & $0.34(0.32-0.37)$ & 1.00 & 44-47 & $0.07(0.05-0.10)$ & 0.00 \\
\hline
\end{tabular}

* $\log _{10}$-transformed 
Table S3. Phylogenetic signal (Blomberg's K) detected in the dietary breadth (total number of food categories consumed) of species from different mammalian orders. Dietary data obtained from MammalDIET and EltonTraits but considering only species with data in both datasets to compare estimates. We report $P_{R}$ as the $P$-values against a randomization test $(N=1000)$ to test if estimates significantly departed from the expected if there was no phylogenetic signal; and $P_{B M}$ as the probability of the observed value being greater or smaller than the expected under a Brownian model of evolution (1000 simulated datasets). $N_{p}$ is the number of species with available data for each trait. Small orders includes mammalian orders with $\leq 20$ species with dietary data: Cingulata, Dermoptera, Hyracoidea, Macroscelidea, Microbiotheria, Monotremata, Notoryctemorphia, Paucituberculata, Peramelemorphia, Perissodactyla, Pholidota, Pilosa, Proboscidea, Scandentia, and Tubulidentata.

\begin{tabular}{lrrrrrrr}
\hline Order & $N_{p}$ & \multicolumn{2}{c}{ MammalDiet } & \multicolumn{2}{c}{ EltonTraits } \\
\hline & & K & $\boldsymbol{P}_{\boldsymbol{R}}$ & $\boldsymbol{P}_{\boldsymbol{B} M}$ & $\mathbf{K}$ & $\boldsymbol{P}_{\boldsymbol{R}}$ & $\boldsymbol{P}_{\boldsymbol{B M}}$ \\
\hline Afrosoricida & 14 & 1.22 & 0.016 & 0.736 & 1.44 & 0.002 & 0.428 \\
Didelphimorphia & 37 & 0.76 & 0.017 & 0.449 & 1.53 & 0.001 & 0.115 \\
Erinaceomorpha & 8 & 0.72 & 0.098 & 0.673 & 0.81 & 0.072 & 0.789 \\
Lagomorpha & 41 & 0.50 & 0.001 & 0.474 & 0.12 & 0.778 & 0.001 \\
Dasyuromorphia & 16 & 0.46 & 0.475 & 0.166 & 0.29 & 0.883 & 0.003 \\
Diprotodontia & 39 & 0.36 & 0.598 & 0.008 & 0.79 & 0.001 & 0.614 \\
Chiroptera & 366 & 0.34 & 0.001 & 0.039 & 0.77 & 0.001 & 0.846 \\
Soricomorpha & 75 & 0.29 & 0.283 & 0.005 & 1.23 & 0.001 & 0.727 \\
Primates & 198 & 0.29 & 0.001 & 0.101 & 0.47 & 0.001 & 0.310 \\
Small_Orders & 56 & 0.23 & 0.011 & 0.008 & 0.32 & 0.003 & 0.076 \\
Artiodactyla & 148 & 0.17 & 0.025 & 0.001 & 0.46 & 0.001 & 0.455 \\
Rodentia & 531 & 0.14 & 0.001 & 0.006 & 0.55 & 0.001 & 0.212 \\
Carnivora & 201 & 0.13 & 0.175 & 0.001 & 0.18 & 0.002 & 0.001 \\
\hline & & & & & & & \\
\hline
\end{tabular}


Table S4. Phylogenetic signal detected in qualitative descriptors (presence/absence) of mammalian dietary composition. Phylogenetic signal is estimated using Fritz and Purvis' D ( $\mathrm{D}=1$ when there is no phylogenetic structure). We report two $P$-values (based on 5000 replicates): $P_{R}$ estimated from randomization tests, and $P_{B M}$ estimated from simulated BM. $N_{p}$ is the number of species with presence $=1$ for each dietary category.

\begin{tabular}{|c|c|c|c|c|c|c|c|c|c|c|c|c|}
\hline \multirow[t]{2}{*}{ Diet category } & \multicolumn{4}{|c|}{ MammalDiet $(N=1921)$} & \multicolumn{4}{|c|}{ EltonTraits $(N=4246)$} & \multicolumn{4}{|c|}{ CUFdiet $(N=73)$} \\
\hline & $N_{p}$ & $\mathbf{D}$ & $P_{R}$ & $\boldsymbol{P}_{B M}$ & $N_{p}$ & $\mathbf{D}$ & $P_{R}$ & $P_{B M}$ & $N_{p}$ & $\mathbf{D}$ & $P_{R}$ & $P_{B M}$ \\
\hline Vert & - & - & - & - & 348 & -0.24 & $<0.001$ & 0.921 & - & - & - & - \\
\hline Vend & 195 & -0.05 & $<0.001$ & 0.658 & 386 & -0.39 & $<0.001$ & 0.991 & $72 *$ & - & - & - \\
\hline Mammal & 182 & -0.09 & $<0.001$ & 0.721 & - & - & - & - & 71 & 0.69 & 0.327 & 0.316 \\
\hline Bird & 124 & 0.13 & $<0.001$ & 0.266 & - & - & - & - & 69 & 0.70 & 0.219 & 0.176 \\
\hline Herptile & 155 & 0.21 & $<0.001$ & 0.099 & 397 & -0.32 & $<0.001$ & 0.977 & 55 & 0.67 & 0.035 & 0.030 \\
\hline Fish & 81 & 0.33 & $<0.001$ & 0.050 & 190 & -0.37 & $<0.001$ & 0.948 & 27 & 0.99 & 0.432 & $<0.001$ \\
\hline Invertebrate & 1055 & 0.13 & $<0.001$ & 0.082 & 2770 & -0.33 & $<0.001$ & $>0.999$ & 61 & 0.42 & 0.006 & 0.151 \\
\hline Fruit & 723 & 0.19 & $<0.001$ & 0.016 & 1661 & -0.29 & $<0.001$ & 0.998 & 43 & 0.33 & $<0.001$ & 0.217 \\
\hline Nectar & 103 & -0.23 & $<0.001$ & 0.879 & 206 & -0.39 & $<0.001$ & 0.953 & 4 & 0.66 & 0.186 & 0.202 \\
\hline Woody & 172 & 0.27 & $<0.001$ & 0.026 & - & - & - & - & 16 & 0.73 & 0.071 & 0.020 \\
\hline Grass & 284 & 0.03 & $<0.001$ & 0.431 & - & - & - & - & 39 & 0.82 & 0.062 & 0.007 \\
\hline Seed & 398 & 0.14 & $<0.001$ & 0.119 & 1314 & -0.32 & $<0.001$ & 0.998 & 20 & 0.63 & 0.016 & 0.037 \\
\hline
\end{tabular}




\begin{tabular}{|c|c|c|c|c|c|c|c|c|c|c|c|c|}
\hline \multirow[t]{2}{*}{ Diet category } & \multicolumn{4}{|c|}{ MammalDiet $(N=1921)$} & \multicolumn{4}{|c|}{ EltonTraits $(N=4246)$} & \multicolumn{4}{|c|}{ CUFdiet $(N=73)$} \\
\hline & $N_{p}$ & $\overline{\mathbf{D}}$ & $\overline{P_{R}}$ & $\boldsymbol{P}_{B M}$ & $\overline{N_{p}}$ & $\overline{\mathbf{D}}$ & $\overline{P_{R}}$ & $\boldsymbol{P}_{B M}$ & $\overline{N_{p}}$ & $\overline{\mathbf{D}}$ & $\overline{P_{R}}$ & $P_{B M}$ \\
\hline Root & 129 & 0.30 & $<0.001$ & 0.038 & - & - & - & - & $1 *$ & - & - & - \\
\hline Plant & - & - & - & - & 2148 & -0.38 & $<0.001$ & $>0.999$ & - & - & - & - \\
\hline Carrion & - & - & - & - & 351 & -0.53 & $<0.001$ & $>0.999$ & 23 & 0.91 & 0.248 & 0.004 \\
\hline Other & 356 & 0.37 & $<0.001$ & $<0.001$ & - & - & - & - & - & - & - & - \\
\hline
\end{tabular}

*These groups were not analyzed because either all-but-one or none-but-one species were classified as consuming the diet category. 
Figure S1. Phylogenetic relationships and dietary composition for 66 large mammalian carnivores (Families Canidae, Ursidae, and Felidae). Dietary composition is described by the presence (black symbol) of seven distinct food item categories: Vend (Mammal and Bird), Herptile, Fish,

Invertebrate, Fruit, Nectar, and Seeds from three different diet databases: MammalDIET (triangle), EltonTraits (asterisk) and CUFdiet (square).

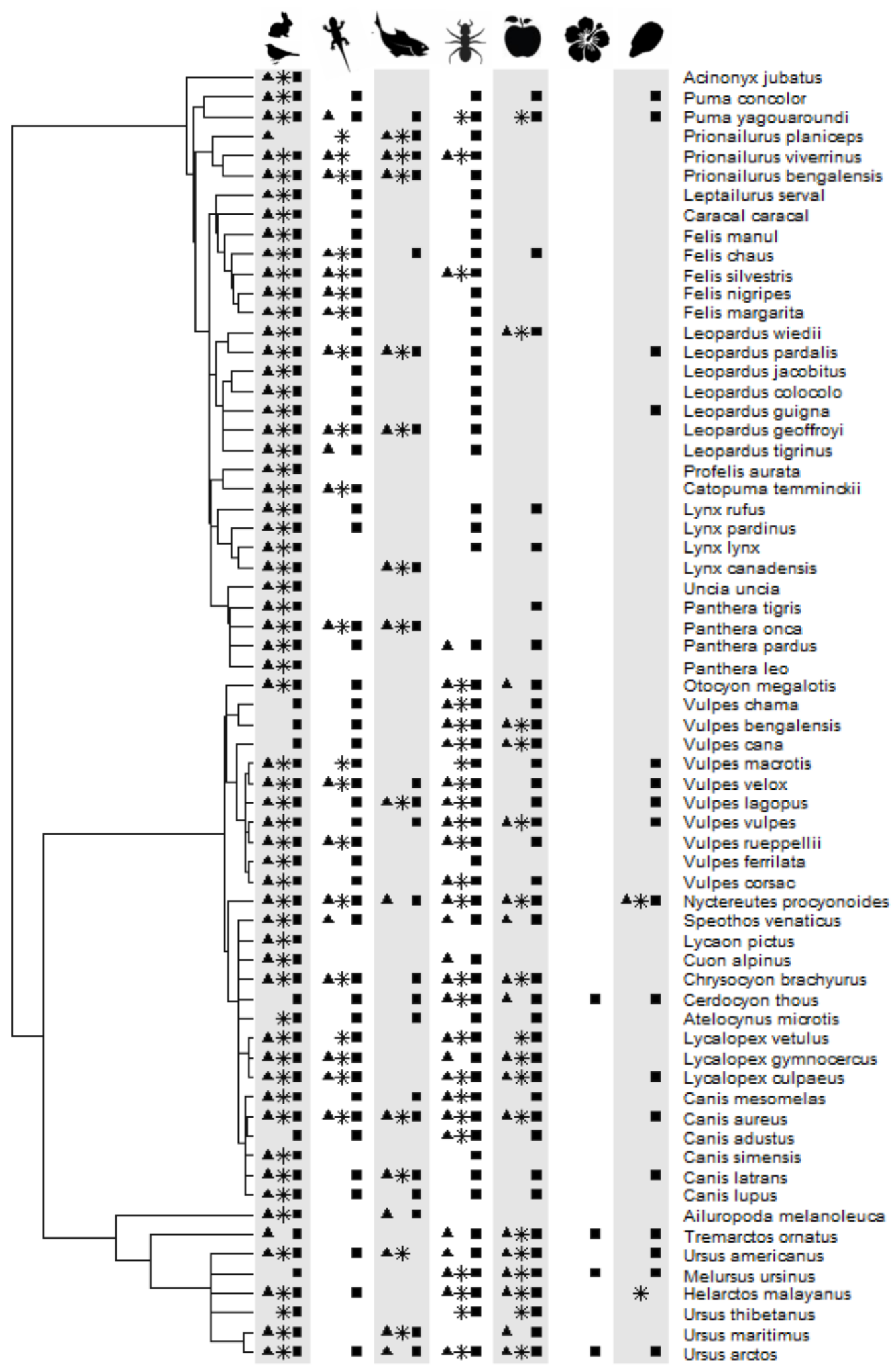

